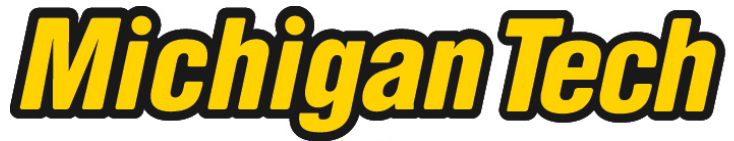 \\ Michigan Technological University Create the Future Digital Commons @ Michigan Tech
}

\section{A Surface Displacement Analysis for Volcan Pacaya from October 2001 through March 2013 by Means of 3-D Modeling of Precise Position GPS Data}

\author{
Brianna R. Hetland \\ Michigan Technological University
}

Follow this and additional works at: https://digitalcommons.mtu.edu/etds

Part of the Geology Commons, and the Geophysics and Seismology Commons Copyright 2014 Brianna R. Hetland

\section{Recommended Citation}

Hetland, Brianna R., "A Surface Displacement Analysis for Volcan Pacaya from October 2001 through March 2013 by Means of 3-D Modeling of Precise Position GPS Data", Master's Thesis, Michigan Technological University, 2014.

https://doi.org/10.37099/mtu.dc.etds/826

Follow this and additional works at: https://digitalcommons.mtu.edu/etds

Part of the Geology Commons, and the Geophysics and Seismology Commons 


\title{
A SURFACE DISPLACEMENT ANALYSIS FOR VOLCÁN PACAYA FROM OCTOBER 2001 THROUGH MARCH 2013 BY MEANS OF 3-D MODELING OF PRECISE POSITION GPS DATA
}

\author{
By \\ Brianna R. Hetland
}

\begin{abstract}
A THESIS
Submitted in partial fulfillment of the requirements for the degree of MASTER OF SCIENCE

In Geology

MICHIGAN TECHNOLOGICAL UNIVERSITY

2014
\end{abstract}

(C) 2014 Brianna R. Hetland 

This thesis has been approved in partial fulfillment of the requirements for the Degree of MASTER OF SCIENCE in Geology.

Department of Geological/Mining Engineering and Sciences

Thesis Advisor: $\quad$ Dr. Gregory P. Waite

Committee Member: Dr. John S. Gierke

Committee Member: Dr. Yushin Ahn

Department Chair: Dr. John S. Gierke 



\section{TABLE OF CONTENTS}

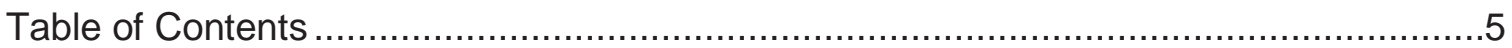

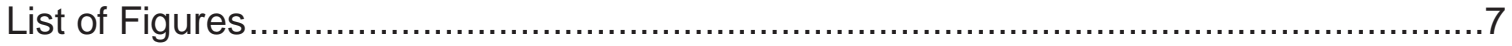

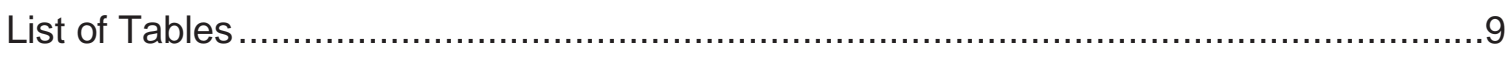

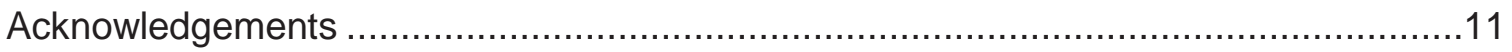

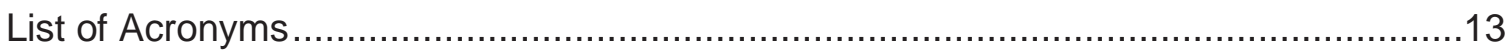

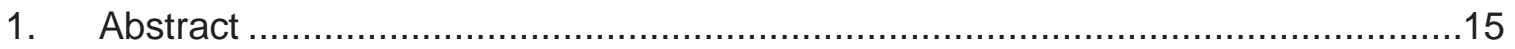

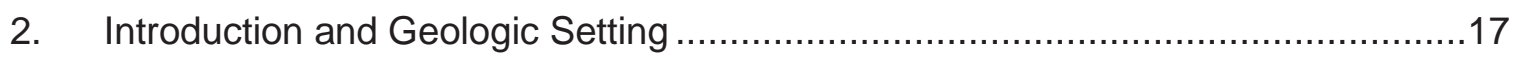

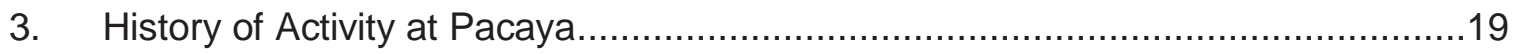

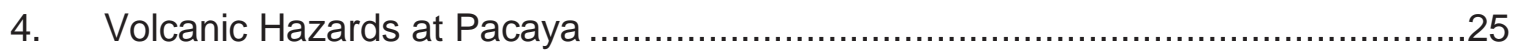

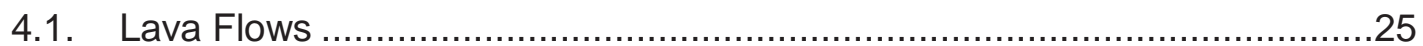

4.2. Ballistics/ashfall/pyroclastic flows/tephra...........................................2

4.3. Edifice Collapse and Debris Avalanche …..........................................29

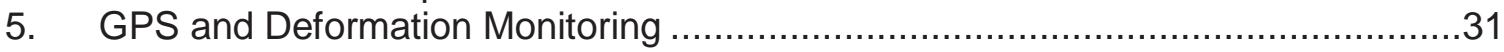

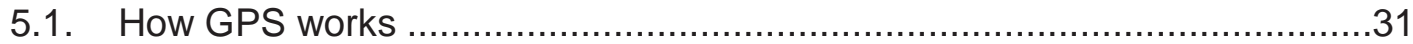

5.2. Use for volcano monitoring ……......................................................

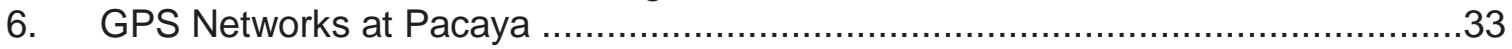

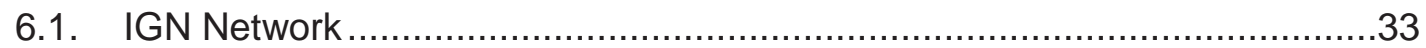

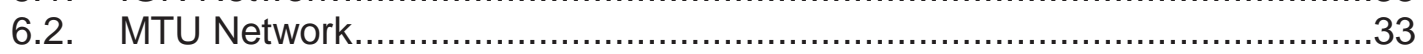

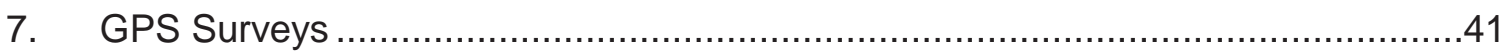

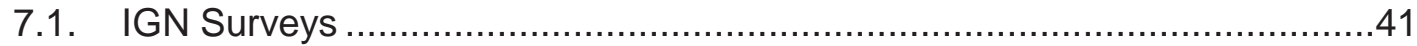

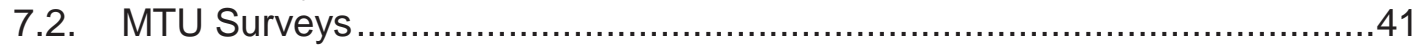

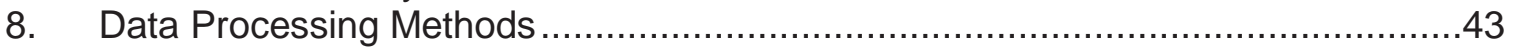

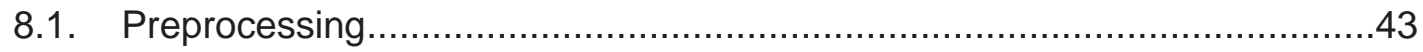

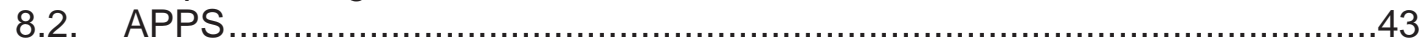

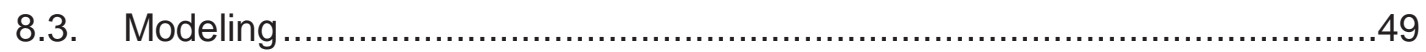

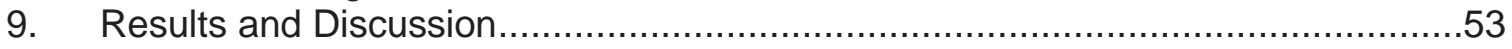

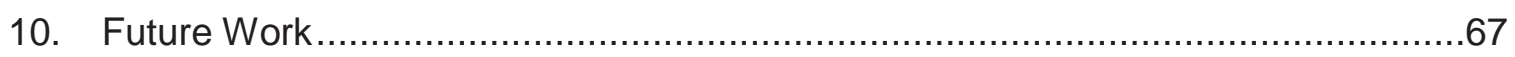

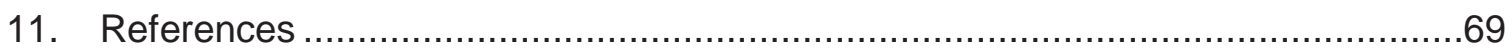

11.1. Personal Communication References.....................................................

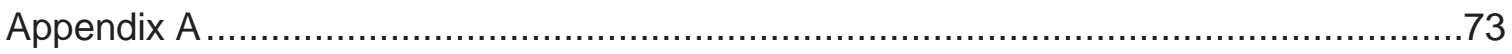

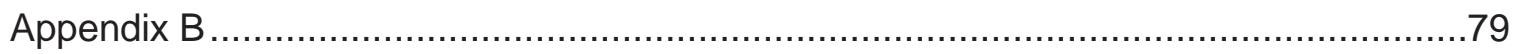





\section{LIST OF FIGURES}

Figure 2.1. Map of Central America including the Quaternary Central American volcanic chain

Figure 3.1. Map showing the southern rim of the Amatitlan Caldera and other ancient eruption craters remnant of historical eruptions of the Pacaya complex ....19

Figure 3.2. A series of photographs showing the growth of MacKenney cone on the western flank of the original cone from 1968 through 1991 .....................21

Figure 3.3. Location of Volcán Pacaya in relation to nearby communities.....................22

Figure 4.1. Geologic map of lava flows erupted at Volcán Pacaya...............................26

Figure 4.2. Bombs ejected during the May 27, 2010 eruption of the volcano and subsequent damages caused.

Figure 4.3. Satellite photograph showing various eruptive features which form a generally north-northwest trend within and surrounding the edifice of Pacaya.

Figure 5.1. Map of GPS monuments at Volcán Pacaya ……………….......................

Figure 7.1. Equipment setup at the BVIS GPS station ..............................................42

Figure 8.1. Screen shot of the APPS processing parameters input page on http://apps.gdgps.net/.

Figure 8.2. Time series plot of IGN station position changes from October 2001 through July 2010.

Figure 8.3. Time series plot of MTU station position change between January 2009 and March 2013.

Figure 8.4. Horizontal and vertical displacement velocity plots for IGN and MTU GPS stations

Figure 8.5. Map of GPS monuments used for displacement modeling .50

Figure 9.1. Pre-eruption best fit horizontal and vertical Kode 200 displacement models. 55

Figure 9.2. Eruption period best fit horizontal and vertical Kode 100 displacement models

Figure 9.3. Post-eruption period best fit horizontal and vertical displacement Kode 100 models 



\section{LIST OF TABLES}

Table 3.1. Concise eruptive history at Volcán Pacaya .................................................23

Table 6.1 Occupation times for four stations (BVIS, CHIQ, CHNO and CHUP) from October 2001 through March 2013........................................................34

Table 6.2 Occupation times for four stations (CRAK, CRAT, LBLK and LLAN) from October 2001 through March 2013 .......................................................36

Table 6.3 Occupation times for four stations (LVES, MEBA, RABN and SCRP) from

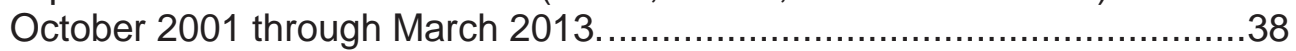

Table 7.1 GPS equipment used for IGN and MTU observations between October 2001

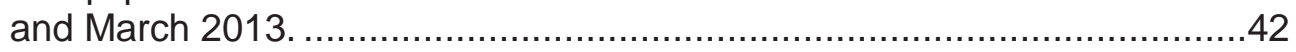

Table 8.1 North, east and up velocities for all stations covering the three distinct periods in the data (pre-eruption, eruption, and post-eruption).

Table 9.1. East, north, vertical and total (3-D) displacement values for each station for the three distinct time periods surrounding the May 2010 eruption of Pacaya.

Table 9.2. Best RMS misfit calculations for all tested Kode 100 models for each of three time periods surrounding the May 2010 eruption at Volcán Pacaya. 63

Table 9.3. Best RMS misfit calculations for all tested Kode 200 and 500 models for each of three time periods surrounding the May 2010 eruption at Volcán Pacaya. 



\section{ACKNOWLEDGEMENTS}

This research was supported by funding provided by the US National Science Foundation through grant number: 0530109. GPS equipment was provided by the GMES department at MTU. Technical guidance was provided mostly by Greg Waite, my adviser, who also deserves many thanks for input and revisions over many drafts of this work. Technical support was also provided by Hans Lechner (MTU PhD candidate) who helped teach me how to perform observations and use the equipment correctly. Many thanks go to the personnel of the PNVPLC for providing guides and access to Pacaya throughout the duration of the project with special thanks to Tornado, my equine guide. Additionally, I thank Rüdiger Escobar Wolf for all his input and help with software issues. Thanks to all of the MTU graduate students who helped me in the field transporting equipment and spending endless hours waiting during observations. The United States Peace Corps provided living costs during the planning phase and part of the execution of this project. Additional credits and thanks must go to the Guatemalan National Geographic Institute (IGN) who provided a large portion of the data to be studied in this work.

I especially want to thank my husband for all of his support, encouragement and patience during the duration of this project. Without his unbounding help in the field, from waiting for four hours on the rim of the crater for the station to collect readings, hiking through up to $30 \mathrm{mph}$ winds at 5:00 am with flashlights on sharp, glassy lava flows, to carrying a 35 pound truck battery on his shoulders to connect the station, this project never would have been completed. Not only was he a help in the field but also provided encouragement during the analysis and writing portion of this project when I needed it the most.

I also have to thank my beautiful daughter for being part of the observation process during my pregnancy, and for supporting the horse riding and hiking and long days in the field during the field work portion of this project. 



\section{LIST OF ACRONYMS}

Spanish (Guatemalan)

CONRED - Consejo Nacional para la Reducción de Desastres; National Coordinator for

Disaster Reduction; the Guatemalan governmental agency for risk management.

IGN - Instituto Geografico Nacional; National Geographic Institute; The Guatemalan

governmental agency that handles geographical data

INE - Instituto Nacional de Estadisticas; National Statistics Institue; the Guatemalan

governmental agency that handles all information related to population data and

all other national statistics collected from the national census.

INSIVUMEH - Instituto Nacional de Sismologia Vulcanologia Meteorologia e Hidrologia;

National institute of Seismology, Volcanology, Meteorology and Hydrology; The

Guatemalan governmental agency that handles all scientific information and spreads that to the public.

PNVPLC - Parque Nacional de Volcán de Pacaya y Laguna Calderas; Pacaya Volcano and Calderas Lagoon National Park; National park and protected area within which is located Volcán Pacaya

English

APPS - Automatic Precise Positioning Service; Precise positioning web interface service provided by JPL and run with GIPSY/OASIS

GDGPS - Global Differential Global Positioning System

GIPSY/OASIS - GNSS-Inferred Positioning System and Orbit Analysis Simulation Software

GNSS - Global Navigation Satellite System

IGS - International GNSS Service

JICA - Japan International Cooperation Agency

JPL - Jet Propulsion Laboratory

MTU - Michigan Technological University

RINEX - Receiver Independent Exchange Format

SIGVP - Smithsonian Institute Global Volcanism Program (www.volcano.si.edu)

UNAVCO - University NAVSTAR Consortium 



\section{ABSTRACT}

Volcán Pacaya is one of three currently active volcanoes in Guatemala. Volcanic activity originates from the local tectonic subduction of the Cocos plate beneath the Caribbean plate along the Pacific Guatemalan coast. Pacaya is characterized by generally strombolian type activity with occasional larger vulcanian type eruptions approximately every ten years. One particularly large eruption occurred on May 27, 2010. Using GPS data collected for approximately 8 years before this eruption and data from an additional three years of collection afterwards, surface movement covering the period of the eruption can be measured and used as a tool to help understand activity at the volcano. Initial positions were obtained from raw data using the Automatic Precise Positioning Service provided by the NASA Jet Propulsion Laboratory. Forward modeling of observed 3-D displacements for three time periods (before, covering and after the May 2010 eruption) revealed that a plausible source for deformation is related to a vertical dike or planar surface trending NNW-SSE through the cone. For three distinct time periods the best fitting models describe deformation of the volcano: 0.45 right lateral movement and $0.55 \mathrm{~m}$ tensile opening along the dike mentioned above from October 2001 through January 2009 (pre-eruption); $0.55 \mathrm{~m}$ left lateral slip along the dike mentioned above for the period from January 2009 and January 2011 (covering the eruption); -0.025 m dip slip along the dike for the period from January 2011 through March 2013 (post-eruption). In all bestfit models the dike is oriented with a $75^{\circ}$ westward dip. These data have respective RMS misfit values of $5.49 \mathrm{~cm}, 12.38 \mathrm{~cm}$ and $6.90 \mathrm{~cm}$ for each modeled period. During the time period that includes the eruption the volcano most likely experienced a combination of slip and inflation below the edifice which created a large scar at the surface down the northern flank of the volcano. All models that a dipping dike may be experiencing a combination of inflation and oblique slip below the edifice which augments the possibility of a westward collapse in the future. 



\section{INTRODUCTION AND GEOLOGIC SETTING}

The country of Guatemala is located on the North American and Caribbean tectonic plates between latitudes $13^{\circ} 45^{\prime}$ and $17^{\circ} 51^{\prime}$ and longitudes $88^{\circ} 13^{\prime}$ and $92^{\circ} 08^{\prime}$. Relative motion between the North American and Caribbean plates of approximately 18-22 mm $\mathrm{yr}^{-1}$ in eastern Guatemala reducing to a few millimeters per year in western Guatemala (Franco et al., 2012) creates extensive transform faulting throughout the central region of the country creating the Motagua and Chixoy-Polochic fault zones. Additionally, subduction of the Cocos plate beneath the Caribbean plate creates a complicated volcanic forearc environment, (Carr, 1984) forming the Guatemalan portion of the Quaternary Central American volcanic chain (Figure 2.1). According to Alvarado et al. (2011) the Caribbean plate moves approximately $15 \pm 2 \mathrm{~mm} \mathrm{yr}^{-1}$ relative to the Cocos plate in a west-northwestward direction parallel to the subduction trench.

The Quaternary volcanic chain of Central America stretches $1100 \mathrm{~km}$ along the Pacific coast, beginning at the Guatemala-Mexico border and trending east-southeast, roughly parallel to the Middle America Trench, until terminating in central Costa Rica (Bardintzeff and Deniel, 1992). The chain is created in the area due to the interaction of the North American, Cocos and Caribbean lithospheric plates. The Guatemalan volcanic front comprises the northern portion of this chain and stretches along the entire Pacific coast of the country. This front contains 324 volcanic vents that have been active within the Quaternary period according to a study completed by Bohnenberger in 1969. The majority of these are only small cinder and lava cones, but included are the approximately 27 stratovolcanoes, silicic volcanoes and dome complexes more widely known within the scientific community (Bohnenberger, 1969; Vallance et al., 1995). Of these 27 eruptive centers, three show present activity. These are Fuego volcano, the Santiaguito dome complex and the Pacaya volcanic complex, which is the focus of this study (Figure 2.1).

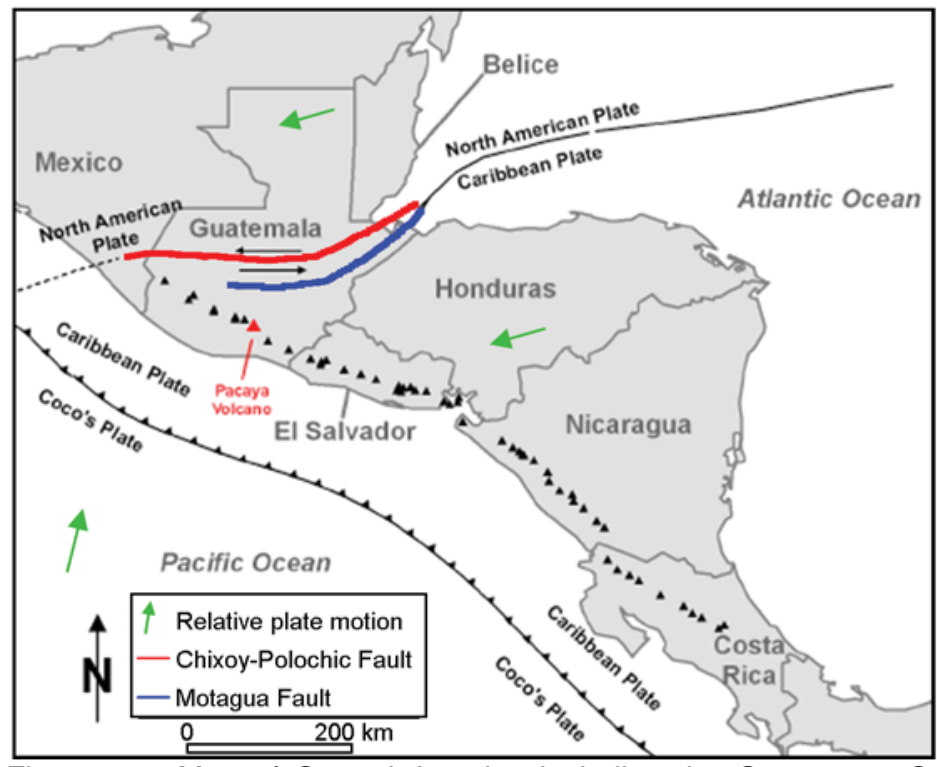

Figure 2.1. Map of Central America including the Quaternary Central American volcanic chain. Volcán Pacaya is shown in red. Additionally shown here are the Motagua and Chixoy-Polochic regional faults through Guatemala. Image adapted from: Matias, O. (2010). 



\section{History OF ACTIVITY at PACAYA}

Early eruptions of the Pacaya volcanic complex began approximately 23,000 years B.P. (Kitamura and Matias, 1995). The complex is located along the southern boundary of the 200 ka Amatitlan Caldera (Koch \& McLean, 1975; Wunderman \& Rose, 1984; Rose et al., 1999) and is comprised of numerous craters from past eruptions (Figure 3.1) including a crater where the township of San Vicente Pacaya is located, a crater named Laguna Calderas and one between the last and Lake Amatitlan (Meyer-Abich, 1956). The volcanic complex is composed of a series of volcanic products ranging from andesitic domes (i.e. Cerro Grande and Cerro Chiquito) to basaltic cinder and composite cones (i.e. Cerro Chino), as well as large deposits of olivine basalts, pyroxene andesites, dacite and rhyodacite lavas and pyroclastics (Eggers, 1971) and of course the present eruptive center, MacKenney Cone. The present volcanic cone is comprised of basaltic lavas, tephra deposits, minor pyroclastics surge deposits and at least one welded tuff (Conway et al., 1992).

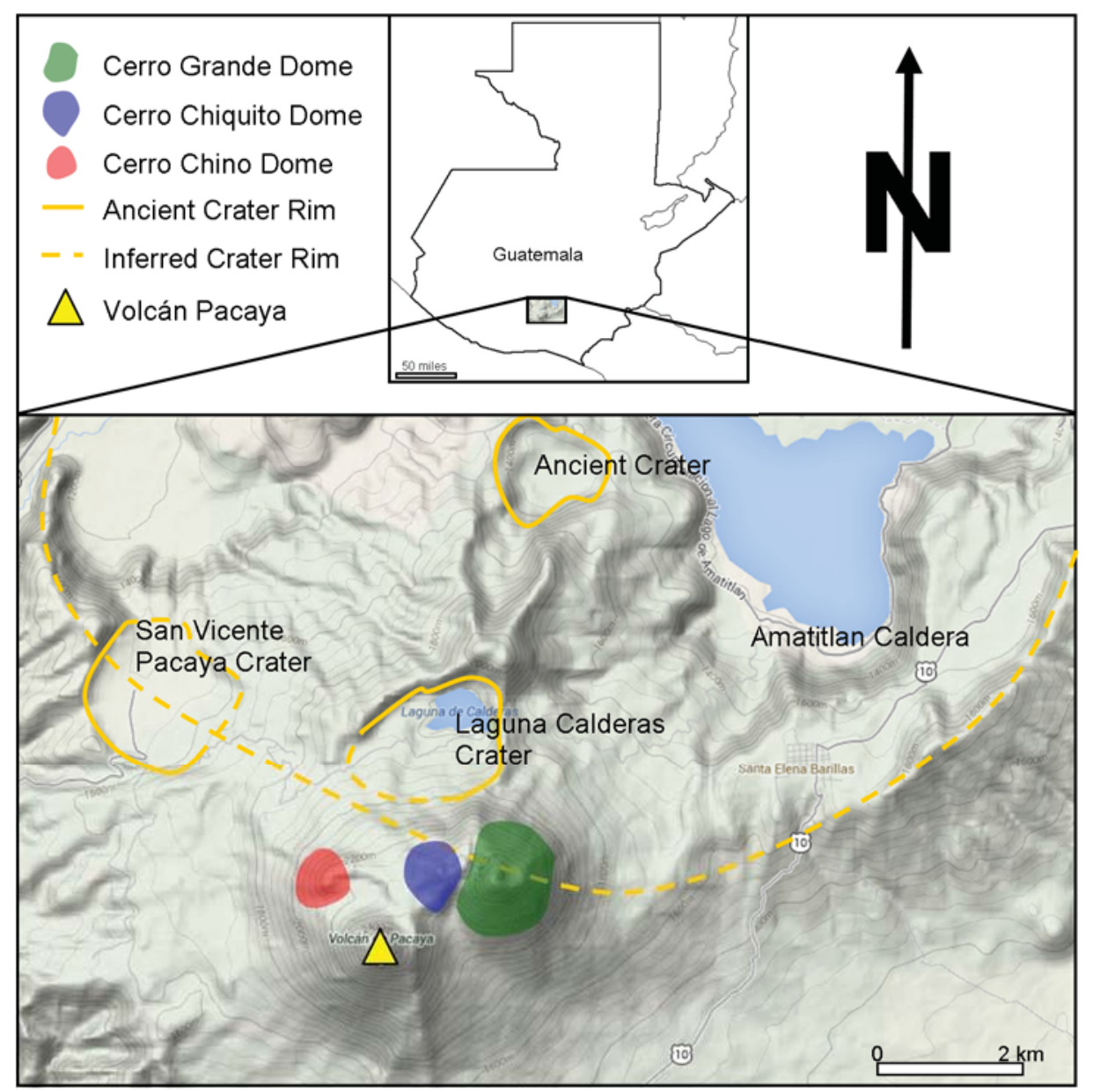

Figure 3.1. Map showing the southern rim of the Amatitlan Caldera and other ancient eruption craters remnant of historical eruptions of the Pacaya complex. Additionally shown are domes that make up the present Pacaya complex. Dashed lines indicate inferred crater or caldera boundaries. Map Data: Google (C) 2014. 
Eggers (1971) divides the history of activity of the volcanological complex into three distinct phases. During Phase I activity was characterized by eruption of pyroxene latiteandesite lavas which can be seen in outcrop together with interbedded layers of bombs, lapilli and scoria. This first phase of activity resulted in what we now see as the crater which holds the Laguna Calderas, a small crater lake contained within the ancient volcanic cone. During Eggers' (1971) second phase of activity, eruptions of large volumes of siliceous to intermediate lava created numerous domes in the surrounding area. Most notable of these are Cerro Grande and Cerro Chiquito, which are located to the east-northeast of the current volcanic cone. The third and most recent eruptive phase began with the eruption of basaltic lavas near the Laguna Calderas crater, transitioned to eruptions out of the Cerro Chino crater during the late 1770s and later the formation of the active volcanic center and continues today with present activity according to Eggers (1971). This period is also inclusive of a proposed edifice collapse event of the "Old Pacaya" cone dated between 400 and 2000 years B.P. (Vallance et al., 1988). Kitamura and Matias (1995) constrain the same event between 600 and 1500 BP.

Earliest recorded volcanic activity began in 1565 consisting of a few "violent explosions of ash" affecting the neighboring town of Antigua and continued sporadically until the 1880's (Meyer-Abich, 1956) after which there was an 80 year period of relative inactivity until an eruption on March 10, 1961 (Eggers, 1971; Bohnenberger, 1966). In 1965, the activity began to form a bulging parasitic cone within a small collapse amphitheater (created during the June 101962 eruption) on the volcano's western flank, which eventually overtook the original cone (Rose et al., 2013). Figure 3.2 presents a series of photographs showing the growth of this bulge. Eventually it overtook the ancestral cone and now is the focus of most present activity. The Pacaya volcano has experienced almost constant effusive activity combined with intermittent, large strombolian or vulcanian type eruptions every 10 years on average since 1961 (Bardintzeff and Deniel, 1992). Table 3.1 shows a list of recent activity (through March 2014). The present day volcanic cone, named the MacKenney Cone (hereon referred to as Volcán Pacaya) in honor of a local Pacaya enthusiast (Alfredo MacKenney) and his countless studies and photographs of the volcano, is formed within the horseshoe shaped scarp (Figure 3.3) created by the collapse of "Old Pacaya" (Rose et al., 2013). 


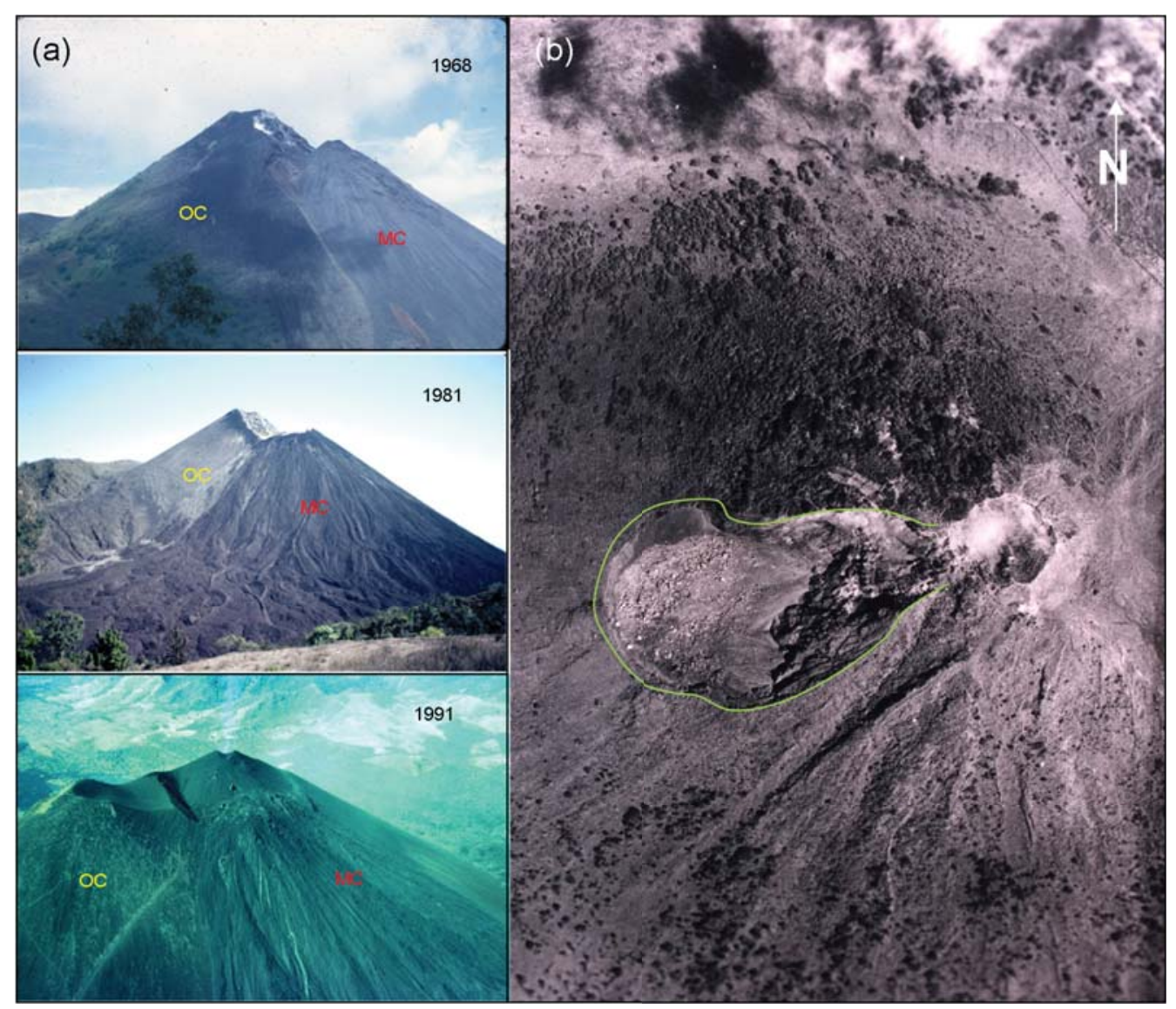

Figure 3.2. (a) A series of photographs showing the growth of MacKenney cone on the western flank of the original cone from 1968 through 1991. OC is the original cone and MC is the parasitic Mackenney Cone. (b) Aerial photograph of the 1962 collapse scarp within which the MacKenney cone began to erupt and grow in 1965. Collapse scarp is outlined in green. Photos (a) 1968 and 1981: adapted from Rose, W.I., Palma, J.L., Escobar Wolf, R., and Matías Gomez, R.O., (2013). A 50 yr eruption of a basaltic composite cone: Pacaya, Guatemala, in Rose, W.I., Palma, J.L., Delgado Granados, H., and Varley, N., eds., Understanding OpenVent Volcanism and Related Hazards: Geological Society of America Special Paper 498, p. 1-21, doi:10.1130/2013.2498(01). Photo (a) 1991: taken by William Rose; used with permission. Photo (b): taken by Instituto Geográfico Nacional de Guatemala (IGN), 1965.

On May 27, 2010 Pacaya experienced the largest eruption since 1964 (Wardman, 2012). This eruption was devastating to many surrounding communities, and had severe impacts on the country's capital, Guatemala City. After eruptive activity ceased completely (including small gas explosions and ash eruptions at the crater) the volcano entered a period of quiescence again. This period lasted until approximately December of 2012 at which point the volcano began to show signs of stirring to life again.

Beginning in January 2013 gas exhalations could be heard at the crater and increased in frequency through March 2013. INSIVUMEH began to report the exhalation of gaseous to ashy plumes rising to a maximum of $500 \mathrm{~m}$ above the crater approximately once every one to two weeks. This activity progressed through the periodic opening of a small lava lake in the crater, increasing exhalations of gas and ash eruptions, increases and changes in seismic activity, eruptions of tephra from the crater and finally into the resurgence of lava flows from the flanks of the volcano. Currently (at the time of writing) there are lava flows located on the western flank of the volcano (information adapted 
from the SIGVP website, personal communications with PNVPLC personnel and the author's own observations).

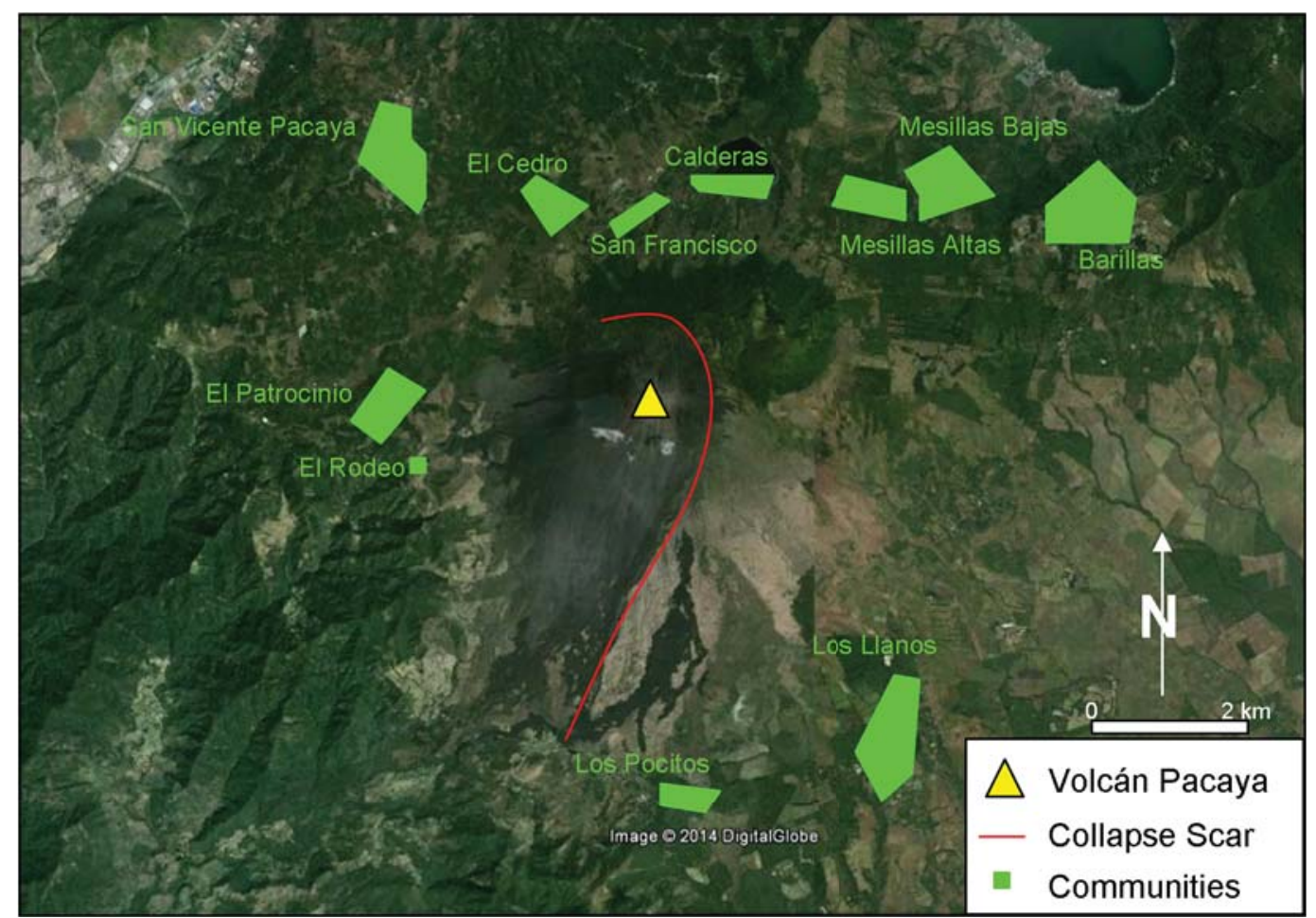

Figure 3.3. Location of Volcán Pacaya in relation to nearby communities (green). The red line indicates the horseshoe shape collapse scar from the 2000 years B.P. collapse. Map Data: Google, Digital Globe ( ) 2014. 
Table 3.1. Concise eruptive history at Volcán Pacaya including only major historical events. Information is adapted from Wardman et al., 2012 and the SIGVP, accessed on March 13, 2014.

\begin{tabular}{|c|c|}
\hline Date & Event \\
\hline 1565 & VEI 3 explosive eruption possibly originated from Cerro Chino cone. \\
\hline 1623 & VEI 3 explosive eruption \\
\hline 1651 & VEI 2 explosive eruption \\
\hline $\begin{array}{l}1655- \\
1699\end{array}$ & Periodic VEI 2 explosive eruptions. \\
\hline 1775 & $\begin{array}{l}\text { VEI } 3 \text { explosive eruption from Cerro Chino cone. Caused a several day "blackout" } \\
\text { and tephra fall in Antigua and a } 6 \mathrm{~km} \text { long basaltic lava flow. }\end{array}$ \\
\hline 1805 & VEI 2 explosive eruption. \\
\hline 1846 & VEI 2 explosive eruption from Cerro Chino cone. \\
\hline 1885 & VEI 2 explosive eruption. \\
\hline 1961 & $\begin{array}{l}\text { March 10: VEI } 2 \text { explosive eruption. Damage to property, lava flows. Eruption } \\
\text { initiated the current } \sim 50 \text { years of constant activity. }\end{array}$ \\
\hline 1964 & $\begin{array}{l}\text { VEI } 3 \text { explosive eruption. Damage to property, pyroclastic flows and lava flows led } \\
\text { to subsequent evacuation. }\end{array}$ \\
\hline \multirow{2}{*}{1987} & $\begin{array}{l}\text { January: Explosive eruptions destroyed } 63 \text { homes and forced } 3000 \text { people to } \\
\text { evacuate. Damage to nearby forests from hot ashfall. }\end{array}$ \\
\hline & $\begin{array}{l}\text { June: Large explosive eruption caused heavy tephra fall up to } 5 \mathrm{~km} \mathrm{SW} \text { of the } \\
\text { volcano. Evacuation of El Caracol, El Rodeo and El Patrocino due to lava flows. }\end{array}$ \\
\hline 1991 & $\begin{array}{l}\text { June-August: threat of pyroclastic flows causes evacuation of villages and tephra fall } \\
\text { reported more than } 20 \mathrm{~km} \text { west of the cone. An estimated tephra volume of } \\
1-8 \times 10^{7} \mathrm{~m}^{3} \text { implies VEI 2-3. }\end{array}$ \\
\hline 1996 & $\begin{array}{l}\text { November: eruption cause tephra fall to southwest of the volcano. An estimated } \\
\text { tephra volume of } 2-6 \times 10^{6} \mathrm{~m}^{3} \text { implies VEI } 1-2 \text {. }\end{array}$ \\
\hline 1997 & $\begin{array}{l}\text { May: eruption distributed tephra to the north, with tephra fall recorded in Guatemala } \\
\text { City. Estimated tephra volume of } 2-3 \times 10^{6} \mathrm{~m}^{3} \text { implies VEI } 1 .\end{array}$ \\
\hline \multirow[t]{2}{*}{2000} & $\begin{array}{l}\text { January: Creation of a cinder cone approximately } 50 \mathrm{~m} \text { high before the eruption. } \\
\text { Fire fountaining approximately } 800 \mathrm{~m} \text { high and tephra fall to the south of the vent } \\
\text { caused the evacuation of } 1000 \text { people in nearby villages, and the closure of La } \\
\text { Aurora international airport. }\end{array}$ \\
\hline & $\begin{array}{l}\text { February: Eruption of tephra column } 2 \mathrm{~km} \text { high and tephra fall on the towns of } \\
\text { Escuintla and Siquinalá resulting in evacuation of the surrounding towns. }\end{array}$ \\
\hline 2001 & VEI 1 explosive eruption. \\
\hline 2002 & VEI 1 explosive eruption. \\
\hline 2004 & VEI 1 explosive eruption, lava flows. \\
\hline 2006 & $\begin{array}{l}\text { March-April: lava flows from Mackenney Cone to the north. Accumulation of lava } \\
\text { next to scarp on northern side implies that the scarp wall no longer confines future } \\
\text { lava flows down north flank. }\end{array}$ \\
\hline 2010 & $\begin{array}{l}\text { May 27: An ash plume } 3 \mathrm{~km} \text { high was produced, along with } 500 \mathrm{~m} \text { fire fountaining. } \\
\text { Ballistic blocks fell up to } 6-7 \mathrm{~km} \text { from the vent. The eruption plume travelled to the } \\
\text { north and northeast, depositing tephra on Guatemala City with an estimated volume } \\
\text { of } 1.3 \times 10^{7} \mathrm{~m}^{3} \text { implying VEI } 3 \text {. }\end{array}$ \\
\hline
\end{tabular}




\begin{tabular}{|l|l|}
\hline Date & Event \\
\hline 2013 & $\begin{array}{l}\text { March-June: Small ash eruptions (25 m above crater) and incandescence seen in } \\
\text { crater accompanied by augmenting weak-moderate frequent explosions. } \\
\text { July-August: Incrementation in activity to include weekly to biweekly weak ash } \\
\text { eruptions ejecting material up to } 200 \mathrm{~m} \text { above the crater and the formation of a } \\
\text { small cone inside the MacKenney cone as the source of moderate Strombolian } \\
\text { eruptions. }\end{array}$ \\
\hline 2014 & $\begin{array}{l}\text { January: Resurgence of lava effusion. Eruption of a lava flow } 3.6 \mathrm{~m} \text { long. } \\
\text { February: Large ash eruptions with plumes reaching up to } 2.5 \mathrm{~km} \text { above the } \\
\text { MacKenney cone. } \\
\text { March 5-11: Small explosions from Pacaya generated diffuse ash plumes. Minor } \\
\text { avalanches descended the W flank. During 8-9 March lava flows were active, and } \\
\text { white and gray steam plumes rose } 200 \mathrm{~m} \text { above the crater and drifted SE. }\end{array}$ \\
\hline
\end{tabular}




\section{Volcanic Hazards at PacaYa}

At present Volcán Pacaya looms at an altitude of 2,552 $\mathrm{m}$ above sea level. There are many small villages and the municipal township within $5 \mathrm{~km}$ of the volcanic vent (Figure 3.3). These communities include San Vicente Pacaya (the municipal seat), El Cedro, San Francisco de Sales, San José Calderas, El Patrocinio, and El Rodeo. Together, the villages and municipal seat have a total population of approximately 17,949 (in the year 2014) as projected from the last census in 2009 (Municipalidad SVP, 2009). Though tourism related to volcanic activity has been a relatively constant source of income for the local population since the return of lava flows in 1961, the active volcano also poses a very real threat to these nearby communities.

At Volcán Pacaya the major hazards are lava flows and eruption ballistics including blocks and bombs, tephra fall and potential ash and pyroclastic flows, though this last threat is less imminent (Conway et al., 1992). INSIVUMEH and JICA created a series of hazard maps for the area surrounding Volcán Pacaya in 2003. Both institutions investigated lava flow, ballistic, ashfall and debris avalanche hazard zones for the area, as these are the most common threats to the region. Due to these hazards, there have been eleven eruption related evacuations of the surrounding towns (mentioned above) since 1987 including the evacuation due to the May 2010 eruption (Matias, 2010).

\subsection{Lava Flows}

The most constant threat that the volcano poses is that of lava flows reaching nearby populations. Since 1961 lava flows have been almost continuous, barring brief pauses after large eruptive events. Flows have originated from the crater and from almost all sides of the volcano and are pahoehoe and more typically a'a lavas (Rose et al., 2013). Figure 4.1 shows a geologic map of mainly lava flow deposition and accumulation between 1961 and 2010 originally published by Matias et al., 2012. The most recent lava flow threat to a community was after a large eruption in May, 2010. In the days following the initial eruption a new secondary vent was created on the southern flanks of MacKenney Cone, outside the collapse scarp (see Figure 4.1). According to a CONRED bulletin released on May 29, 2010 (CONRED, 2010), this flow moved initially at a rate of 100 meters per hour and slowed to approximately $15 \mathrm{~m} / \mathrm{hr}$ by June 6 and to about $1 \mathrm{~m} / \mathrm{hr}$ by June 8 (Escobar, 2011) traveling directly toward the village of Los Pocitos and a few nearby coffee farms. The flow destroyed three temporary shelters built within the farm Pacaya Grande and covered many acres of farmland, though there were no casualties due to the flow.

In 2006 there was a threat of flows reaching the community of San Francisco de Sales. Flows had been filling the "Old Pacaya" collapse scarp since 1961 and in 2006 the flows were able to flow out and over the edge of the scarp and travel in the direction of the village of San Francisco (Figures 3.3, 4.1). Soon after this happened the source of the flows changed and the flows ceased their advance and fortunately, the inhabited area was not reached by the flows, but it was none the less impacting on the population. Additionally, in 1972 flows traveling down the western flank of MacKenney cone came dangerously close to reaching the villages of El Patrocinio and El Rodeo, though topographic barriers aided in preventing the flows from advancing and the source ceased before they were able to reach populated areas. 


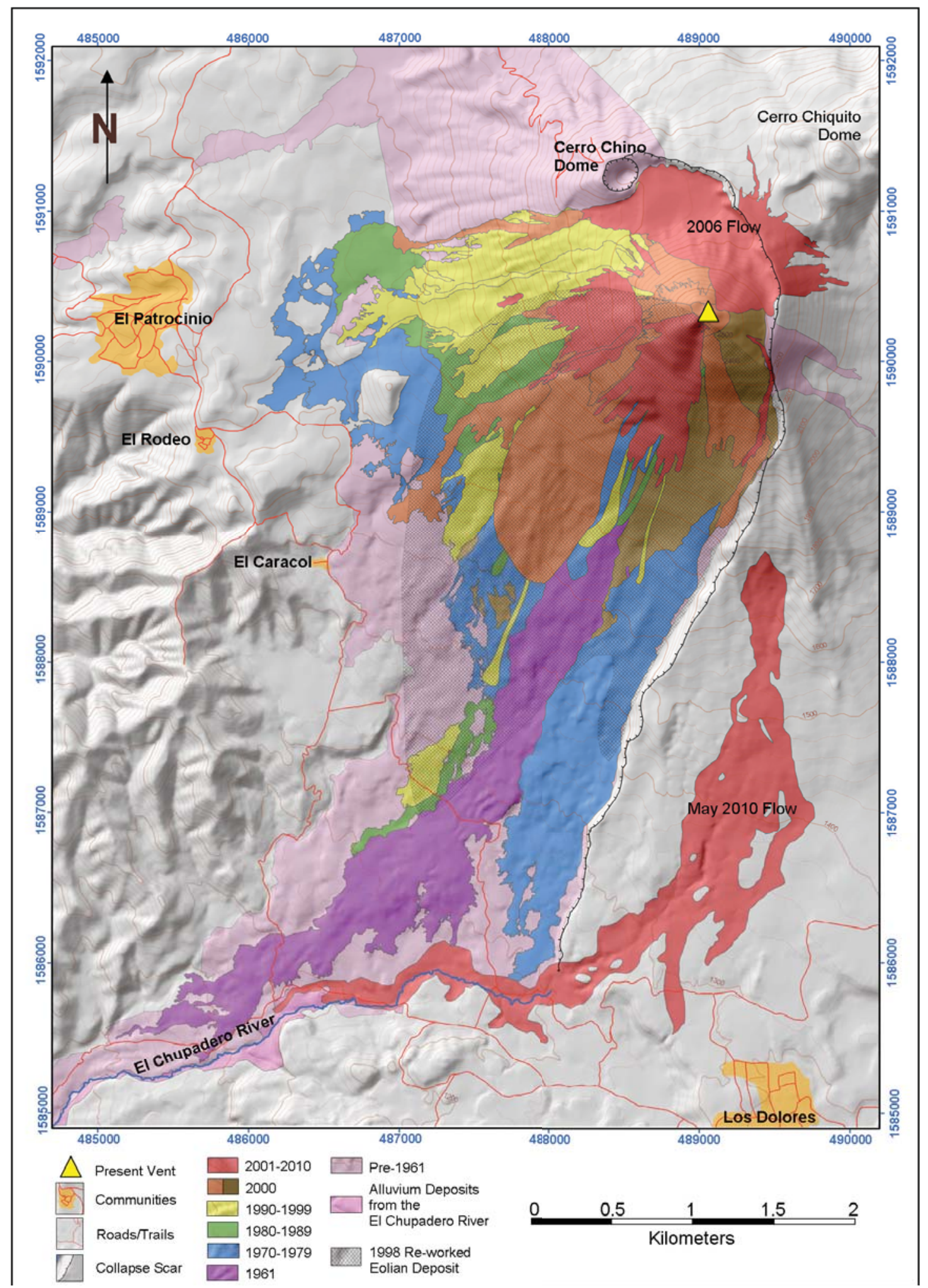

Figure 4.1. Geologic map of lava flows erupted at Volcán Pacaya. Each color represents all deposits within the time period indicated in the legend. Units include pahoehoe and a'a' lava flows and also pyroclastic flows, ashfall, scoria, spatter and other deposits from eruptions at Pacaya. Topographic interval is 20 meters Map adapted from Matias et al., 2012. 


\subsection{Ballistics/ashfall/pyroclastic flows/tephra}

The other common hazard at Volcán Pacaya is that of ballistic material and ashfall. During the May 2010 eruption, ash was ejected up to $1.5 \mathrm{~km}$ above the crater and subsequently dispersed over a large area. According to Escobar (2011) the ash covered an area of over $1000 \mathrm{~km}^{2}$ to the north-northeast of the volcano and produced a tephra blanket with an approximate volume of $1.3 \times 10^{7} \mathrm{~m}^{3}$ (Rose et al., 2013). Reports from INSIVUMEH dated soon after the eruption indicated that incandescent material was launched up to $500 \mathrm{~m}$ vertically above the crater. This eruption column was sustained for approximately 45 minutes (timed by author). Large ballistic material fell mostly on the communities of San Jose Calderas, San Francisco de Sales, El Cedro, Mesillas Altas and Bajas and San Vicente Pacaya.

The smaller communities to the north of the volcano were most impacted by volcanic ballistics. Through many conversations with the locals the author learned that there were lava bombs hitting the ground and exploding on impact due to very high gas content in the lava. Some of these bombs were reported to be up to $0.5 \mathrm{~m}^{3}$ in size according to the villagers and witnesses. Figure 4.2 shows photographs of some of the ballistics found around the volcano and within the village of San Francisco de Sales. Additionally, tephra accumulation over the hours and days following the eruption reached up to $20 \mathrm{~cm}$ in total in nearby communities and diminished towards the northeast, travelling to and falling as far as the Izabal Lake. This tephra fall even caused the Guatemalan government to close the national airport due to ash accumulation on the runways and the tops of the planes as well as in the city's drainage system and on the streets. In the months after the eruption (June through August) small ash eruptions from the crater were occurring on a weekly basis, depositing very small quantities of ash on the immediate skirts of the volcano, barely reaching any of the surrounding population.

Small pyroclastic flows were also observed originating at the cone in the days and months following this eruption. Generally these events were small and occurred on average twice a week during a few weeks following the eruption and dwindled to around once every two weeks in the following month. The last event was recorded (by the author) on July 25,2010 . Most commonly these flows were minor and travelled along the western flank of the volcano and dissipated before reaching the nearby communities of EI Patrocinio and EI Rodeo and causing any damage, though subsequent light ashfall within the communities was almost always noticed.

Ashfall from Volcán Pacaya has also historically included significant ashfall over the communities to the south of the crater. During the 2000 eruption more than 1000 people were evacuated from the villages of El Caracol, El Rodeo and El Patrocinio due to ashfall. In 1998 there was another considerable ashfall over Guatemala City which caused the closure of the La Aurora National Airport (information from INSIVUMEH). Additional hazards include various instances of ash coverage of Antigua, Guatemala located approximately $25 \mathrm{~km}$ to the northwest of the crater. Some of these events were characterized by "blackouts" of the city, though the last time this happened was in 1775 (Table 3.1). 


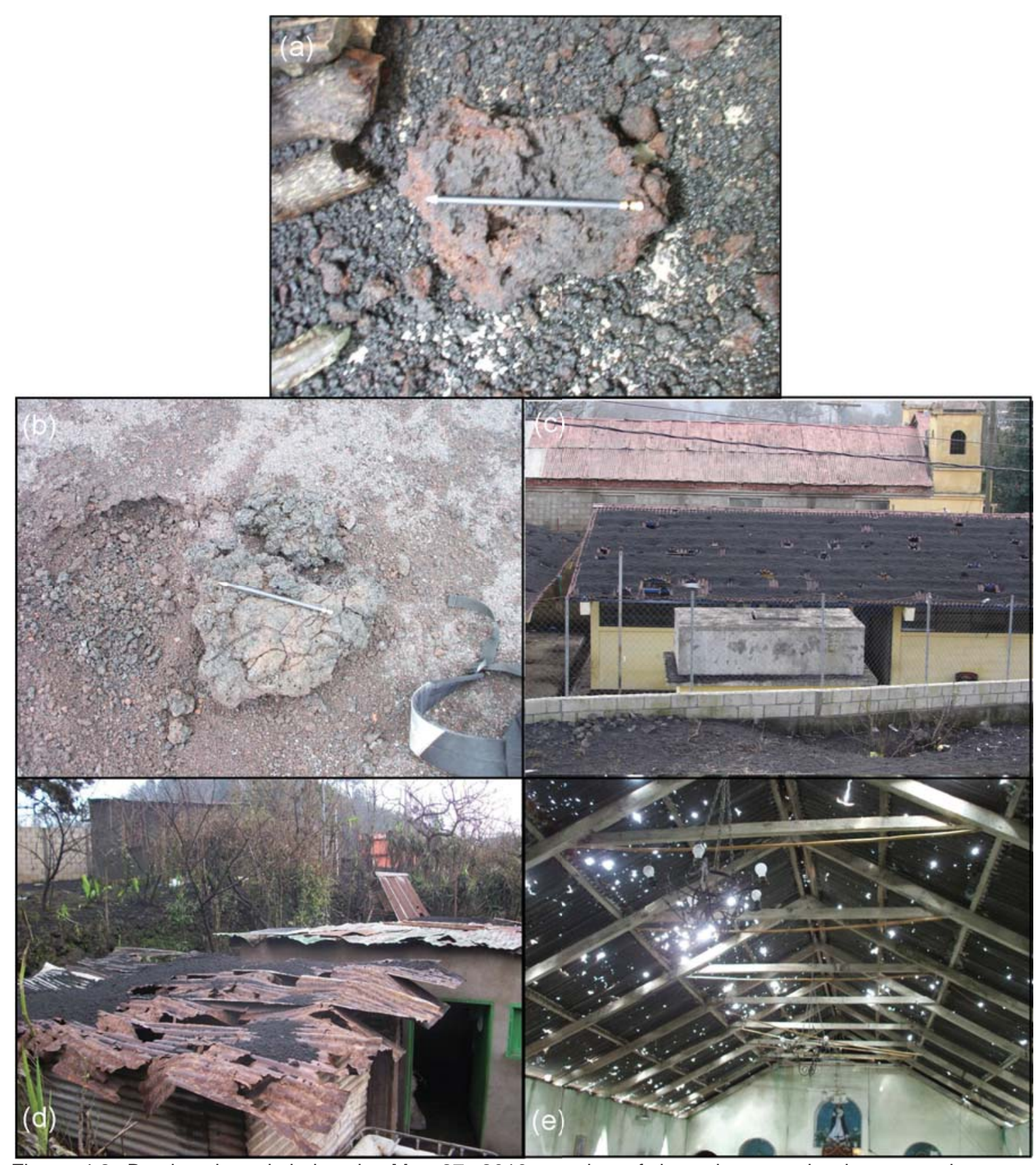

Figure 4.2. Bombs ejected during the May 27, 2010 eruption of the volcano and subsequent damages caused. Photos (a) and (b) show very brittle basaltic bombs with high bubble content. This type of bomb traveled far enough to reach the nearby communities of San Francisco, San Jose Calderas and El Cedro, piercing roofs of schools, homes and churches roofed with aluminum sheet metal (c, d, and e). Photos by author. 


\subsection{Edifice Collapse and Debris Avalanche}

The possibility of edifice collapses and debris avalanches cannot be ruled out at Pacaya as a future hazard. Taking into consideration the edifice collapse that created the horseshoe shaped scar (Vallance et al., 1988; Kitamura and Matias, 1995) within which the volcano is currently erupting and growing, and small collapse events that have occurred in congruence with large eruptions (i.e. June, 1962), this is a real, though less common, hazard at Pacaya. Vallance et al. (1995) have outlined the history of two of these events. The first is the previously mentioned collapse creating the still-visible scar around Volcán Pacaya. The second event that they define is a debris avalanche that flows south with a source at Pacaya.

Escobar (2011) discusses in his report the possibility of present-day edifice movement. He proposes that the large trough created by the May 2010 eruption could be resultant of large edifice movement. He additionally proposes that the orientation of the trough, the new lava vent and other structural failures form a rather linear north-northwest trend (Figure 4.3) and that this trend could be a potential "warning sign" for future failures of the Pacaya edifice, though this is only his hypothesis. Additionally, Schaefer et al. (2013) conducted a study of the possibility of collapse at Pacaya which yielded results indicating that many factors combine at Pacaya to influence and increase the possibility of large-scale failure in the future. Results from their study are discussed further on. Rose et al. (2013) also suggest that edifice collapse at Pacaya is a future hazard to be investigated and that if it were to occur a directed blast to the west could result and seriously affect populations in that region.

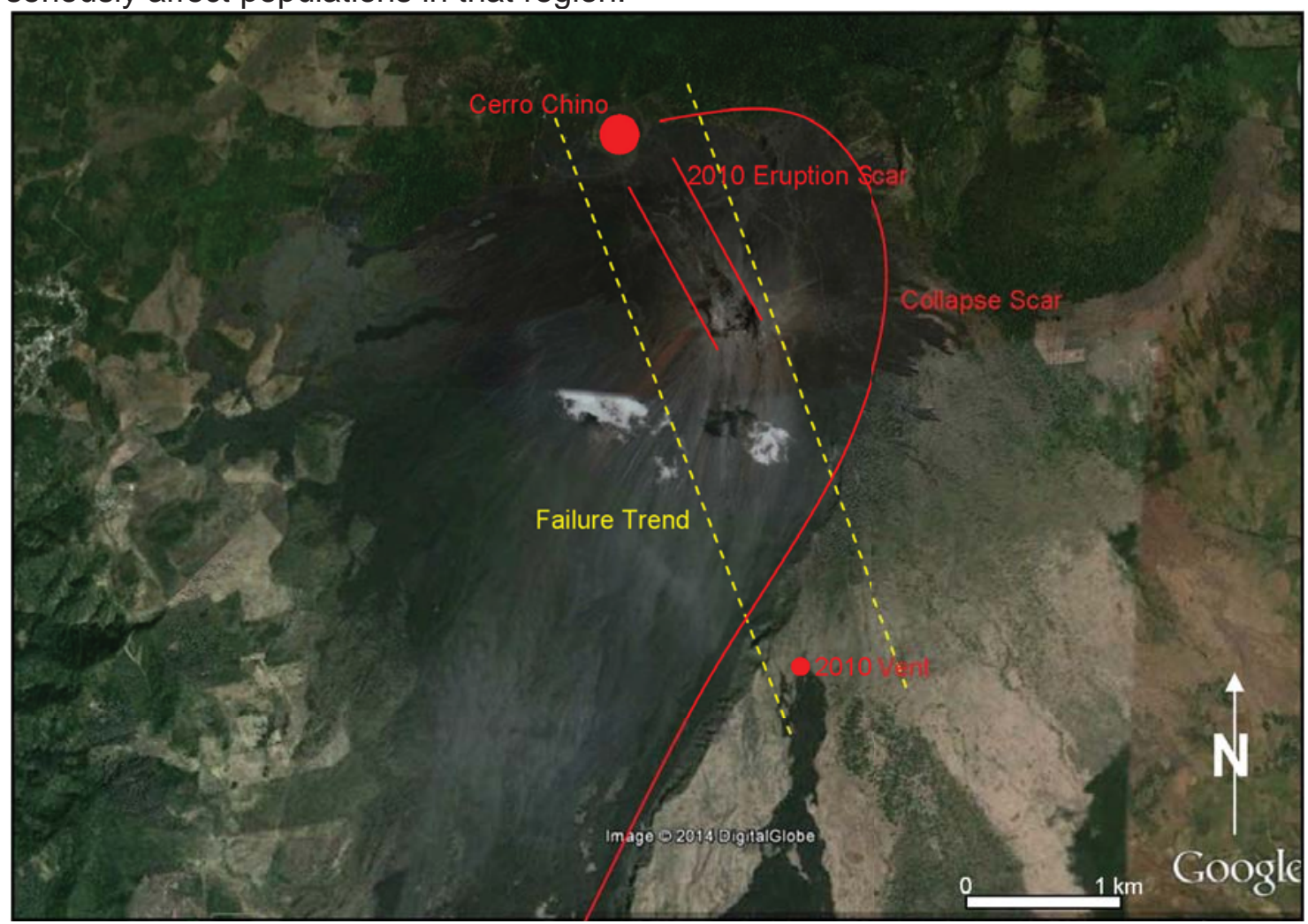

Figure 4.3. Satellite photograph showing various eruptive features which form a generally north-northwest trend within and surrounding the edifice of Pacaya. Map Data: Google, Digital Globe (c) 2014. 



\section{GPS AND DEFORMATION MONITORING}

\subsection{How GPS works}

The Global Positioning System (GPS) is a Global Navigation Satellite System (GNSS) which consists of 24 satellites put in orbit by the US Department of Defense. Originally intended for military operations, it was later expanded to include the hundreds of day-today applications it is used for currently. The general public uses GPS information and positioning most commonly for driving directions in cars and instant positioning in cell phones as handheld and personal devices become increasingly more common. It is also the principal navigational tool used in the air and at sea. These applications generally use instant positioning for the quickest response to changes in position. Instant positions usually have errors on the order of a few meters. For the aforementioned purposes these errors are acceptable. In navigation the most accurate receivers are used to acquire better position solutions. The U.S. Coast Guard implements Differential GPS (DGPS) which provides positions to about $10 \mathrm{~cm}$ accuracy. Differential GPS uses the difference between satellite signals to fixed receivers of known location and moving receivers of unknown location (rovers) to calculate a more accurate position. Recently, techniques have been developed to calculate more precise positions for satellite to receiver signals. These are called precise positions and are calculated similarly to the instant positions we see in handheld devices, however they are more precise due to longer observations times and averaging of positions calculated over long periods of time. JPL, part of the California Institute of Technology and funded by NASA has created a software packages called GIPSY-OASIS that can calculate precise positions with accuracy of up to $3 \mathrm{~cm}$ for signals with observation times of a few hours.

Generally, a GPS-based position is achieved by calculating the travel time of signals between satellites with known positions and a receiver of unknown position. To calculate a position there must be a minimum of three satellites sending a signal to the receiver for position trilateration. Signal travel times from the three or more satellites are then used to calculate distances. These signals are sent in two patterns, or phases: code phase and carrier phase. Code phase consists of a long string of codes that, when combined with the known times associated with them, can be used to determine the distance. However, because the codes are long, accuracy of at best $1 \mathrm{~m}$ can be achieved. The carrier phase can then be used to improve the accuracy of the distance calculation because it uses only a modulation of the carrier frequency. For example, one can receive a signal that indicates a distance of 175,295,176 meters from the satellite according to the code phase, while the carrier phase indicates a distance of $5.9 \mathrm{~cm}$ times an unknown number of cycles (Javad, 1998). However, we cannot simply combine these two patterns to achieve accuracy in position of up to one millimeter. Various factors introduce error, such as the clocks in the satellite and/or receiver, satellite orbit errors, atmospheric interference errors, manmade errors and other source and receiver calculation errors. A complete explanation of the workings of GPS and each error that can be introduced is beyond the scope of this paper. A very good, though basic, explanation can be found in Javad (1998) and a more technical explanation of GPS and some of its applications in Dixon (1991).

\subsection{Use for volcano monitoring}

Considering the relatively continuous activity of Volcán Pacaya, monitoring this activity is 
critical for reducing risk from eruption hazards. It allows the scientific community as a whole to better understand the processes at work at a particular volcano and transmit that information to the general population to mitigate risks. High precision (or differential) GPS monitoring is an efficient way to monitor surface deformation due to the accuracy of position measurements.

In 2009, an eight station local GPS monument network was installed around the volcanic cone (Figure 5.1) to monitor its surface deformation through periodic observations of the network. Escobar (2011) indicates that using GPS to monitor the edifice movement of the volcano could be a tool to investigate the possibility of future edifice collapse related to the current activity. In addition continuous GPS data can be used as a tool to understand subsurface magmatic processes, plumbing system evolution and eruption dynamics (Cabral-Cano et al., 2008). Though the GPS stations at Pacaya are not continuously collecting data, episodic measurements allow for temporally coarser (more long-term) monitoring of deformation.

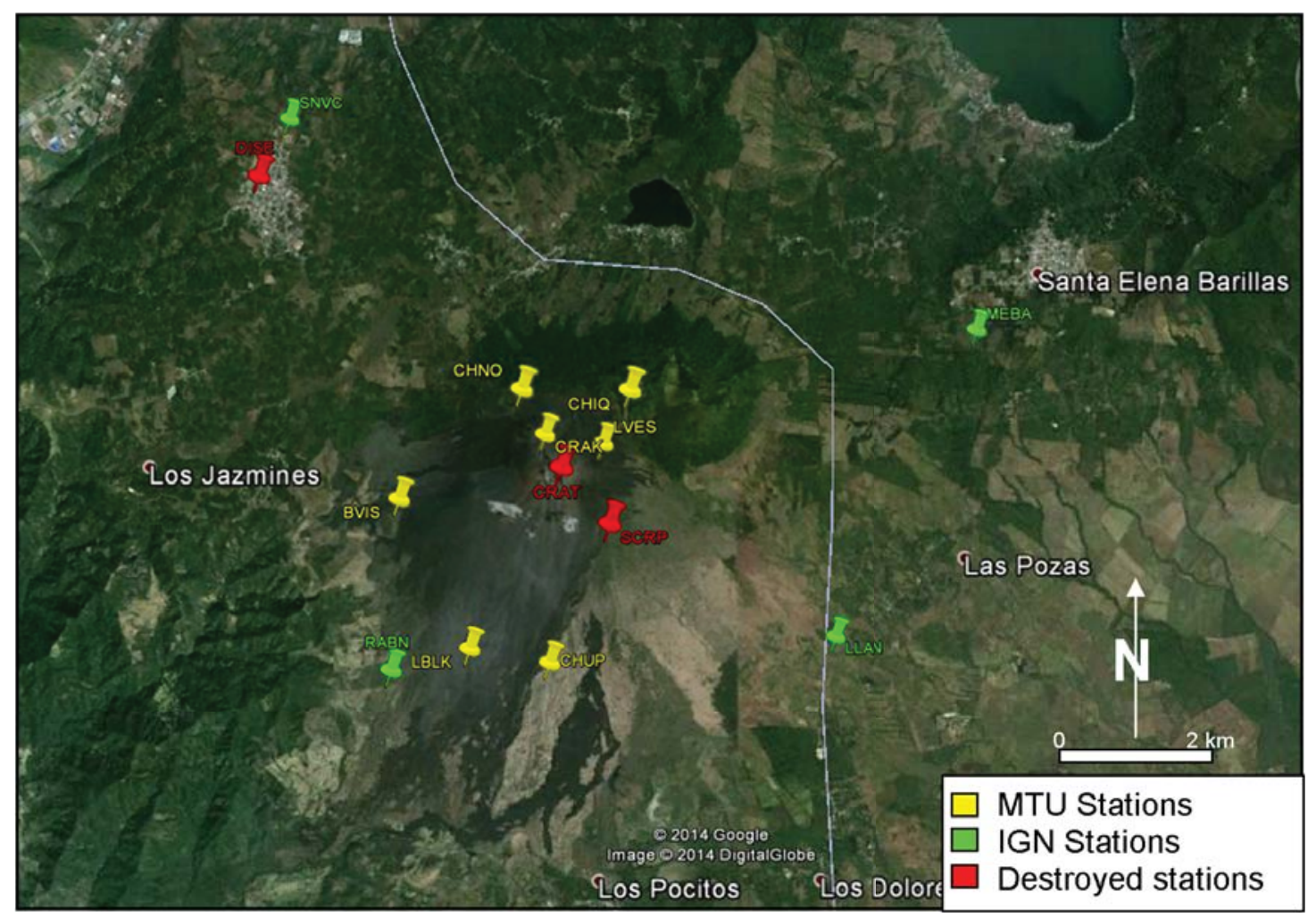

Figure 5.1. Map of GPS monuments at Volcán Pacaya. Green pins indicate active stations from the IGN GPS network. Yellow pins indicate stations within the MTU network. Red pins indicate destroyed stations. Map Data: Google, Digital Globe (C) 2014. 


\section{GPS NetWorks at PACAYA}

\subsection{IGN Network}

The GPS monument network established by IGN was first observed in 2001 . This network includes four monuments that have been regularly measured with GPS. One monument functions as a base station (SNVC) and three others operate as field stations (MEBA, LLAN, RABN). This small GPS network has geographic coverage around the eastern-southeastern half of the edifice. Initial intentions for this network are unclear. During the July 2010 observations after the large May 2010 eruption of Pacaya future observations were discussed, though never actually carried out. The SNVC data is not used in this study due to the distance from the volcano. This station was installed to be used as a base station for differential GPS analysis of the three rover stations, thus the large distance from the volcano.

\subsection{MTU Network}

The MTU GPS network at Pacaya was installed in its majority in January of 2009. The network included a base station located in the municipality of San Vicente Pacaya approximately $5 \mathrm{~km}$ to the north-northwest of the crater and 8 stations located around the volcanic cone. The stations initially consisted of the base station (DISE) installed on the roof of the local tourism police station and 7 rover stations (BVIS, CHIQ, CHNO, CHUP, CRAT, LBLK, SCRP). Tables 6.1 through 6.3 contain the name of each station and its corresponding four character station code (except the base station). During the May 2010 eruption of Pacaya the CRAT and SCRP stations were destroyed and in April of 2012 the DISE base station was removed by police officials due to closing of the station. In September of 2011 an additional field station (LVES) was installed on the eastern flank of the volcano and in August of 2012 the CRAK station was installed within the large trough that opened on the northern flank of the active crater after the May 2010 eruption, and was subsequently covered with lava in November of 2013.

The network was designed to have geographic coverage around the volcano on all flanks and provide a solid picture of movement from every angle. Through the destruction and installation of new stations, the volcano-surrounding geography was maintained for the duration of this study. Like the IGN network, the MTU network was initially intended to be used for differential GPS analysis using baseline solutions. Due to software issues and the destruction of the base station halfway through this project, the DISE station data was discarded from this project and differential GPS analysis not carried out.

The intended use of this network was predominately focused on understanding the movement of the volcano through its constant activity and also to determine the possibilities of using GPS as a monitoring tool, potentially in conjunction with seismic data, by periodic data collection. 
Table 6.1 Occupation times for four stations (BVIS, CHIQ, CHNO and CHUP) from October 2001 through March 2013. A red line indicates pre construction of the station. Distance to crater is approximate and calculated as the distance between the station and the destroyed CRAT station.

\begin{tabular}{|c|c|c|c|c|}
\hline & $\begin{array}{c}\text { Cerro Buena } \\
\text { Vista }\end{array}$ & $\begin{array}{c}\text { Cerro } \\
\text { Chiquito }\end{array}$ & Cerro Chino & El Chupadero \\
\hline & BVIS & CHIQ & CHNO & CHUP \\
\hline Latitude & 14.377872 & 14.389502 & 14.389666 & 14.359492 \\
\hline Longitude & -90.621040 & -90.593935 & -90.606154 & -90.603997 \\
\hline Elevation (m) & 1726.92 & 2381.43 & 2242.12 & 1537.25 \\
\hline Distance to crater (m) & 2131 & 1203 & 1046 & 2439 \\
\hline Date & \multicolumn{4}{|c|}{ Occupation Time (HH:MM) } \\
\hline $10 / 16 / 2001$ & & 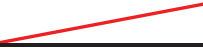 & & \\
\hline $11 / 21 / 2001$ & & 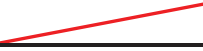 & & 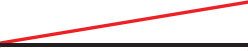 \\
\hline $1 / 16 / 2002$ & & & & \\
\hline $3 / 20 / 2002$ & & & & \\
\hline $5 / 23 / 2002$ & & . & & \\
\hline $6 / 21 / 2002$ & 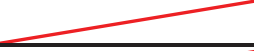 & $=$ & - & \\
\hline $8 / 28 / 2002$ & & & & \\
\hline $11 / 26 / 2002$ & - & & & \\
\hline $1 / 22 / 2003$ & & 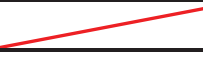 & & \\
\hline 4/3/2003 & & & & \\
\hline $5 / 20 / 2003$ & & . & & \\
\hline $8 / 7 / 2003$ & & & & \\
\hline 9/24/2003 & 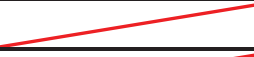 & 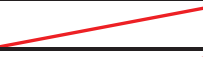 & & \\
\hline $11 / 28 / 2003$ & & & & \\
\hline $2 / 17 / 2004$ & & 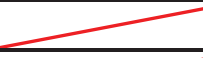 & & \\
\hline $5 / 12 / 2004$ & & & & \\
\hline $6 / 16 / 2004$ & & & & \\
\hline $11 / 9 / 2004$ & & & & \\
\hline $12 / 14 / 2004$ & & 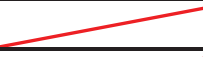 & . & \\
\hline 2/3/2005 & & & & \\
\hline $5 / 25 / 2005$ & 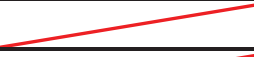 & 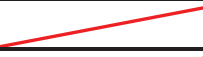 & 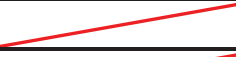 & 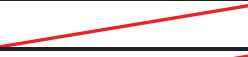 \\
\hline 9/13/2005 & & & - & \\
\hline $11 / 9 / 2005$ & 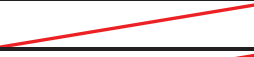 & 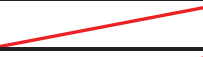 & 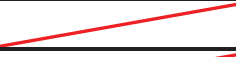 & . \\
\hline $3 / 6 / 2006$ & 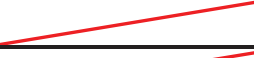 & & 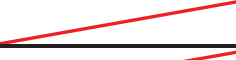 & \\
\hline $7 / 2 / 2008$ & 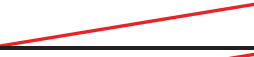 & $=$ & 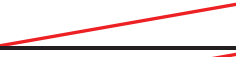 & 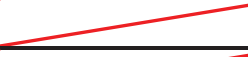 \\
\hline $10 / 31 / 2008$ & & & 叛 & \\
\hline $1 / 19 / 2009$ & $7: 58$ & & & \\
\hline $1 / 20 / 2009$ & & & & $7: 52$ \\
\hline $1 / 21 / 2009$ & & & & \\
\hline $1 / 22 / 2009$ & & & & \\
\hline $1 / 23 / 2009$ & & 9:29 & $7: 46$ & \\
\hline $1 / 24 / 2009$ & & & & \\
\hline $7 / 28 / 2010$ & 6:02 & & & \\
\hline
\end{tabular}




\begin{tabular}{|c|c|c|c|c|}
\hline Date & BVIS & $\mathrm{CHIQ}$ & CHNO & CHUP \\
\hline $1 / 20 / 2011$ & & & 7:01 & \\
\hline $1 / 21 / 2011$ & & $8: 02$ & & \\
\hline $1 / 22 / 2011$ & & & & \\
\hline $1 / 23 / 2011$ & & & & \\
\hline $1 / 24 / 2011$ & & & & \\
\hline $1 / 25 / 2011$ & & & & 5:08 \\
\hline $1 / 26 / 2011$ & $7: 13$ & & & \\
\hline $9 / 20 / 2011$ & & $3: 00$ & $4: 11$ & \\
\hline $9 / 21 / 2011$ & $6: 15$ & & & \\
\hline $9 / 22 / 2011$ & & & & $3: 22$ \\
\hline $9 / 24 / 2011$ & & & & \\
\hline $11 / 30 / 2011$ & $4: 33$ & & & \\
\hline 12/1/2011 & & & & \\
\hline $12 / 2 / 2011$ & & $3: 59$ & & \\
\hline $12 / 3 / 2011$ & & & $4: 01$ & \\
\hline $12 / 4 / 2011$ & & & & $4: 15$ \\
\hline $12 / 5 / 2011$ & & & & \\
\hline $12 / 6 / 2011$ & & & & \\
\hline $1 / 6 / 2012$ & & & & \\
\hline 1/7/2012 & & & $4: 16$ & \\
\hline $1 / 8 / 2012$ & & $3: 49$ & & \\
\hline 1/9/2012 & $4: 03$ & & & \\
\hline $1 / 10 / 2012$ & & & & 4:02 \\
\hline $4 / 10 / 2012$ & & & & $4: 03$ \\
\hline $4 / 11 / 2012$ & $4: 51$ & & & \\
\hline $4 / 12 / 2012$ & & & $4: 02$ & \\
\hline $8 / 26 / 2012$ & & & & $4: 10$ \\
\hline $8 / 27 / 2012$ & & $5: 02$ & & \\
\hline $8 / 28 / 2012$ & & & $6: 02$ & \\
\hline 8/29/2012 & $5: 10$ & & & \\
\hline $11 / 29 / 2012$ & & & & $4: 04$ \\
\hline $11 / 30 / 2012$ & & & $6: 08$ & \\
\hline $12 / 1 / 2012$ & & $5: 45$ & & \\
\hline $12 / 2 / 2012$ & $6: 53$ & & & \\
\hline $1 / 11 / 2013$ & $6: 36$ & & & \\
\hline $1 / 12 / 2013$ & & $4: 14$ & $4: 30$ & \\
\hline $1 / 13 / 2013$ & & & & 4:09 \\
\hline $3 / 28 / 2013$ & $2: 20$ & & & 4:04 \\
\hline $3 / 29 / 2013$ & & $3: 55$ & $3: 36$ & \\
\hline tal \# of Obs & 11 & 9 & 10 & 10 \\
\hline
\end{tabular}


Table 6.2 Occupation times for four stations (CRAK, CRAT, LBLK and LLAN) from October 2001 through March 2013. A red line indicates either pre construction or post destruction of the station. Distance to crater is approximate and calculated as the distance between the station and the destroyed CRAT station.

\begin{tabular}{|c|c|c|c|c|}
\hline & Crack & Crater & $\begin{array}{c}\text { Lavas } \\
\text { Suroeste }\end{array}$ & Los Llanos \\
\hline & CRAK & CRAT & LBLK & LLAN \\
\hline Latitude & 14.384957 & 14.381670 & 14.360952 & 14.362480 \\
\hline Longitude & -90.603351 & -90.600289 & -90.613432 & -90.570489 \\
\hline Elevation $(\mathrm{m})$ & 2390.55 & 2574.12 & 1422.51 & 1378.58 \\
\hline Distance to crater (m) & 447 & & 2606 & 3936 \\
\hline Date & \multicolumn{4}{|c|}{ Occupation Time (HH:MM) } \\
\hline $10 / 16 / 2001$ & $\longrightarrow$ & 2 & 2 & 3:08 \\
\hline $11 / 21 / 2001$ & $\ldots$ & 2 & 2 & \\
\hline $1 / 16 / 2002$ & . & $\longrightarrow$ & $\longrightarrow$ & \\
\hline $3 / 20 / 2002$ & 2 & 2 & 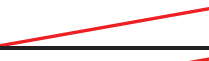 & 2:39 \\
\hline $5 / 23 / 2002$ & 2 & 2 & 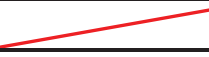 & $2: 03$ \\
\hline $6 / 21 / 2002$ & 工 & $\longrightarrow$ & 2 & \\
\hline $8 / 28 / 2002$ & 2 & 2 & 2 & $2: 34$ \\
\hline $11 / 26 / 2002$ & 2 & 2 & 2 & \\
\hline $1 / 22 / 2003$ & 工 & $\ldots$ & 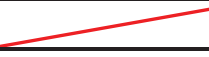 & 2:00 \\
\hline $4 / 3 / 2003$ & 2 & 2 & 2 & $2: 17$ \\
\hline $5 / 20 / 2003$ & 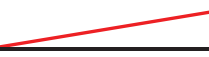 & 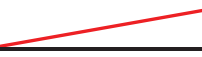 & 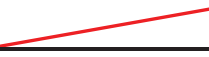 & 2:06 \\
\hline $8 / 7 / 2003$ & 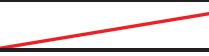 & 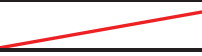 & 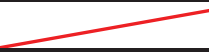 & \\
\hline $9 / 24 / 2003$ & 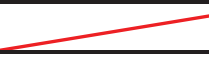 & 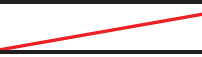 & 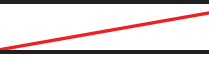 & $2: 27$ \\
\hline $11 / 28 / 2003$ & 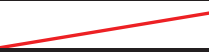 & 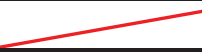 & 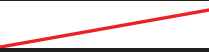 & $2: 12$ \\
\hline $2 / 17 / 2004$ & 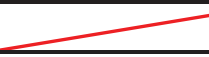 & 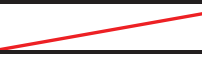 & 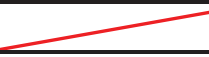 & $2: 27$ \\
\hline $5 / 12 / 2004$ & 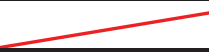 & 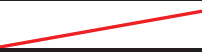 & 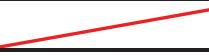 & $2: 00$ \\
\hline $6 / 16 / 2004$ & 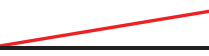 & 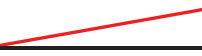 & 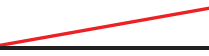 & \\
\hline $11 / 9 / 2004$ & 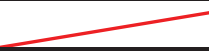 & 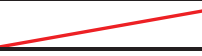 & 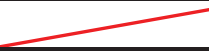 & \\
\hline $12 / 14 / 2004$ & 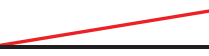 & $\longrightarrow$ & $\longrightarrow$ & $1: 07$ \\
\hline $2 / 3 / 2005$ & 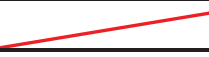 & 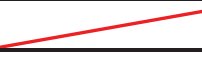 & 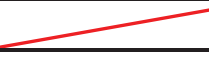 & $1: 04$ \\
\hline $5 / 25 / 2005$ & 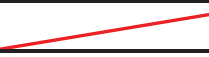 & 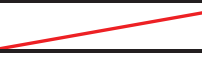 & 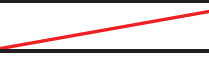 & $3: 33$ \\
\hline 9/13/2005 & 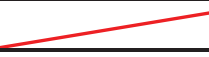 & 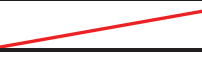 & 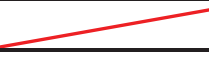 & 1:09 \\
\hline $11 / 9 / 2005$ & 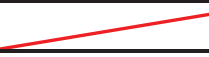 & 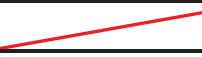 & 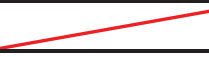 & $1: 59$ \\
\hline $3 / 6 / 2006$ & 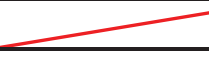 & 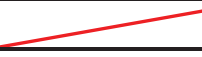 & 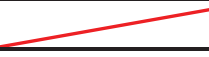 & $3: 23$ \\
\hline $7 / 2 / 2008$ & 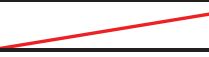 & 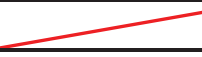 & 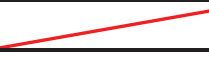 & $1: 11$ \\
\hline $10 / 31 / 2008$ & 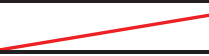 & 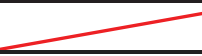 & 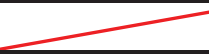 & $1: 19$ \\
\hline $1 / 19 / 2009$ & 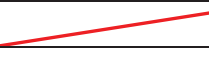 & & & \\
\hline $1 / 20 / 2009$ & 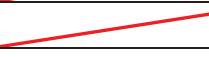 & & $8: 44$ & \\
\hline $1 / 21 / 2009$ & 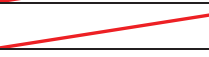 & $7: 53$ & & \\
\hline $1 / 22 / 2009$ & 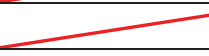 & & & \\
\hline $1 / 23 / 2009$ & $\longrightarrow$ & & & \\
\hline $1 / 24 / 2009$ & $\gamma_{2}$ & & & $7: 44$ \\
\hline $7 / 28 / 2010$ & r & & $5: 46$ & 5:08 \\
\hline
\end{tabular}




\begin{tabular}{|c|c|c|c|c|}
\hline Date & CRAK & CRAT & LBLK & LLAN \\
\hline $1 / 20 / 2011$ & 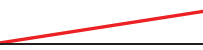 & 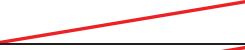 & & \\
\hline $1 / 21 / 2011$ & 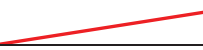 & 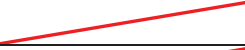 & & \\
\hline $1 / 22 / 2011$ & 2 & L & $7: 16$ & \\
\hline $1 / 23 / 2011$ & 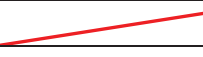 & 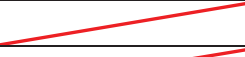 & & \\
\hline $1 / 24 / 2011$ & 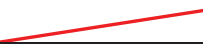 & 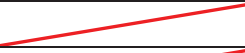 & & \\
\hline $1 / 25 / 2011$ & 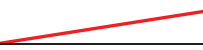 & 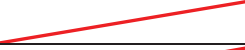 & & \\
\hline $1 / 26 / 2011$ & 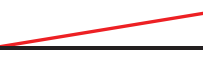 & 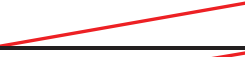 & & \\
\hline $9 / 20 / 2011$ & 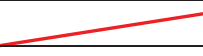 & 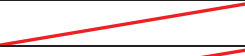 & & \\
\hline $9 / 21 / 2011$ & 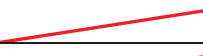 & 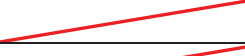 & 4:00 & \\
\hline $9 / 22 / 2011$ & L & 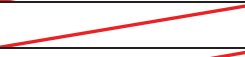 & & \\
\hline $9 / 24 / 2011$ & 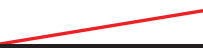 & 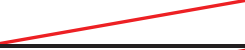 & & \\
\hline $11 / 30 / 2011$ & $\omega_{2}$ & ${ }_{2}$ & & \\
\hline $12 / 1 / 2011$ & 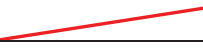 & 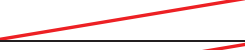 & & \\
\hline $12 / 2 / 2011$ & 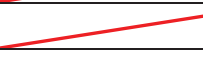 & 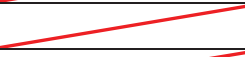 & & \\
\hline $12 / 3 / 2011$ & 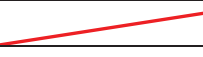 & $\longrightarrow$ & & \\
\hline $12 / 4 / 2011$ & L & L & & \\
\hline $12 / 5 / 2011$ & 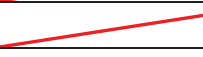 & L & & \\
\hline $12 / 6 / 2011$ & 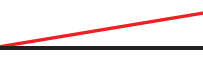 & 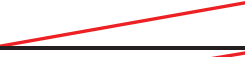 & $4: 02$ & \\
\hline $1 / 6 / 2012$ & 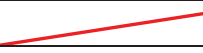 & L & $6: 07$ & \\
\hline $1 / 7 / 2012$ & 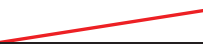 & 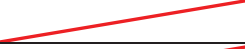 & & \\
\hline $1 / 8 / 2012$ & $\ldots$ & 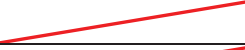 & & \\
\hline 1/9/2012 & 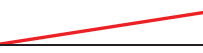 & 工 & & \\
\hline $1 / 10 / 2012$ & 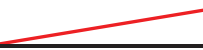 & 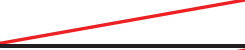 & & \\
\hline $4 / 10 / 2012$ & L & $\ldots$ & & \\
\hline $4 / 11 / 2012$ & L & 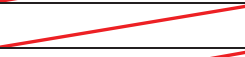 & $4: 01$ & \\
\hline 4/12/2012 & 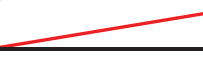 & 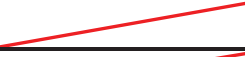 & & \\
\hline $8 / 26 / 2012$ & & 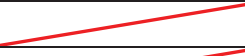 & & \\
\hline $8 / 27 / 2012$ & & 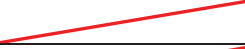 & & \\
\hline $8 / 28 / 2012$ & $4: 13$ & L & & \\
\hline $8 / 29 / 2012$ & & 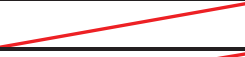 & 4:05 & \\
\hline $11 / 29 / 2012$ & & W & & \\
\hline $11 / 30 / 2012$ & $4: 06$ & $\longrightarrow$ & & \\
\hline 12/1/2012 & & 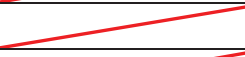 & & \\
\hline $12 / 2 / 2012$ & & $\longrightarrow$ & $4: 29$ & \\
\hline $1 / 11 / 2013$ & & $\longrightarrow$ & $4: 02$ & \\
\hline $1 / 12 / 2013$ & 4:07 & 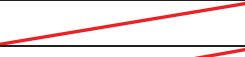 & & \\
\hline $1 / 13 / 2013$ & & 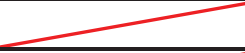 & & \\
\hline $3 / 28 / 2013$ & & W & $5: 32$ & \\
\hline $3 / 29 / 2013$ & $3: 34$ & W & & \\
\hline Total \# of Obs & 4 & 1 & 11 & 21 \\
\hline
\end{tabular}


Table 6.3 Occupation times for four stations (LVES, MEBA, RABN and SCRP) from October 2001 through March 2013. A red line indicates either pre construction or post destruction of the station. Distance to crater is approximate and calculated as the distance between the station and the destroyed CRAT station.

\begin{tabular}{|c|c|c|c|c|}
\hline & \\
\hline & Lavas Este & Mesillas Bajas & El Rabon & El Escarpe \\
\hline & LVES & MEBA & RABN & SCRP \\
\hline Latitude & 14.384023 & 14.413824 & 14.358425 & 14.375296 \\
\hline Longitude & -90.597068 & -90.564318 & -90.622754 & -90.596566 \\
\hline Elevation $(\mathrm{m})$ & 2385.28 & 1574.97 & 1359.45 & 2192.26 \\
\hline Distance to CRAT (m) & 575 & 5376 & 3414 & 866 \\
\hline Date & \multicolumn{4}{|c|}{ Occupation Time (HH:MM) } \\
\hline $10 / 16 / 2001$ & 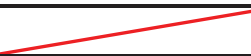 & $3: 12$ & $3: 05$ & 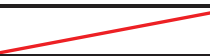 \\
\hline $11 / 21 / 2001$ & 2 & $2: 49$ & 3:05 & 3 \\
\hline $1 / 16 / 2002$ & 2 & & $2: 08$ & 2 \\
\hline $3 / 20 / 2002$ & 2 & $1: 52$ & $2: 05$ & 2 \\
\hline $5 / 23 / 2002$ & 2 & $2: 03$ & & 2 \\
\hline $6 / 21 / 2002$ & 2 & $2: 23$ & $2: 08$ & 2 \\
\hline $8 / 28 / 2002$ & 2 & $2: 31$ & & 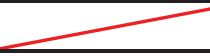 \\
\hline $11 / 26 / 2002$ & 2 & $2: 11$ & $2: 17$ & 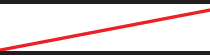 \\
\hline $1 / 22 / 2003$ & 2 & & $2: 09$ & 2 \\
\hline $4 / 3 / 2003$ & 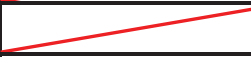 & $2: 35$ & $2: 13$ & 2 \\
\hline $5 / 20 / 2003$ & 2 & $2: 26$ & $2: 06$ & 2 \\
\hline $8 / 7 / 2003$ & 2 & $1: 26$ & $2: 01$ & 2 \\
\hline 9/24/2003 & 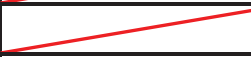 & $2: 29$ & $2: 02$ & 2 \\
\hline $11 / 28 / 2003$ & 2 & $2: 14$ & & 2 \\
\hline $2 / 17 / 2004$ & 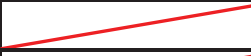 & & $2: 12$ & $\infty$ \\
\hline $5 / 12 / 2004$ & 2 & & $2: 03$ & 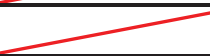 \\
\hline $6 / 16 / 2004$ & 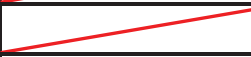 & & $2: 15$ & 2 \\
\hline $11 / 9 / 2004$ & 2 & & $5: 02$ & 2 \\
\hline $12 / 14 / 2004$ & 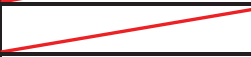 & $1: 05$ & $3: 00$ & 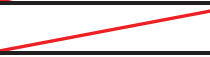 \\
\hline $2 / 3 / 2005$ & 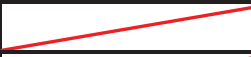 & $1: 01$ & 1:08 & 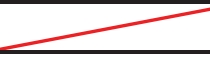 \\
\hline $5 / 25 / 2005$ & 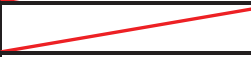 & $1: 01$ & $2: 41$ & 2 \\
\hline $9 / 13 / 2005$ & 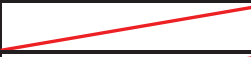 & & & $\ldots$ \\
\hline $11 / 9 / 2005$ & 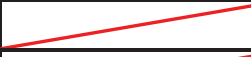 & $1: 53$ & $1: 14$ & 2 \\
\hline $3 / 6 / 2006$ & 2 & $2: 08$ & $2: 57$ & 2 \\
\hline $7 / 2 / 2008$ & 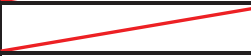 & $1: 03$ & $1: 05$ & 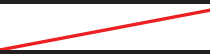 \\
\hline $10 / 31 / 2008$ & 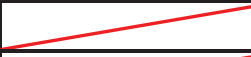 & $1: 37$ & & 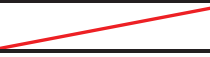 \\
\hline $1 / 19 / 2009$ & 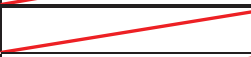 & & & \\
\hline $1 / 20 / 2009$ & 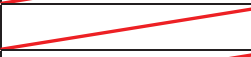 & & & \\
\hline $1 / 21 / 2009$ & 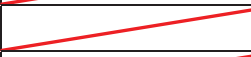 & & & \\
\hline $1 / 22 / 2009$ & 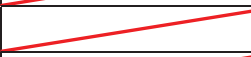 & & & \\
\hline $1 / 23 / 2009$ & 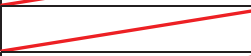 & & & \\
\hline $1 / 24 / 2009$ & r & $9: 55$ & $8: 13$ & $7: 54$ \\
\hline $7 / 28 / 2010$ & 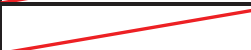 & $6: 24$ & $5: 54$ & $m_{2}$ \\
\hline
\end{tabular}




\begin{tabular}{|c|c|c|c|c|}
\hline Date & LVES & MEBA & RABN & SCRP \\
\hline $1 / 20 / 2011$ & 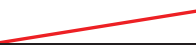 & & & 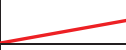 \\
\hline $1 / 21 / 2011$ & 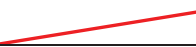 & & & 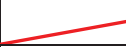 \\
\hline $1 / 22 / 2011$ & 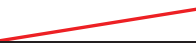 & & & 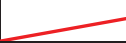 \\
\hline $1 / 23 / 2011$ & 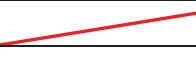 & & & 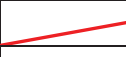 \\
\hline $1 / 24 / 2011$ & 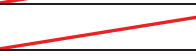 & & & 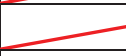 \\
\hline $1 / 25 / 2011$ & 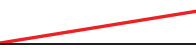 & & & 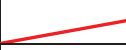 \\
\hline $1 / 26 / 2011$ & 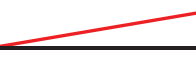 & & & 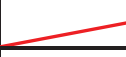 \\
\hline $9 / 20 / 2011$ & & & & 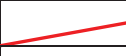 \\
\hline $9 / 21 / 2011$ & & & & 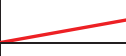 \\
\hline $9 / 22 / 2011$ & & & & 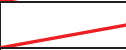 \\
\hline $9 / 24 / 2011$ & $3: 59$ & & & 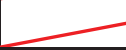 \\
\hline $11 / 30 / 2011$ & & & & 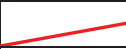 \\
\hline $12 / 1 / 2011$ & & & & 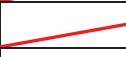 \\
\hline $12 / 2 / 2011$ & $3: 50$ & & & 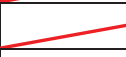 \\
\hline $12 / 3 / 2011$ & & & & 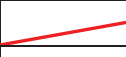 \\
\hline $12 / 4 / 2011$ & & & & 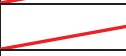 \\
\hline $12 / 5 / 2011$ & & & & 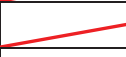 \\
\hline $12 / 6 / 2011$ & & & & 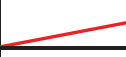 \\
\hline $1 / 6 / 2012$ & & & & $\ldots$ \\
\hline $1 / 7 / 2012$ & & & & 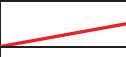 \\
\hline $1 / 8 / 2012$ & 4:04 & & & 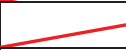 \\
\hline $1 / 9 / 2012$ & & & & 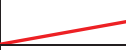 \\
\hline $1 / 10 / 2012$ & & & & 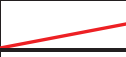 \\
\hline $4 / 10 / 2012$ & & & & 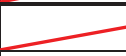 \\
\hline $4 / 11 / 2012$ & & & & 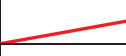 \\
\hline $4 / 12 / 2012$ & & & & 2 \\
\hline $8 / 26 / 2012$ & & & & 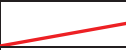 \\
\hline $8 / 27 / 2012$ & $4: 14$ & & & 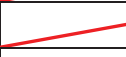 \\
\hline $8 / 28 / 2012$ & & & & 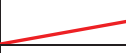 \\
\hline $8 / 29 / 2012$ & & & & 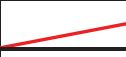 \\
\hline $11 / 29 / 2012$ & & & & 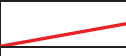 \\
\hline $11 / 30 / 2012$ & & & & 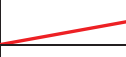 \\
\hline $12 / 1 / 2012$ & $4: 10$ & & & 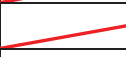 \\
\hline $12 / 2 / 2012$ & & & & $\sim$ \\
\hline $1 / 11 / 2013$ & & & & 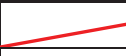 \\
\hline $1 / 12 / 2013$ & $4: 17$ & & & 2 \\
\hline $1 / 13 / 2013$ & & & & 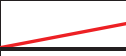 \\
\hline $3 / 28 / 2013$ & & & & 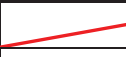 \\
\hline $3 / 29 / 2013$ & 4:09 & & & 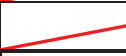 \\
\hline Total \# of Obs & 7 & 21 & 23 & 1 \\
\hline
\end{tabular}





\section{GPS SURVEYS}

\subsection{IGN Surveys}

Between October 2001 and January of 2009 IGN conducted a total of 28 network observations. From 2001 through 2005 these observations occurred on average every 2.5 months. There was one observation in 2006, two in 2008 and the last observation in January of 2009 in conjunction with the team from MTU. Individual observation durations varied considerably over time, but on average were centered around 1.5 hours (Tables 6.1 -6.3). IGN stations, including the base station, are designed to be used with a tripod mount. Table 7.1 outlines the equipment used by both IGN and MTU for GPS observations. Observational sample rates for IGN data files vary from $5-15$ seconds.

\subsection{MTU Surveys}

The first occupation of the MTU GPS benchmarks took place immediately after their installation in January of 2009. After this occupation, no permanent plans were made to continue observing the points and collecting data until after the eruption of 2010. In July of 2010, with support from IGN, INSIVUMEH and CONRED, the IGN GPS benchmarks were observed along with two of the MTU benchmarks (LBLK and BVIS). Following this occupation there was another in January of 2011 after which it was decided to continue with periodic observations of the GPS monuments beginning in September of 2011. Surveys were made on average every three months until March 2013 yielding 8 additional surveys and a total of 11 surveys made by MTU. For the first few surveys GPS observations were made for around eight hours per station. Beginning with the September 2011 survey however observation time was reduced by half and the stations were observed for four hours each. Tables $6.1-6.3$ delineate exact observation time for each occupation and station.

All MTU stations were installed and intended to be used with a steel pole mount (Figure 7.1). Initially, an adapter was designed for the pole to allow for North orientation of the antenna. The adapter and pole combo were designed to be exactly $0.661 \mathrm{~m}$ in height. Northward orientation was later deemed unnecessary, and the use of the adapter was abandoned for one solid pole measuring the same $0.661 \mathrm{~m}$ high. 


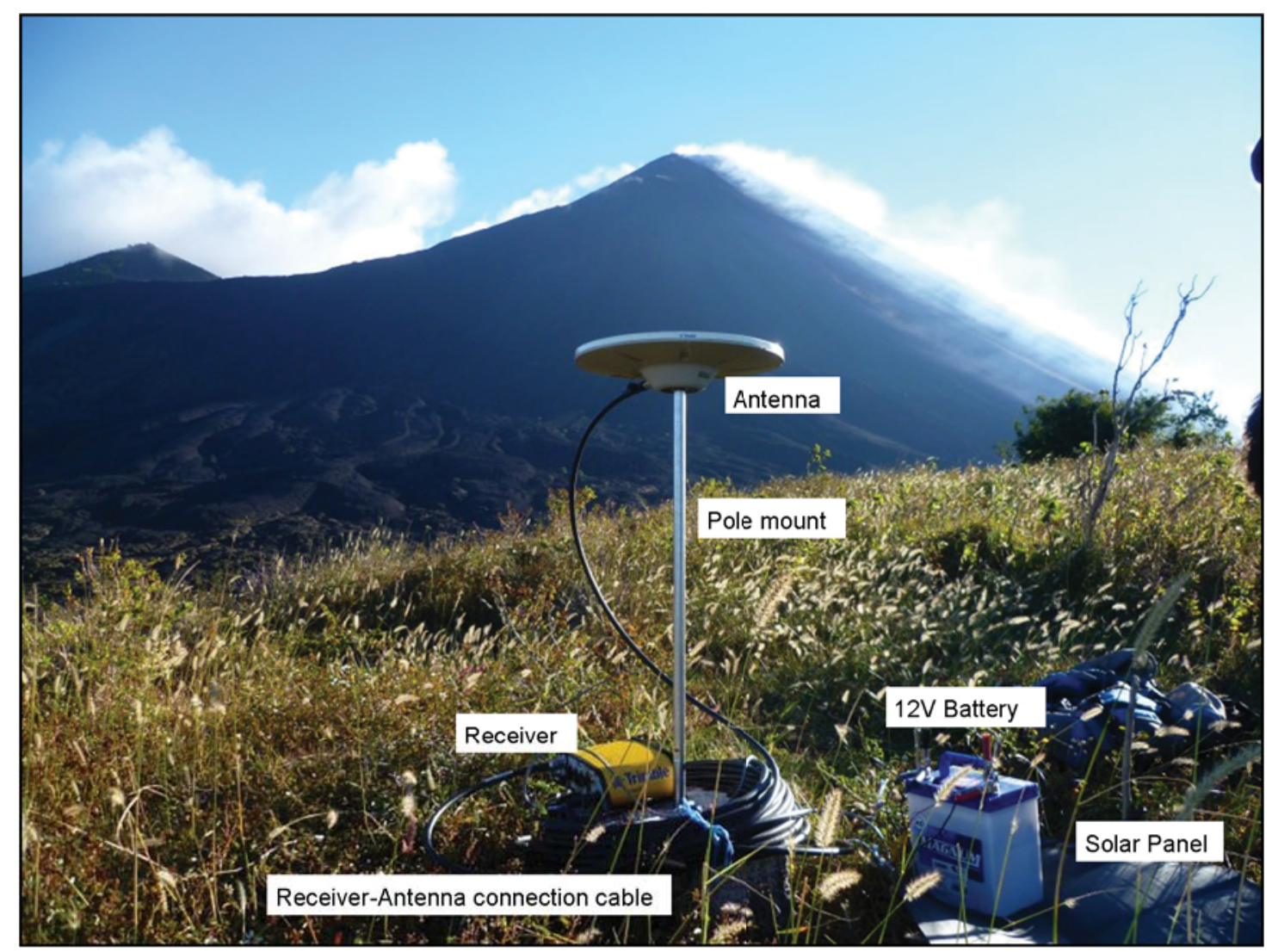

Figure 7.1. Equipment setup at the BVIS GPS station. The pictured setup includes the $0.661 \mathrm{~m}$ pole without the antenna adapter, the antenna, the receiver, the 12 volt battery and solar panel. Date: January 12, 2013. Photo by author.

Trimble NetRS receivers were used exclusively for the MTU base and rover station data collection surveys except for the survey in September 2011 during which a Trimble R7 receiver was used for the occupation of several of the field stations. Both are 24-channel dual-frequency receivers. Antennas used by MTU were all Trimble Zephyr Geodetic antennas. The receivers used were set to collect data using an elevation mask of 15 degrees. Observational sample rates were most commonly set to 30 seconds, with a few instances of settings at 5 or 15 seconds.

Table 7.1 GPS equipment used for IGN and MTU observations between October 2001 and March 2013.

\begin{tabular}{|l|l|l|l|}
\hline Date & Receiver & Antenna & Institution \\
\hline October 2001-July 2006 & Trimble 5700 & $\begin{array}{l}\text { Trimble Zephyr Geodetic / } \\
\text { Trimble Zephyr }\end{array}$ & IGN \\
\hline October 2008 - July 2010 & Leica ATX 1230 & LEI ATX 1230GG & IGN \\
\hline $\begin{array}{l}\text { January 2009 - March } \\
2013\end{array}$ & Trimble NetRS & Trimble Zephyr Geodetic & MTU \\
\hline September 2010 & $\begin{array}{l}\text { Trimble R7 / } \\
\text { NetRS }\end{array}$ & Trimble Zephyr Geodetic & MTU \\
\hline
\end{tabular}




\section{Data Processing Methods}

\subsection{Preprocessing}

Data files were downloaded at the end of each field day and placed in date and station specific folders, as well as archived to maintain a database of raw data files. All data files created by the Trimble receivers had to be first converted into the Receiver Independent Exchange (RINEX) format for analysis. During conversion, the four character station name and antenna height were checked for accuracy and changed if necessary. For the IGN data files the field input antenna heights were assumed accurate to the bottom of antenna mount due to a lack of observational data.

Preprocessing was completed with TEQC, a program created by UNAVCO used exclusively for RINEX file data manipulation. The first preprocessing step was to decimate all data files to a 30 second sample rate to maintain uniformity between all surveys. Secondly, any erroneous data points (for example, data points recorded during PC communication and data download after field sessions) were removed from data files. Thirdly, as some data files contained readings from two separate stations, these files were separated into individual station files and subsequently each file's header was edited to contain the correct four character station ID and starting position for the corresponding station. The next step was to splice any data saved in one hour long observation files to create one single file per observation. Lastly, all data files were run through TEQC quality control to check the quality of observational data.

\subsection{APPS}

All data collected after the MTU network installation in January 2009 were processed using the internet interface Automatic Precise Positioning Service (APPS) program of the GDGPS System. According to "APPS - Under the Hood" this service uses the fifth version of JPL's GIPSY-OASIS software and estimates station coordinates, among other parameters, of RINEX format files. All data were processed more than two weeks after collection and so JPL's final satellite orbit solutions were available and used for calculations. Satellite orbit solutions are calculated using the most precise clock solutions and have an error of approximately $3 \mathrm{~cm}$ RMS. Satellite orbit solutions are produced in an ITRF08, thus as are position solutions, and reference frame and satellite and antenna phase center variation maps are applied following IGS standards ("APPS Under the Hood"). Following are the signal and ground models applied by GIPSY (quoted from "APPS - Under the Hood" http://apps.gdgps.net/):

- GPS yaw attitude [Bar-Sever, 1997]

- Phase windup [Wu et el., 1993]

- GMF troposphere mapping function

○ Apriori hydrostatic delay $=1.013 * 2.27$ * $\exp (-.000116 * h)$ meters, where $h$ is the station height above the ellipsoid in meters

- Apriori for wet delay is $0.1 \mathrm{~m}$

○ Tropospheric gradients [Bar-Sever et al., 1997]

- Relativity

- Pole, and solid tide [IERS Tech Note \#23]

- Ocean tides [Desai]

- Second order ionospheric delay [Kedar et al., 2003] 
To perform data analysis using the APPS web interface the user is asked to upload a file and select parameters for analysis. Figure 8.1 displays the parameters selected by the user (the author) during data analysis. During data upload the RINEX .XXo files (observational data) as well as the .XXm files (meteorological data) were uploaded for processing. The reason for this is that including the meteorological information in the upload should allow for a better approximation of the troposphere mapping function. This is useful for these data because the atmosphere above tropical regions is generally wetter and can create errors in position measurement due to troposphere delay. This also can help correct for higher tropospheric delay for data collected during the Guatemalan rainy season (approximately May through September).

\begin{tabular}{|l|l|}
\hline \multicolumn{2}{|c|}{ APPS Options } \\
\hline Processing Mode & $\begin{array}{l}\text { Static } \\
\text { Kinematic }\end{array}$ \\
\hline Measurement Type & $\begin{array}{l}\text { Single Frequency } \\
\text { Dual Frequency }\end{array}$ \\
\hline L1 Code & $\begin{array}{l}\text { CA Code } \\
\text { P Code }\end{array}$ \\
\hline Model Pressure Data? & Yes No \\
\hline $\begin{array}{l}\text { Elevation Dependent } \\
\text { Data Weighting }\end{array}$ & Flat Sin Sqrt(sin) \\
\hline Advanced Options & $\begin{array}{l}15 \\
\text { Elevation Angle Cutoff }\end{array}$ \\
\hline
\end{tabular}

Figure 8.1. Screen shot of the APPS processing parameters input page on http://apps.gdgps.net/

Disadvantages of using the APPS web interface include reduced user input and reduced control over variables. For example, when using full GIPSY-OASIS software, one is able to change analysis options for the input file. The user is able to manipulate information about the elevation angle cutoff, phase and range data weights, range and phase window for output, slip for phase break, number of iterations, the random walk parameter and even tide and wet versus dry troposphere models. A fixed analysis with APPS does not allow for manipulation of these variables and thus produces a less precise position calculation in cases when the default values are not optimal.

Another disadvantage to using APPS, as with all GPS positioning methods, is that the observation length plays a key factor in the precision of the results. Shorter observation times lead to less precise results, thus quick field excursions do not yield satisfactory positions. For the majority of the observations completed by MTU the sessions were a minimum of 4 hours, though on occasion faulty equipment or inclement weather yielded sessions with shorter observation times. These shorter observation times have much 
higher position errors and are less reliable for calculations. IGN observations were commonly between 1 and 2.5 hours which yielded generally noisy results with regard to position. Positions and their errors can be viewed in Appendix A. APPS automatically calculates a 1- $\sigma$ error in each direction (X, Y and Z) for each position. Positions are in Earth-centered Cartesian coordinates.

Calculated $X, Y$ and $Z$ coordinates for each GPS station as well as calculated errors were transformed to obtain latitude, longitude and UTM coordinates for simpler evaluation. Additionally, using the same information, a displacement value from initial was calculated for each station observation. The new converted coordinates and displacements were used to create the time series and velocity plots in Figures 8.2, 8.3 and 8.4. The time series plots also include the APPS calculated errors shown as error bars at each point. The MTU data has errors on the order of a few centimeters per observation, where the IGN data show errors up to a quarter or half meter in some cases. Though these errors are quite high, the actual time series line remains generally within the error bars so a trend could be gathered from the data. However, even with the IGN data covering a long period of time, no substantial trend can be seen in the time series plots. The MTU data shows a generally negative east trend for all of the stations, and strong negative north and vertical trends for the stations LBLK and CHNO. The rest of the stations seem to remain relatively stationary in the time series plots. This is most likely a factor of the scale and size of the plot. Changes are better seen observing the displacement velocity plots of each station. 


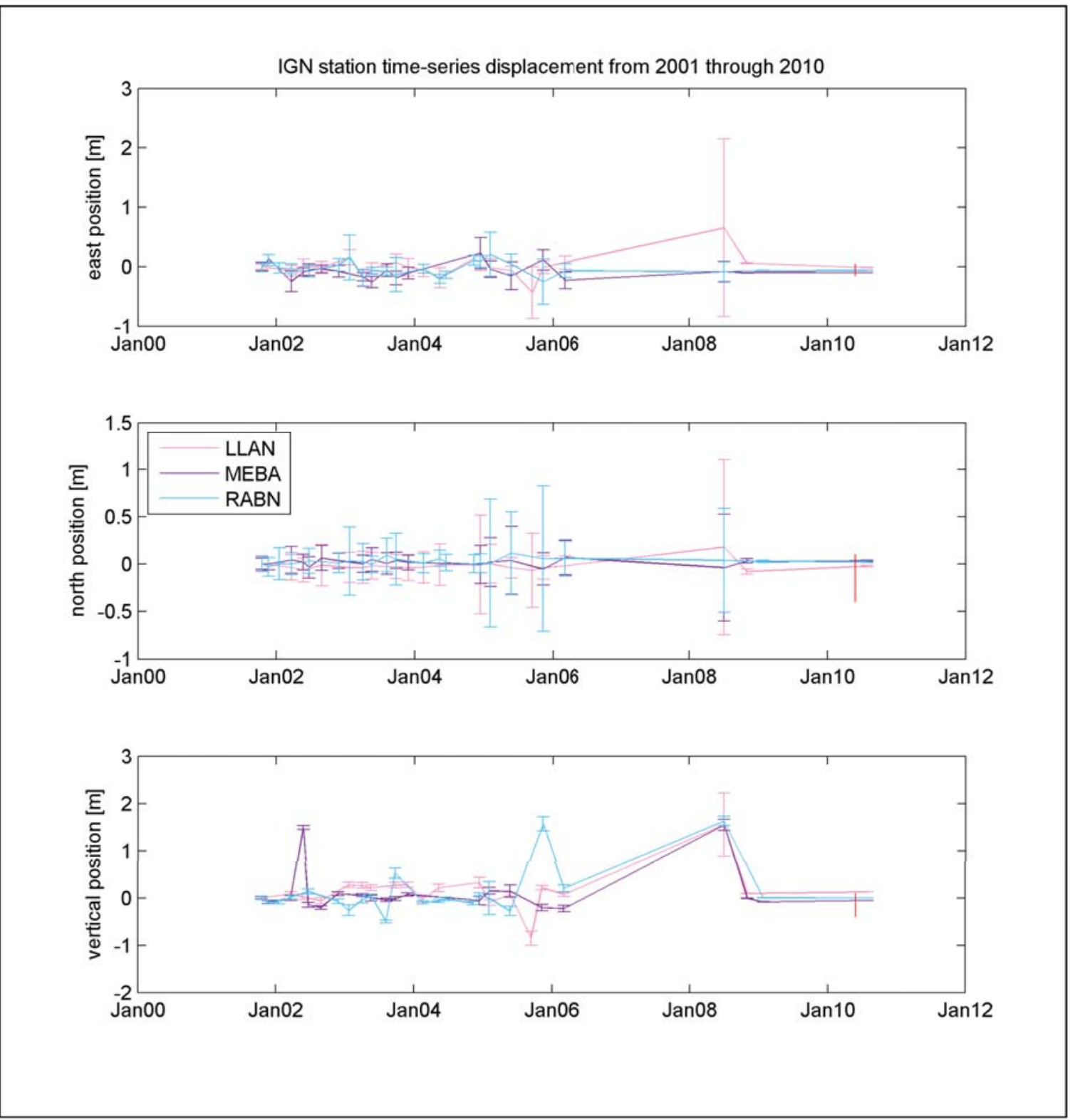

Figure 8.2. Time series plot of IGN station position changes from October 2001 through July 2010. 

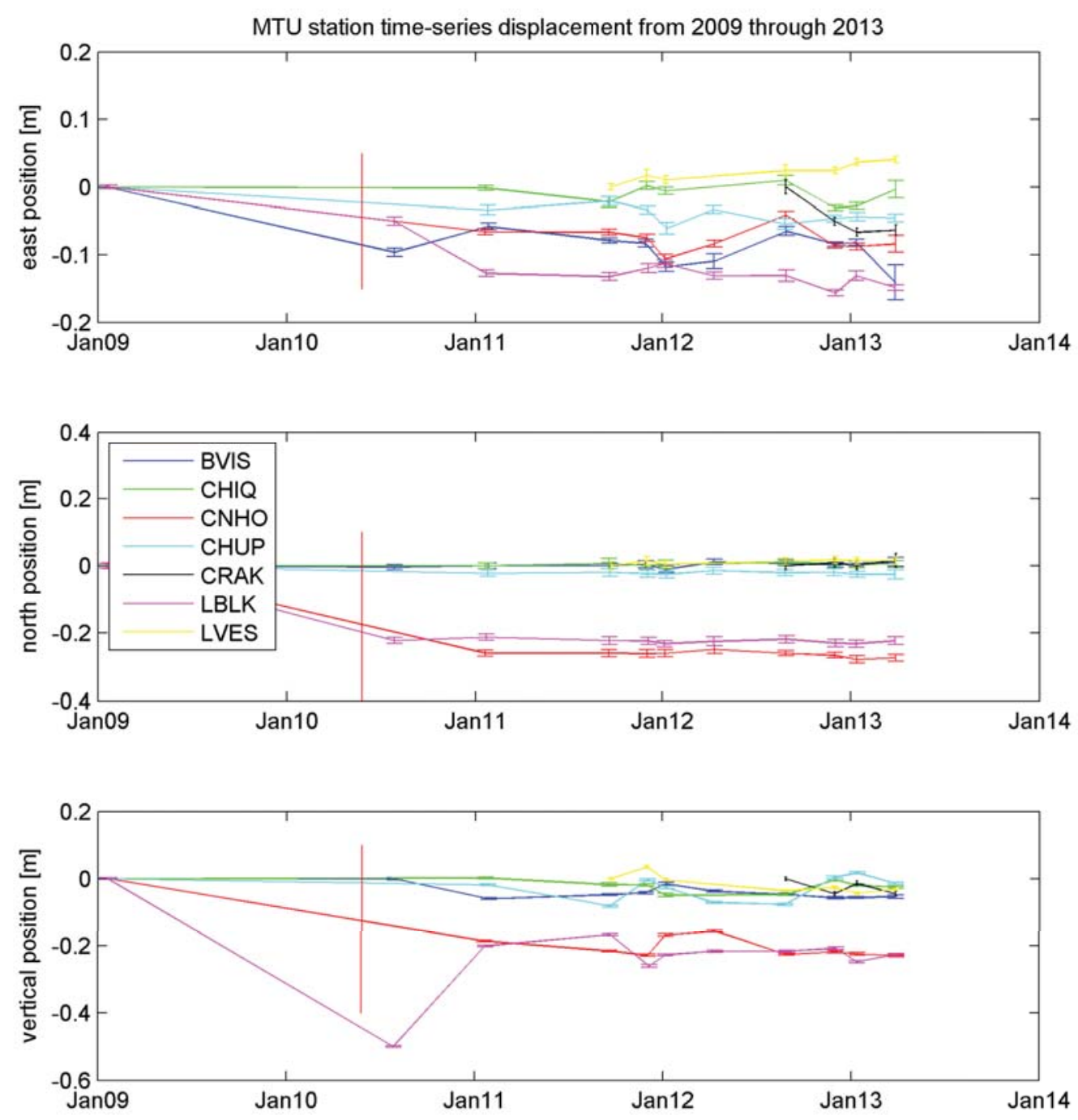

Figure 8.3. Time series plot of MTU station position change between January 2009 and March 2013.

In order to interpret the precise point position data, relative positions were used to compute station velocity vectors for each station. Positions were corrected for general plate motion of $2.1 \pm 0.6 \mathrm{~mm} \mathrm{yr}^{-1}$ north and $2.1 \pm 0.8 \mathrm{~mm} \mathrm{yr}^{-1}$ east according to DeMets, 2007. Figure 8.4 shows station velocity for periods before (October 2001 through January 2009), covering (January 2009 through January 2011) and after (January 2011 through March 2013) the May 2010 eruption. Table 8.1 shows the calculated north, east and up parameters for the velocity vectors in $\mathrm{mm} \mathrm{yr}^{-1}$. Values range from fractions of a millimeter per year to upwards of $100 \mathrm{~mm} \mathrm{yr}^{-1}$ between the three time periods.

Pre-eruption velocities, from the IGN data, are quite large, especially in the vertical. For the period covering the eruption on May 27, 2010, velocities are also quite large for most stations, on the order of a few centimeters per year. These velocities are calculated for 
the change in position from the January 2009 observation to the July 2010 (RABN, MEBA, LLAN) or January 2011 (all MTU stations) observation, thus these data include any displacement that could have occurred between January 2009 and May 2010, and also any that may have occurred after the eruption. This, therefore, could remove any large unlingering inflation and/or deflation signature immediately preceding or following the eruption. However, long-term displacement is still preserved and that is what is modeled forthwith.

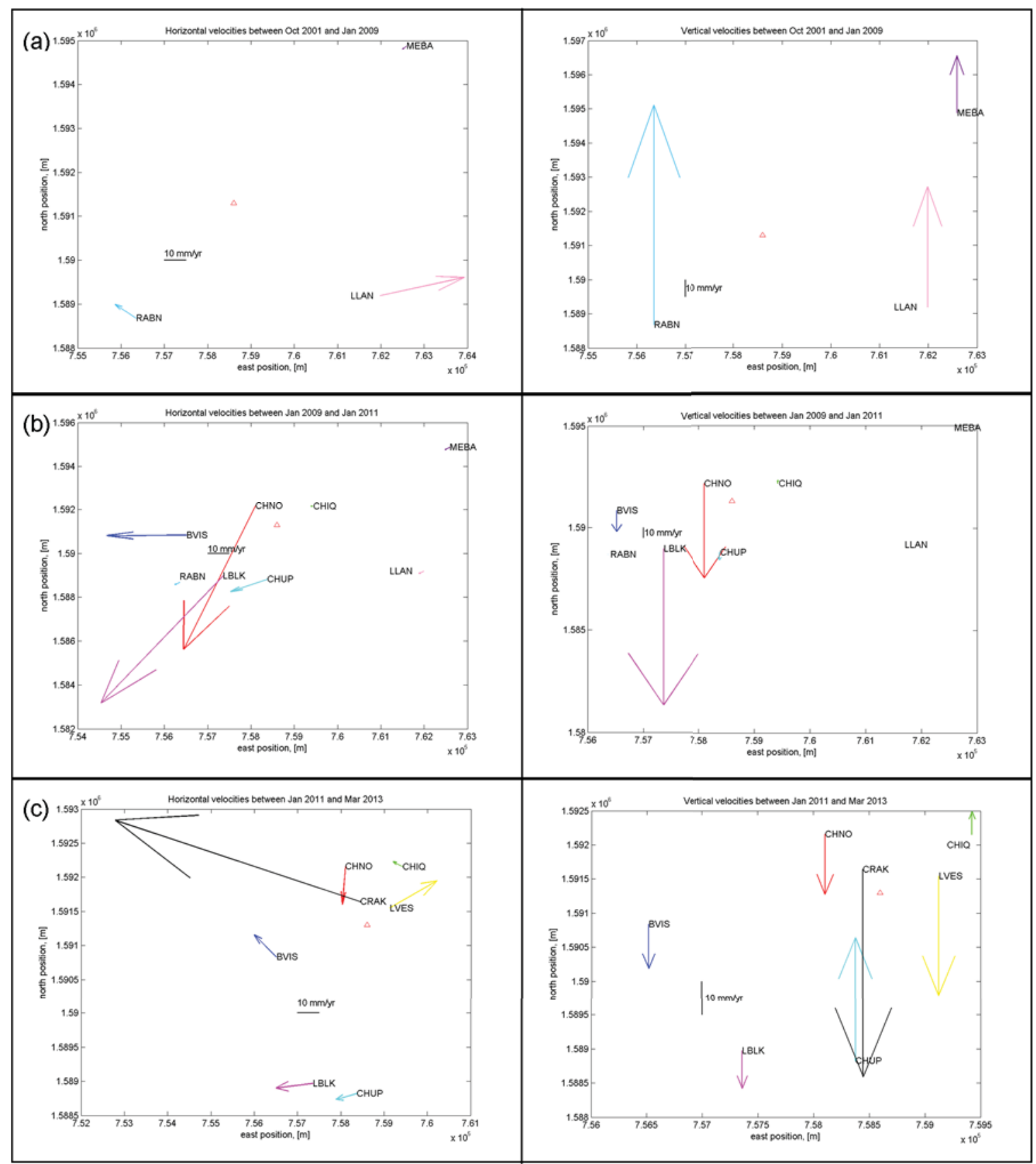

Figure 8.4. Horizontal and vertical displacement velocity plots for IGN and MTU GPS stations for periods between (a) October 2001 and January 2009 (pre-eruption); (b) January 2009 and January 2011 (eruption period); and (c) January 2011 to March 2013 (post-eruption period). 
Table 8.1 North, east and up velocities for all stations covering the three distinct periods in the data (preeruption, eruption, and post-eruption). Positive velocities indicate the direction mentioned, negative north is movement to the south, negative east is movement to the west and negative up indicates downward movement.

\begin{tabular}{|c|c|c|r|r|r|r|}
\cline { 2 - 7 } \multicolumn{1}{c|}{} & \multicolumn{2}{c|}{$\begin{array}{c}\text { Pre-eruption Velocities } \\
\text { mm yr }\end{array}$} & \multicolumn{3}{c|}{$\begin{array}{c}\text { Eruption Velocities } \\
\text { mm yr }\end{array}$} \\
\hline $\begin{array}{c}\text { Station } \\
\text { Code }\end{array}$ & North & East & Up & \multicolumn{1}{c|}{ North } & \multicolumn{1}{c|}{ East } & \multicolumn{1}{c|}{ Up } \\
\hline BVIS & & & & -0.4942 & -36.8258 & -20.3560 \\
\hline CHIQ & & & & 0.0377 & -0.7189 & 3.1754 \\
\hline CHNO & & & & -130.4523 & -33.1958 & -91.2567 \\
\hline CHUP & & & & -11.2230 & -16.8563 & -6.8431 \\
\hline LBLK & & & & -115.5493 & -56.2806 & -152.5179 \\
\hline LLAN & 8.3423 & 38.7675 & 70.5610 & -2.0695 & -2.1348 & 0.0171 \\
\hline MEBA & -1.4856 & -1.7140 & 33.4966 & -2.0915 & -2.1010 & 0.0149 \\
\hline RABN & 6.3019 & -9.7160 & 128.6817 & -2.1003 & -2.0961 & -0.0002 \\
\hline
\end{tabular}

\begin{tabular}{|c|r|r|r|}
\cline { 2 - 4 } \multicolumn{1}{c|}{} & \multicolumn{3}{c|}{ Post-eruption Velocities } \\
mm yr $^{-1}$
\end{tabular}

Observing velocity values in Table 8.1 a few general trends can be seen in station velocities. Vertical velocities are generally larger than horizontal velocities for all three time periods. The eruption covering and post-eruption periods show exclusively negative east (westward) velocities, generally larger than north-south values. Western stations all show negative vertical (downward) velocities covering the eruption and for the posteruption period. Eastern stations show positive vertical (upward) velocities for the eruption and post-eruption periods

\subsection{Modeling}

The displacements used to calculate the velocity vectors were also used to model local deformation at each GPS station. All calculations were made in homogeneous halfspace with elastic moduli appropriate for the shallow crust using Young's modulus of $8 \times 10^{5}$ bars, Poisson's ratio of 0.25 , and an effective coefficient of internal friction of 0.4 (similar to Roman and Heron, 2007). Modeling was done using the Coulomb 3.3.1 code package (hereafter referred to as Coulomb) provided by USGS (Toda et al., 2005 and Lin and Stein, 2004). This code uses analytic functions to model displacement (and stress changes) from simple sources buried in a homogeneous half space. There are limitations in this type of modeling, for example very few actual displacement or stress 
change environments are characterized by completely homogeneous half space, but advantages include rapid computation and ease of implementation.

The first step using Coulomb modeling software was to determine the correct models to use for comparison at Volcán Pacaya. Both dike inflation/deflation and point source inflation/deflation models were chosen for the comparison. Parameters changed in the models included a combination of tensile opening, dip slip, right lateral slip and dip of the dike. For all models inflation is modeled by positive tensile opening and deflation by negative tensile opening. Right lateral slip is positive and left lateral slip is negative and similarly reverse dip slip is positive and normal dip slip is negative. All other parameters in the models were assumed constant and/or static.

The dike used in the models was oriented as beginning at the CHNO GPS station and passing "through" the crack created during the May 2010 eruption to finish at a location near the new lava vent that formed from the same eruption south-southeast of the summit (Figure 8.5). The dike could not be oriented to terminate exactly at the vent because the three features (CHNO, the crack and the vent) are not oriented in a perfectly straight line. Optimum modeling results were obtained for a dike modeled as a plane extending from $0.24 \mathrm{~km}$ to $6.76 \mathrm{~km}$ deep, $26.52 \mathrm{~km}$ in length. Optimum modeling results for a point source were obtained by modeling the source as the center point of a small $3 \mathrm{~km}$ long by $5 \mathrm{~km}$ deep imaginary plane with the point source at a depth $2.5 \mathrm{~km}$ below the volcanic vent (Figure 8.5).

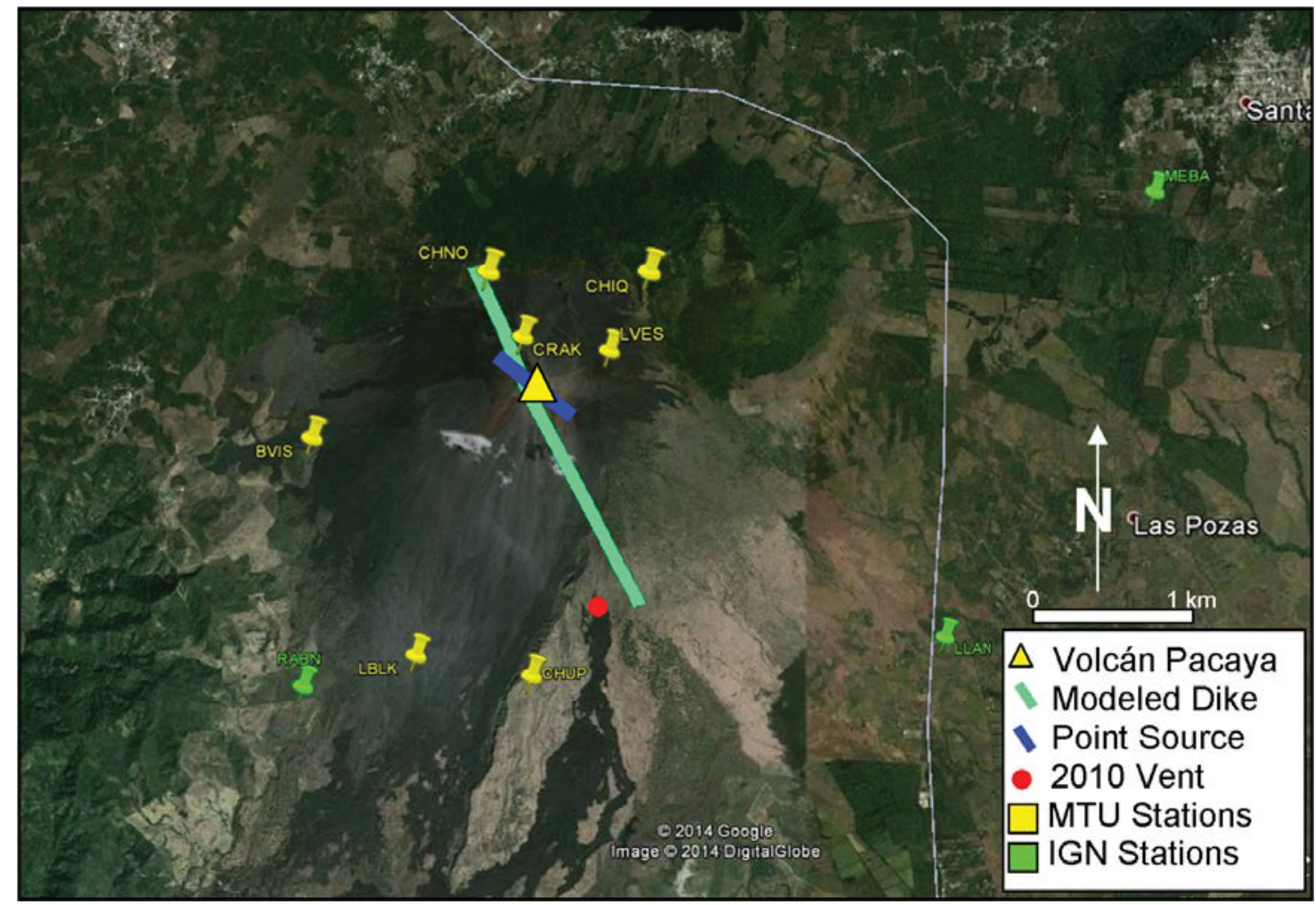

Figure 8.5. Map of GPS monuments used for displacement modeling and the orientation of the proposed dike (green line) and the point source surface plane (blue line) used in the Coulomb 3.3.1 models. Map Data: Google, Digital Globe (c) 2014. 
For the models a "Kode 100," "Kode 200" or "Kode 500" source is used as the basis for input. All sources are available within the Coulomb code package. The Kode 100 source models simple dike movement with right-lateral slip and/or dip slip. Kode 200 models a dike experiencing right lateral slip and/or tensile opening. A Kode 500 for a point source allows for input of inflation. The following models were tested and compared to GPS data for fit determination:

- Kode 100 source

- Kode 100 source with slip tapering

- Kode 100 source with westward dip of $75^{\circ}$

- Kode 100 source with westward dip of $75^{\circ}$ with slip tapering

- Kode 200 source

- Kode 200 source with slip tapering

- Kode 200 source with westward dip of $75^{\circ}$

- Kode 200 source with westward dip of $75^{\circ}$ with slip tapering

- Kode 500 source experiencing inflation

Each model for the Kode 100 and 200 sources was run changing each of the two input variables while the other remained at a value of zero until optimum results were obtained. Additionally, each was run varying both input values simultaneously until the optimum output was achieved. Slip tapering was added at the edges of the dike to add a more realistic parameter to the model. This taper was added in the form of five nested rectangles placed at $0.5 \mathrm{~km}$ along dip and $0.5 \mathrm{~km}$ along strike of the dike to produce optimum results. Input for Kode 500 sources was simply a variance in the inflation parameter. After opening existing example files for each model (Kode) the study area was moved to be centered at Pacaya. For the dike models, dike parameters were altered to the orientation mentioned above (Figure 8.5) and for the point source model the source was moved below the volcano.

Next, GPS data were overlain and vertical and horizontal displacements were tested using varying inflation and slip values until the best match of modeled displacement values compared to observed GPS displacement was found. The parameter used to test this best fit was a root mean squared (RMS) misfit calculated by the following equation:

$$
\sqrt{ }\left(1 / 3 n\left(\Sigma\left(\left(o b s(x)_{n}-\operatorname{calc}(x)_{n}\right)^{2}+\left(o b s(y)_{n}-\operatorname{calc}(y)_{n}\right)^{2}+\left(o b s(z)_{n}-\operatorname{calc}(z)_{n}\right)^{2}\right)\right)\right)
$$

where $o b s(x)_{n}$ is the $x$, or east, component of the observed displacement at station $n$, and $\operatorname{calc}(x)_{n}$ is the $x$ component of the calculated displacement at station $n$. Similarly, $o b s(y)_{n}-c a l c(y)_{n}$ is the difference in the calculated and observed $y$ (north) and obs $(z)_{n}-$ calc $(z)_{n}$ is the difference in the calculated and observed $z$ (vertical/up) displacements for station $n$, where $n$ is also the total number of GPS stations. .

Observed displacements are user input into Coulomb and calculated displacements are output in separate files. When GPS data are overlain in Coulomb, the software automatically calculates a displacement value for the exact GPS point for a Kode 100 source. For these sources RMS misfit calculations were made by comparing these automatically generated modeled displacement vectors to the observed displacement at each site following the calculation above. Because these automatic displacement calculations are based on a Kode 100 source, methodology for calculating the RMS 
misfit was changed for the Kode 200 and 500 sources. For these sources, the study area grid was reduced in size to a $0.5 \mathrm{~km} \times 0.5 \mathrm{~km}$ grid and the $X, Y$ and $Z$ components of the modeled displacements for each GPS station were approximated using bilinear interpolation within a $0.5 \mathrm{~km}^{2}$ area. After altering model parameters the observed GPS displacements were compared to calculated horizontal displacement vectors calculated over the entire study area. Tables 9.2 and 9.3 show misfit calculations for each best-fit model. 


\section{RESULTS AND DISCUSSION}

Displacement calculations for each station for each of three distinct time periods are shown in are shown in Table 9.1. On average, the period covering the eruption shows the most displacement, with pre-eruption displacement following and post-eruption displacement being the least of the three. These results are to be expected being that the energy released by the eruption in 2010 should have created a significant displacement. Pre-eruption data cover a significant time period so would theoretically produce expectedly large displacements, though due to the distance from the volcano large displacements are not seen. Post-eruption displacements are expectedly somewhat small due to the lack of volcanic activity during this time period.

Table 9.1. East, north, vertical and total (3-D) displacement values for each station for the three distinct time periods surrounding the May 2010 eruption of Pacaya.

\begin{tabular}{|c|c|c|c|c|c|c|}
\hline \multicolumn{7}{|c|}{ Pre-eruption Period: October 2001 through January 2009} \\
\hline $\begin{array}{c}\text { Station } \\
\text { Code }\end{array}$ & $\begin{array}{l}\text { Longitude } \\
\left(^{\circ}\right)\end{array}$ & $\begin{array}{l}\text { Latitude } \\
\left({ }^{\circ}\right)\end{array}$ & $\begin{array}{c}\Delta \text { East } \\
(\mathrm{m})\end{array}$ & $\Delta$ North (m) & $\begin{array}{c}\Delta \text { Vertical } \\
(\mathrm{m})\end{array}$ & $\Delta$ Total $(\mathrm{m})$ \\
\hline LLAN & -90.5708 & 14.3624 & 0.0740 & -0.0676 & 0.1107 & 0.1493 \\
\hline MEBA & -90.5646 & 14.4138 & -0.0774 & -0.0344 & -0.0676 & 0.1084 \\
\hline RABN & -90.6230 & 14.3584 & -0.0473 & -0.0414 & 0.0159 & 0.0648 \\
\hline \multicolumn{7}{|c|}{ Eruption Period: January 2009 through January 2011} \\
\hline $\begin{array}{c}\text { Station } \\
\text { Code }\end{array}$ & $\begin{array}{l}\text { Longitude } \\
\left(^{\circ}\right)\end{array}$ & $\begin{array}{c}\text { Latitude } \\
\left({ }^{\circ}\right)\end{array}$ & $\begin{array}{c}\Delta \text { East } \\
(\mathrm{m})\end{array}$ & $\Delta$ North $(\mathrm{m})$ & $\begin{array}{c}\Delta \text { Vertical } \\
(\mathrm{m})\end{array}$ & $\Delta$ Total $(\mathrm{m})$ \\
\hline BVIS & -90.6213 & 14.3778 & -0.0929 & -0.0006 & 0.0030 & 0.0930 \\
\hline $\mathrm{CHIQ}$ & -90.5942 & 14.3895 & 0.0028 & 0.0043 & 0.0063 & 0.0081 \\
\hline $\mathrm{CHNO}$ & -90.6065 & 14.3897 & -0.0619 & -0.2556 & -0.1815 & 0.3195 \\
\hline CHUP & -90.6043 & 14.3595 & -0.0297 & -0.0184 & -0.0138 & 0.0376 \\
\hline LBLK & -90.6137 & 14.3609 & -0.0471 & -0.2189 & -0.4962 & 0.5444 \\
\hline LLAN & -90.5708 & 14.3624 & -0.0700 & 0.0614 & 0.0344 & 0.0993 \\
\hline MEBA & -90.5646 & 14.4138 & -0.0020 & 0.0171 & 0.0299 & 0.0345 \\
\hline RABN & -90.6230 & 14.3584 & 0.0078 & -0.0006 & -0.0004 & 0.0078 \\
\hline \multicolumn{7}{|c|}{ Post-eruption Period: January 2011 through March 2013} \\
\hline $\begin{array}{c}\text { Station } \\
\text { Code }\end{array}$ & $\begin{array}{c}\text { Longitude } \\
\left(^{\circ}\right)\end{array}$ & $\begin{array}{c}\text { Latitude } \\
\left({ }^{\circ}\right)\end{array}$ & $\begin{array}{c}\Delta \text { East } \\
(\mathrm{m})\end{array}$ & $\Delta$ North (m) & $\begin{array}{c}\Delta \text { Vertical } \\
(\mathrm{m})\end{array}$ & $\Delta$ Total $(\mathrm{m})$ \\
\hline BVIS & -90.6213 & 14.3778 & -0.0393 & 0.0205 & -0.0480 & 0.0653 \\
\hline $\mathrm{CHIQ}$ & -90.5942 & 14.3895 & 0.0028 & 0.0097 & -0.0220 & 0.0242 \\
\hline $\mathrm{CHNO}$ & -90.6065 & 14.3897 & -0.0130 & -0.0094 & -0.0392 & 0.0424 \\
\hline CHUP & -90.6043 & 14.3595 & -0.0070 & 0.0017 & 0.0090 & 0.0115 \\
\hline CRAK & -90.6034 & 14.3850 & -0.0622 & -0.0166 & -0.0429 & 0.0774 \\
\hline LBLK & -90.6137 & 14.3609 & -0.0926 & 0.0048 & 0.2789 & 0.2939 \\
\hline LVES & -90.6971 & 14.3840 & 0.0436 & 0.0184 & -0.0283 & 0.0551 \\
\hline
\end{tabular}


Pre-eruption data best fits a model of a $75^{\circ}$ westward dipping dike experiencing $0.45 \mathrm{~m}$ of right-lateral slip and $0.55 \mathrm{~m}$ of tensile opening, or swelling, and slip tapering at the edges of the dike (Kode 200 source). Tables 9.2 and 9.3 show RMS misfit calculations for the rest of the models tested for this time period. Figure 9.1 shows a graphic of the modeled displacement (black vectors) as a background comparison to calculated displacement (red vectors) and the observed displacement (blue vectors) at each GPS station. The red calculated displacement vectors are calculated for a Kode 100 source, not Kode 200 thus they do not represent an accurate estimate of calculated displacement at each station for this model. The RMS misfit calculation for the model with the previous parameters is $5.49 \mathrm{~cm}$. Average position error for this time period is $13.97 \mathrm{~cm}$. Due to the large distance between the volcano and these three stations the displacement vectors are quite small. Station vectors show average displacement between 6 and 15 centimeters for the time period.

Due to their relatively small magnitude and distance from the edifice, it is difficult to determine whether the activity closer to the volcano truly underwent the movement described by the model or if the stations were experiencing changes due to regional stresses. The displacements were corrected for overall plate motion, but that does not account for any localized earthquake activity nor any ground settling that could have taken place in the area. These data cover a period of approximately 8 years, so a regional signature could very well be what is seen in these displacement vectors and not movements on the outskirts of a dike experiencing significant lateral slip. Additionally, due to the large errors in the positions and high discrepancy between the RMS misfit and the position error, these data are not significantly reliable for model comparison. 


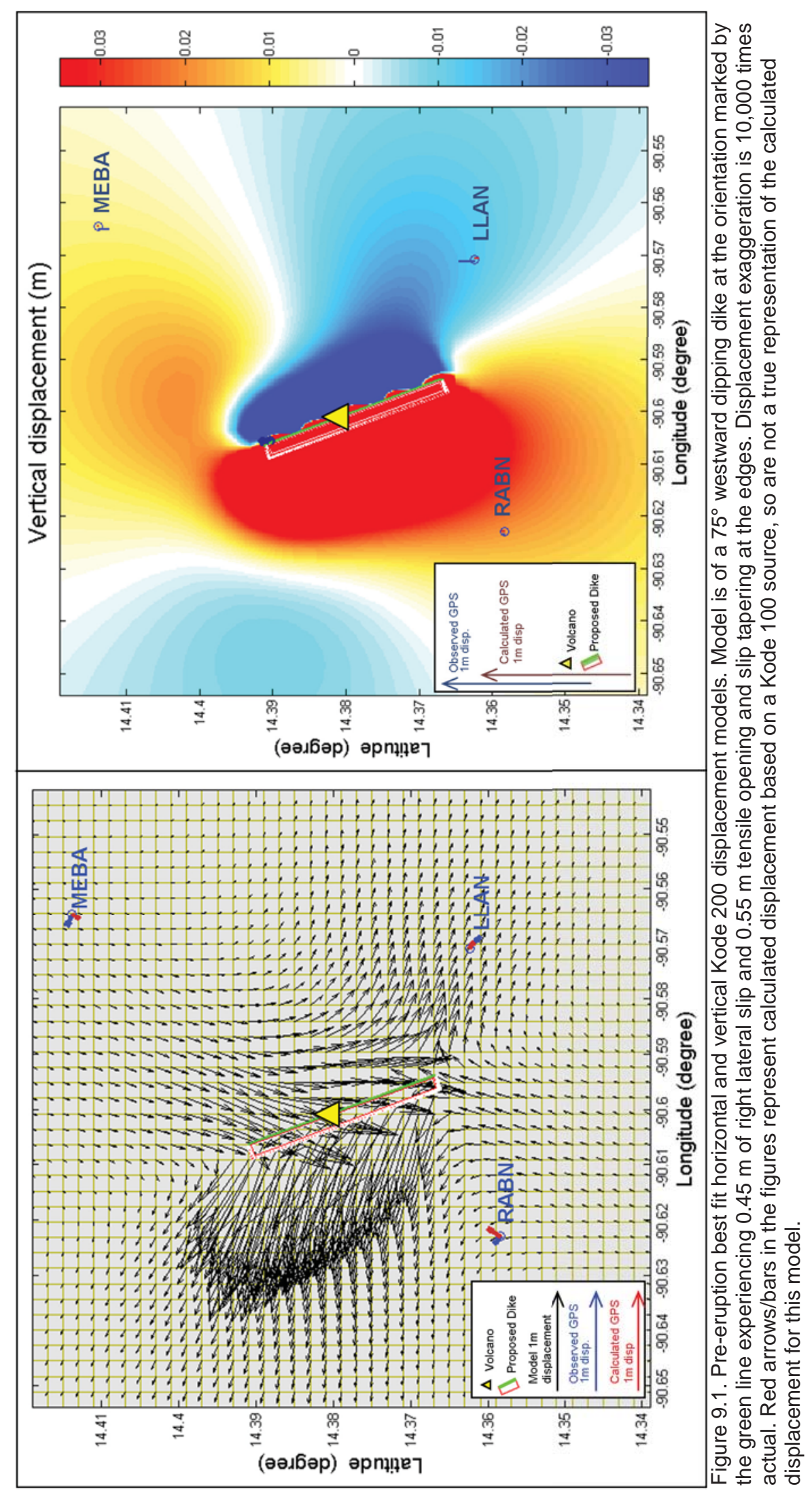


The model that best fits the observed displacement for the eruptive time period is of a dike dipping $75^{\circ}$ westward and experiencing $0.55 \mathrm{~m}$ of left-lateral slip (Kode 100). Figure 9.2 shows modeled displacement compared to observed and calculated displacement at each GPS station. RMS misfit for the model with this inflation parameter is approximately $12.38 \mathrm{~cm}$. Average error for all position displacement calculations for this time period is $5.33 \mathrm{~cm}$. High misfit values are partially due to the LBLK and CHNO stations experiencing movement one order of magnitude greater than the rest of the stations during this time period, which could be in part due to small error introduction. The first reading of the CHNO station within this time period was in January of 2009 when the station was installed. The following reading was not until September of 2011 and the station pin showed signs of extreme damage. The threads were worn and appeared as if they had been damaged by heavy impact, such as by a hammer. The pin was quite loose which could be resultant of the same activity. The pin was installed in a location not far from the main tourist trail and therefore could have attracted attention. It is possible the data show a large displacement partly due to this physical damage occurring between installation and the second reading. Error at the LBLK station could have been introduced by the explosive activity of the eruption. The pin was installed in a large boulder located on the southern skirts of the volcano. Though this boulder easily possesses a volume of $2 \mathrm{~m}^{3}$, it is possible that large amounts of energy released during the May 2010 eruption of Pacaya caused the boulder to dislodge slightly, thus resulting in a somewhat "false" displacement signature for the period covering the eruption. The rest of the stations do not exhibit any physical damage, nor are they installed in locations that could have been affected by large short-term energy release of the volcano as they are installed in permanently fixed objects and would not have shifted unless the ground experienced displacement.

Movement during this period could potentially be the origin of the resulting surface scar that can be seen along the northern flank of the volcano (Figure 4.4). After a large eruptive event like the one at Pacaya, one would expect to see deflation of the volcanic edifice due to evacuation of the magma chamber and gas release. Though this is not explicitly shown in the model, observed displacement arrows all pointing generally westward, even for stations east of the fault, which could be a result of settling of the volcano due to evacuation of the magma chamber and pressure release. Westward settling could be a side effect of possible expansion and contraction of the volcano before and/or during the eruption, or result of settling of the surface afterwards. This is termed as "possible" because this expansion and contraction is most likely hidden under the overall displacement signature for the time period and therefore can only be proposed based on observed volcanic activity.

There is also one other explanation to take into consideration for this time period. If, in fact, there is a vertical dike located at the orientation tested in the models that is experiencing oblique slip, in small or large amounts, this could be a precursor to an edifice collapse event. Slip along this feature could represent the initial stages of a collapse event similar to the collapse of "Old Pacaya" proposed to have occurred between 600 and 1500 BP (Kitamura and Matias, 1995). Due to the fact that Pacaya has in the past experienced small and large edifice collapse events, there is no reason to rule out that possibility for the future. According to Vallance (1994) a collapse can occur when the driving forces overcome forces of resistance. Forces favoring failure at Pacaya include its repetitive and frequent eruptions, historical collapse events, weak layers at 
the base of the edifice, a sloping basement and potential buttressing to the north as well as the asymmetrical accumulation of material on the western flank of the volcano (Schaefer et al., 2013). Vallance (1994) also states that factors impeding the collapse of an edifice include the strength of the rock within the volcano. A recent study by Schaefer et al. (2013) examining the possibility of failure at Pacaya based on rock strengths concluded that for a vertical dike extending from the cone to 1000 meters depth experiencing constant magma pressure of $8.4 \mathrm{MPa}$ there is a $90 \%$ chance of the edifice reaching instability. Their model also included the weak pyroclastic layer beneath the volcano as an influencing factor in failure. In static conditions the cone was determined to be constantly stable; however the surface deformation indicates that the volcano is experiencing expansion and/or lateral movement of the modeled dike and is therefore not perfectly stable. All sources of weakening for the present cone combined with rock stability studies previously conducted, as well as modeled and observed displacement, indicate that collapse is a plausible future result of present volcanic activity. 



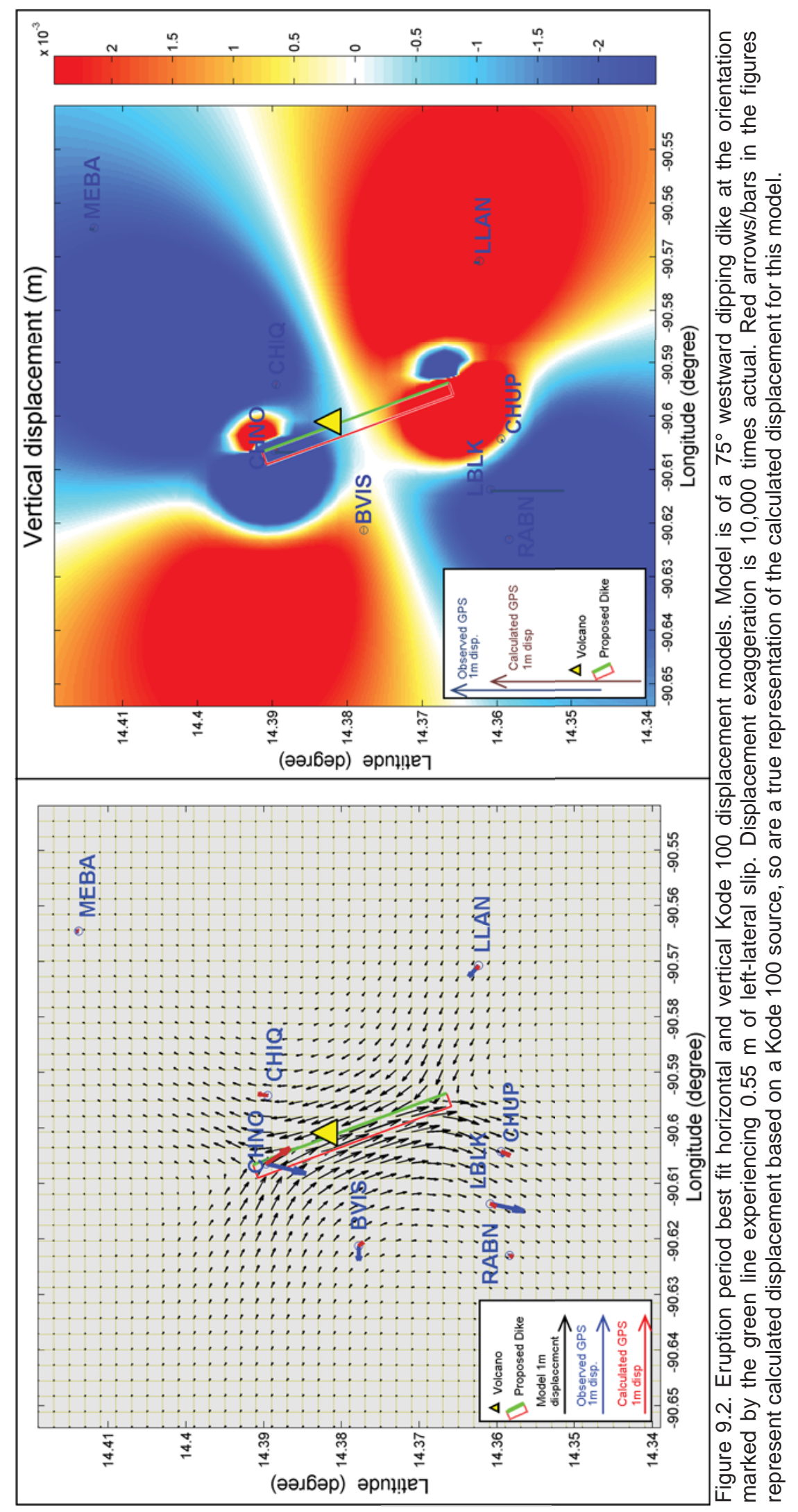


Observed GPS for the period from January 2011 through March 2013 is best fit by a $75^{\circ}$ westward dipping dike experiencing $-0.025 \mathrm{~m}$ of dip slip (Kode 100) and including slip taper at the edges of the dike (Figure 9.3). RMS misfit for this model is $6.90 \mathrm{~cm}$. Average error for the post-eruption position calculations is $6.91 \mathrm{~cm}$. Due to both values being almost equivalent it is difficult to say if the model truly represents displacement at the volcano. Other RMS calculations for models covering this time period are quite similar to the bestfit value and should also be taken into consideration as an applicable model for the time period. Between January 2011 and the last observation in March 2013 the volcano was beginning to show signs of resurgence. The return of lava flows in 2013 indicate that internal pressure most likely has exceeded the limits of the surface and thus began emission of lava as a measure of pressure release. Thus, the conduit system was likely experiencing an increase in pressure which is reflected in the bestfit Kode 200 models containing an inflation parameter.

Significant westward movement can be seen by observing the observed displacement vectors for all of the stations on the western side of the edifice which continues to concur with the hypothesis that collapse could be a future result of Pacaya's activity. Though the vectors represent only a few centimeters of movement, the short time period over which that movement occurred is concerning, especially considering the lack of observable volcanic activity for the majority of the time period. Additionally, if the western half of the edifice continues to move westward the collapse influencing factors mentioned previously may begin to introduce a strong influence on the behavior of the edifice, especially since according to Schaefer et al. (2013) the volcano exhibits a tendency for collapse in a westward direction. Another overall trend for all time periods that could influence a future collapse is that all bestfit models are of a westward dipping dike which provides an additional failure surface within the edifice in addition to the weak layer below the volcano. 


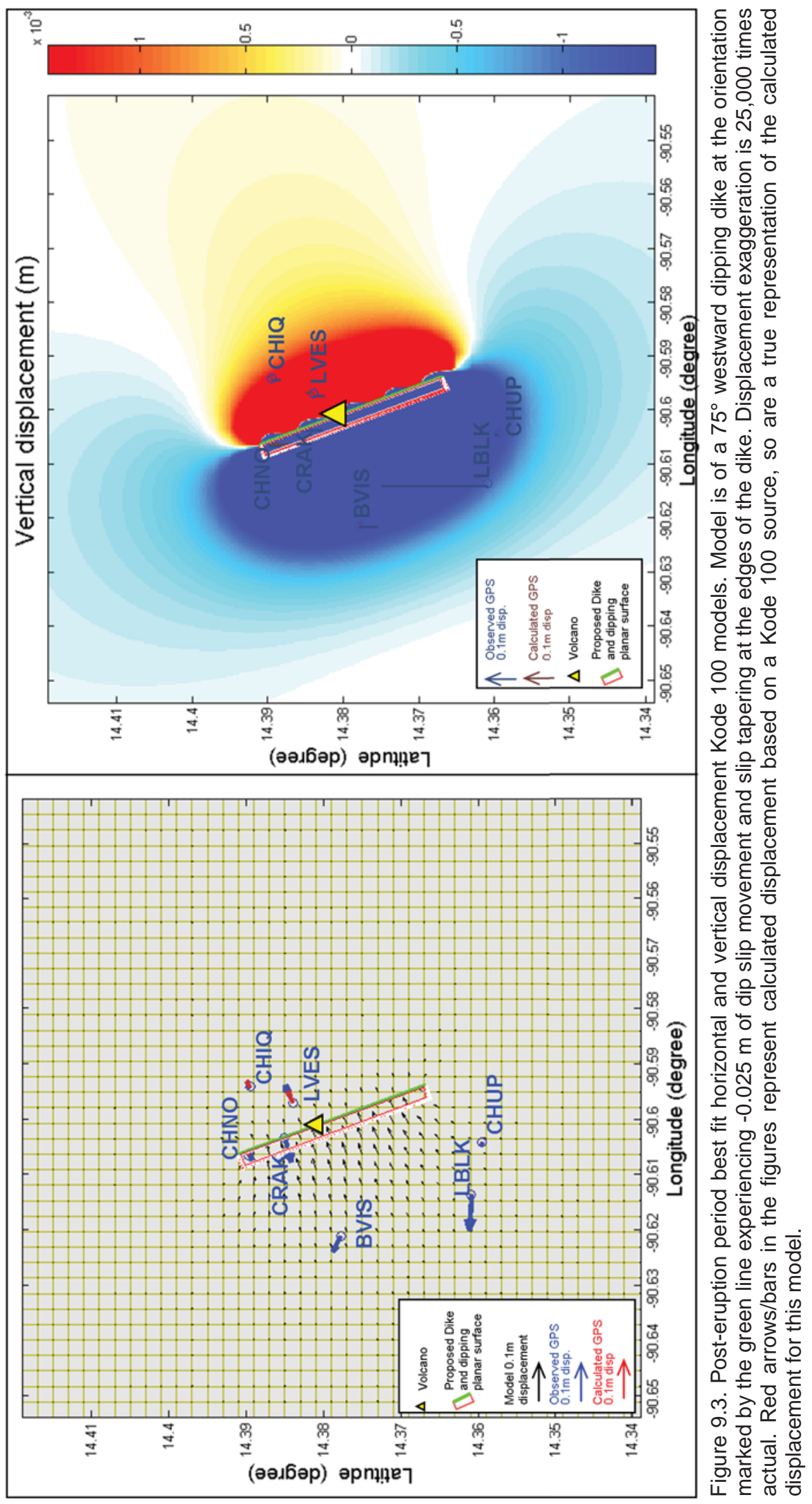





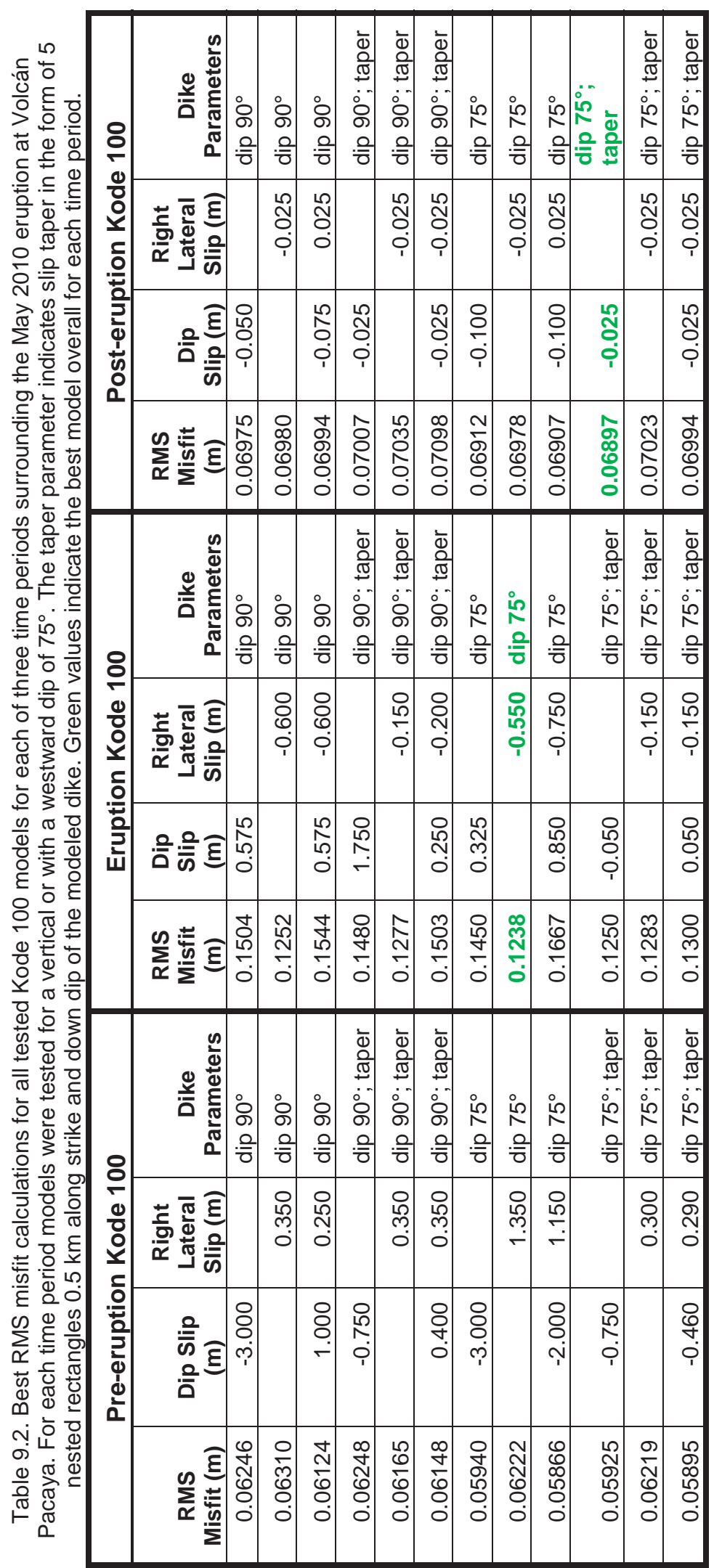





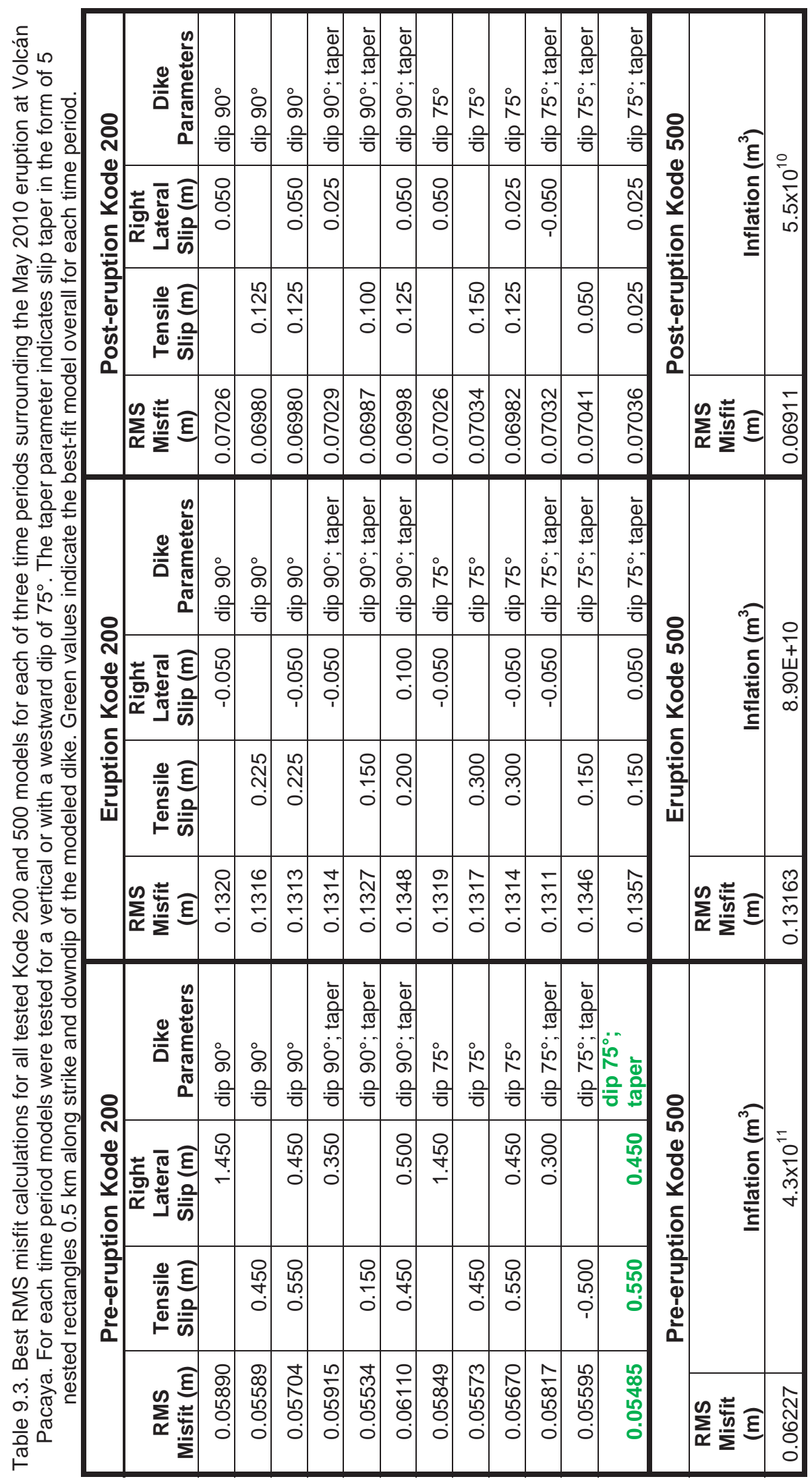





\section{FUTURE WORK}

Firstly, the author would recommend a more precise analysis of the observed GPS data using GIPSY-OASIS software. Errors using this software package could potentially be reduced to the order of less than a centimeter and thus a more thorough analysis of surface behavior at the volcano conducted.

It is also the author's recommendation that more regular observations be made of the GPS stations around the edifice. This report is obviously only a preliminary analysis and more investigation should be done to verify the observations made here. However, taking into consideration all hypotheses, Volcán Pacaya could potentially be an imposing threat of greater proportions than previously thought for populations in the area. If, in fact, the western flank of the volcano is detaching from the eastern half and slipping to the south, this is something that needs to be very closely monitored and verified.

Additional studies that could be incorporated with the GPS are seismicity studies for the data covering the eruption (if it still exists) to determine sources of seismic events and seismic moment to corroborate the movement seen in the GPS observations. Also, infrasound and gravity data could be used in conjunction with other methods to have a more complete, multiarray study of the behavior at the surface and below. 



\section{REFERENCES}

Alvarado, D., DeMets, C., Tikoff, B., Hernandez, D., Wawrzyniec, T. F., Pullinger, C., .. . Correa-Mora, F. (2011). Forearc motion and deformation between El Salvador and Nicaragua; GPS, seismic, structural, and paleomagnetic observations. Lithosphere, 3(1), 3-21. doi:http://dx.doi.org/10.1130/L108.1

Bardintzeff, J. M., \& Deniel, C. (1992). Magmatic evolution of Pacaya and Cerro Chiquito volcanological complex, Guatemala. Bulletin of Volcanology, 54(4), 267-283.

Bar-Sever, Y.E., "A New Model for GPS Yaw Attitude", Journal of Geodesy, 70, pp 714723, 1996

Bar-Sever, Y.E., P.M. Kroger, and J.A. Borjesson, "Estimating Horizontal Gradients of Tropospheric Path Delay with a Single GPS Receiver", J. Geophys. Res., 103, pp 5019-5035, 1998

Bohnenberger, O. H. (1966). Los focos eruptivos Cuaternaricos de Guatemala (The Quaternary eruptive centers of Guatemala). Publicaciones Geologicas Del ICAITI, , 44-45.

Cabral-Cano, E., Correa-Mora, F., \& Meertens, C. (2008). Deformation of Popocatépetl volcano using GPS; regional geodynamic context and constraints on its magma chamber. Journal of Volcanology and Geothermal Research, 170(1-2), 24-34. doi:http://dx.doi.org/10.1016/j.jvolgeores.2007.09.008

Carr, M. J. (1984). Symmetrical and segmented variation of physical and geochemical characteristics of the Central American volcanic front. Journal of Volcanology and Geothermal Research, 20(3-4), 231-252.

CONRED, Boletin informativo No. 748, May 29, 2010, 23:16

Conway, F.M., Diehl, J.F., and Matias, O., 1992, Paleomagnetic constraints on eruption patterns at the Pacaya composite Volcano, Guatemala. Bulletin of Volcanology $55,25-32$.

DeMets, C. (2001). A new estimate for present-day Cocos-Caribbean plate motion; implications for slip along the Central American volcanic arc. Geophysical Research Letters, 28(21), 4043-4046. doi:http://dx.doi.org/10.1029/2001GL013518

DeMets, C., Mattioli, G., Jansma, P., Rogers, R. D., Tenorio, C., \& Turner, H. L. (2007). Present motion and deformation of the Caribbean plate; constraints from new GPS geodetic measurements from Honduras and Nicaragua. Special Paper Geological Society of America, 428, 21-36. doi:http://dx.doi.org/10.1130/2007.2428(02

Dixon, T. H. (1991). An introduction to the global positioning system and some geological applications. Reviews of Geophysics, 29(2), 249-276. doi:http://dx.doi.org/10.1029/91RG00152Eggers, A.A., 1971, The Geology and Petrology of the Amatitlán Quadrangle, Guatemala [Ph.D. thesis]: Hanover, New Hampshire, Dartmouth College, $221 \mathrm{p}$.

Eggers, A. (1971). The geology and petrology of the Amatitlan quadrangle, Guatemala. Ph. D. Dissertation. Dartmouth College, Hanover, New Hampshire. 221 pp.

Escobar Wolf, R., (2011) The eruption of Volcan de Pacaya on May-June, 2010. Report in progress, Michigan Technological University. 
Franco, A., Lasserre, C., Lyon-Caen, H., Kostoglodov, V., Molina, E., Guzman-Speziale, M., Manea, V. C. (2012). Fault kinematics in northern Central America and coupling along the subduction interface of the Cocos plate, from GPS data in Chiapas (Mexico), Guatemala and El Salvador. Geophysical Journal International, 189(3), 1223-1236. doi:http://dx.doi.org/10.1111/j.1365246X.2012.05390.x

Javad Positioning Systems, (1998). A GPS tutorial: Basics of High-Precision Global Positioning Systems.

Jet Propulsion Laboratory. (n.d.). APPS - Under the Hood. Retrieved from http://apps.gdgps.net/apps underhood.php.

Kedar, S., Hajj, G. A., Wilson, B. D., \& Heflin, M. B. (2003). The effect of the second order GPS ionospheric correction on receiver positions. Geophysical Research Letters, 30(16), 4. doi:http://dx.doi.org/10.1029/2003GL017639

Kitamura, S., Matías, O., (1995). Tephra stratigraphic approach to the eruptive history of Pacaya volcano, Guatemala. Sci. Rep. Tohoku Univ., 7th Series (Geography) 45, $1-41$.

Lin, J. and R.S. Stein, 2004, Stress triggering in thrust and subduction earthquakes, and stress interaction between the southern San Andreas and nearby thrust and strike-slip faults, Journal of Geophysical Research, v. 109, B02303, doi:10.1029/2003JB002607.

Matias, O., 2010, Volcanological map of the 1961 - 2009 eruption of Volcan de Pacaya, Guatemala. MS. Thesis. Michigan Technological University, Houghton, Michigan. $57 \mathrm{pp}$

Matias Gomez, R.O., Rose, W.I., Palma, J.L. and Escobar-Wolf, R., 2012, Notes on a map of the 1961-2010 eruption of Pacaya volcano, Guatemala. GSA Digital Map and Chart Series 10, 10 p.

Municipalidad San Vicente Pacaya (SVP), (2009). Diagnostico General del Municipio de San Vicente Pacaya, Escuintla.

Roman, D. C., \& Heron, P. (2007). Effect of regional tectonic setting on local fault response to episodes of volcanic activity. Geophysical Research Letters, 34(13), 0-L13310. doi:http://dx.doi.org/10.1029/2007GL030222

Rose, W.I., Palma, J.L., Escobar Wolf, R., and Matías Gomez, R.O., (2013). A 50 yr eruption of a basaltic composite cone: Pacaya, Guatemala, in Rose, W.I., Palma, J.L., Delgado Granados, H., and Varley, N., eds., Understanding Open-Vent Volcanism and Related Hazards: Geological Society of America Special Paper 498, p. 1-21, doi:10.1130/2013.2498(01).

Toda, S., R. S. Stein, K. Richards-Dinger and S. Bozkurt, 2005, Forecasting the evolution of seismicity in southern California: Animations built on earthquake stress transfer, Journal of Geophysical Research, v. 110, B05S16, doi:10.1029/2004JB003415.

Vallance, J. W., Siebert, L., Rose, William I., Jr, Giron, J. R., \& Banks, N. G. (1995). Edifice collapse and related hazards in Guatemala. Journal of Volcanology and Geothermal Research, 66(1-4), 337-355. doi:http://dx.doi.org/10.1016/03770273(94)00076-S

Wardman, J., Sword-Daniels, V., Stewart, C. and Wilson, T. 2012. Impact assessment of the May 2010 eruption of Pacaya volcano, Guatemala, GNS Science Report 2012/09. 90 p. 
Wu, J.T., S.C. Wu, G.A. Hajj, W.I. Bertiger, and S.M. Lichten "Effects of Antenna Orientation on GPS Carrier Phase" Manuscripta Geodaetica, Vol. 18, No. 2, pp. 91-98, 1993

Zumberge, J. F., Heflin, M. B., Jefferson, D. C., Watkins, M. M., \& Webb, F. H. (1997). Precise point positioning for the efficient and robust analysis of GPS data from large networks. Journal of Geophysical Research, 102, 5005-5017. doi:http://dx.doi.org/10.1029/96JB03860

\subsection{Personal Communication References}

Morales, Humberto: Acting director of the Pacaya PNVPLC; Personal communication on March 20, 2014 via an e-mail questionnaire.

Alberto, Luis: PNVPLC park guide; Personal communications via telephone in January, March, October and November 2013 and February 2014. 

APPENDIX A -Table of all calculated positions and errors obtained from APPS analysis. 

Table A 1. All APPS calculated positions in Cartesian coordinates and 1- $\sigma$ errors associated with each calculated position.

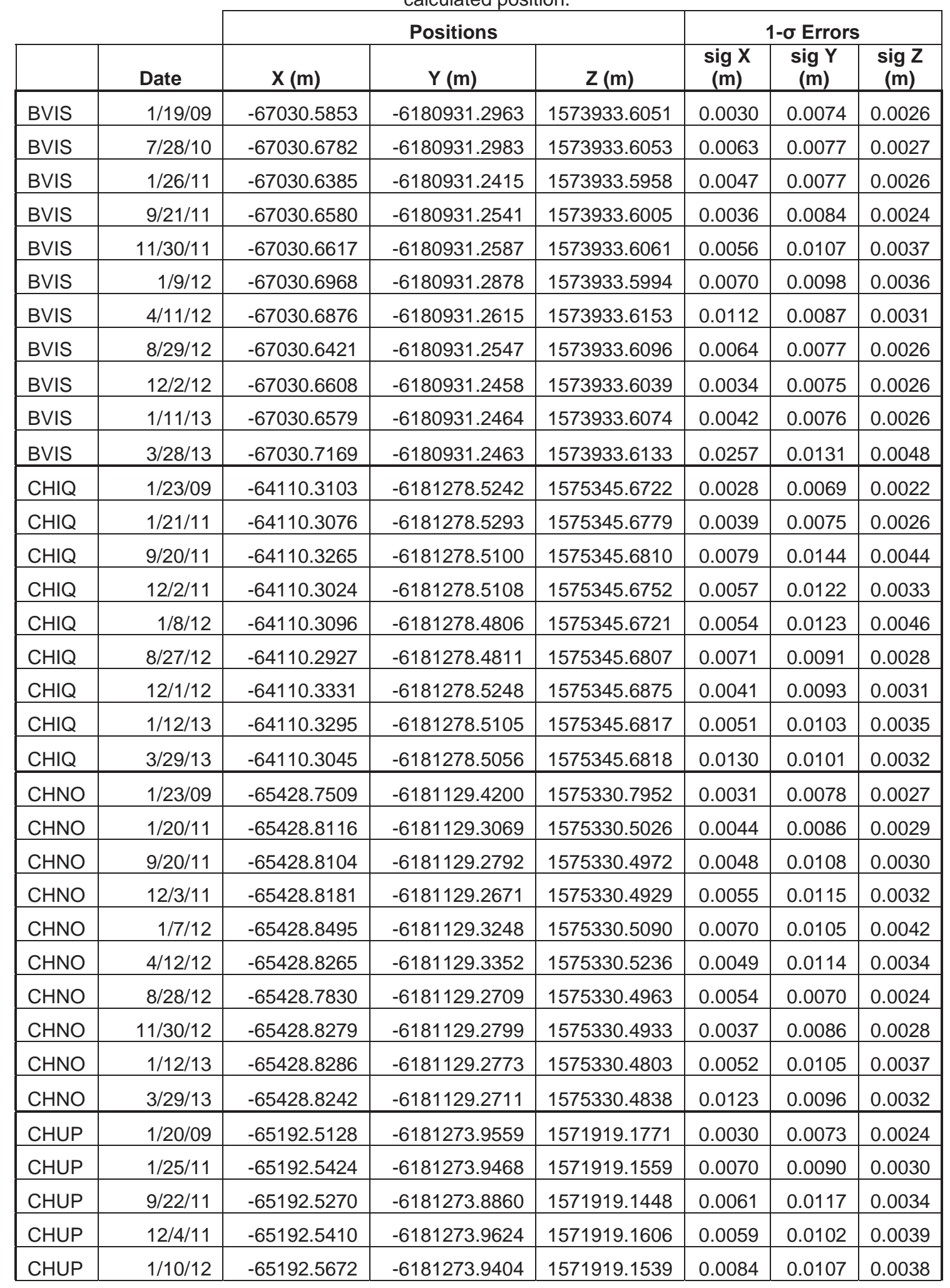




\begin{tabular}{|c|c|c|c|c|c|c|c|}
\hline CHUP & $4 / 10 / 12$ & -65192.5386 & -6181273.8959 & 1571919.1538 & 0.0060 & 0.0094 & 0.0031 \\
\hline CHUP & $8 / 26 / 12$ & -65192.5590 & -6181273.8923 & 1571919.1480 & 0.0080 & 0.0090 & 0.0030 \\
\hline CHUP & $11 / 29 / 12$ & -65192.5511 & -6181273.9700 & 1571919.1695 & 0.0050 & 0.0108 & 0.0039 \\
\hline CHUP & $1 / 13 / 13$ & -65192.5484 & -6181273.9848 & 1571919.1669 & 0.0063 & 0.0093 & 0.0035 \\
\hline CHUP & $3 / 28 / 13$ & -65192.5495 & -6181273.9550 & 1571919.1598 & 0.0056 & 0.0136 & 0.0037 \\
\hline CRAK & $8 / 28 / 12$ & -65095.7036 & -6181421.9515 & 1574867.6358 & 0.0106 & 0.0118 & 0.0049 \\
\hline CRAK & $11 / 30 / 12$ & -65095.7530 & -6181421.9059 & 1574867.6329 & 0.0059 & 0.0131 & 0.0066 \\
\hline CRAK & $1 / 12 / 13$ & -65095.7690 & -6181421.9376 & 1574867.6353 & 0.0059 & 0.0138 & 0.0062 \\
\hline CRAK & $3 / 29 / 13$ & -65095.7653 & -6181421.9050 & 1574867.6418 & 0.0078 & 0.0209 & 0.0080 \\
\hline LBLK & $1 / 20 / 09$ & -66208.3457 & -6181110.2813 & 1572043.6387 & 0.0031 & 0.0073 & 0.0024 \\
\hline LBLK & $7 / 28 / 10$ & -66208.3882 & -6181109.8544 & 1572043.3036 & 0.0063 & 0.0095 & 0.0028 \\
\hline LBLK & $1 / 22 / 11$ & -66208.4673 & -6181110.1415 & 1572043.3885 & 0.0047 & 0.0086 & 0.0028 \\
\hline LBLK & $9 / 21 / 11$ & -66208.4713 & -6181110.1774 & 1572043.3890 & 0.0056 & 0.0117 & 0.0034 \\
\hline LBLK & $12 / 6 / 11$ & -66208.4572 & -6181110.0874 & 1572043.3654 & 0.0066 & 0.0105 & 0.0038 \\
\hline LBLK & $1 / 6 / 12$ & -66208.4508 & -6181110.1222 & 1572043.3655 & 0.0057 & 0.0089 & 0.0029 \\
\hline LBLK & $4 / 11 / 12$ & -66208.4683 & -6181110.1309 & 1572043.3759 & 0.0054 & 0.0131 & 0.0036 \\
\hline LBLK & $8 / 29 / 12$ & -66208.4673 & -6181110.1300 & 1572043.3827 & 0.0089 & 0.0107 & 0.0031 \\
\hline LBLK & $12 / 2 / 12$ & -66208.4925 & -6181110.1417 & 1572043.3745 & 0.0049 & 0.0106 & 0.0037 \\
\hline LBLK & $1 / 11 / 13$ & -66208.4663 & -6181110.1033 & 1572043.3635 & 0.0073 & 0.0106 & 0.0037 \\
\hline LBLK & $3 / 28 / 13$ & -66208.4837 & -6181110.1224 & 1572043.3774 & 0.0041 & 0.0115 & 0.0031 \\
\hline LLAN & $10 / 16 / 2001$ & -61577.2685 & -6181079.5692 & 1572198.3017 & 0.0435 & 0.0854 & 0.0276 \\
\hline LLAN & $3 / 20 / 2002$ & -61577.3354 & -6181079.6664 & 1572198.2885 & 0.0879 & 0.1324 & 0.0403 \\
\hline LLAN & $5 / 23 / 2002$ & -61577.2445 & -6181079.6101 & 1572198.2438 & 0.1064 & 0.1272 & 0.0564 \\
\hline LLAN & $8 / 28 / 2002$ & -61577.2786 & -6181079.5170 & 1572198.2760 & 0.0994 & 0.2192 & 0.0657 \\
\hline LLAN & $1 / 22 / 2003$ & -61577.1078 & -6181079.8480 & 1572198.3342 & 0.1308 & 0.1609 & 0.0570 \\
\hline LLAN & $4 / 3 / 2003$ & -61577.4666 & -6181079.8304 & 1572198.3323 & 0.1424 & 0.1698 & 0.0618 \\
\hline LLAN & $5 / 20 / 2003$ & -61577.2895 & -6181079.7856 & 1572198.3373 & 0.0911 & 0.1391 & 0.0617 \\
\hline LLAN & 9/24/2003 & -61577.1963 & -6181079.8440 & 1572198.3437 & 0.1418 & 0.1244 & 0.0599 \\
\hline LLAN & $11 / 28 / 2003$ & -61577.2736 & -6181079.8537 & 1572198.3385 & 0.1495 & 0.1367 & 0.0581 \\
\hline LLAN & 2/17/2004 & -61577.3225 & -6181079.5519 & 1572198.2641 & 0.1032 & 0.1649 & 0.0563 \\
\hline LLAN & $5 / 12 / 2004$ & -61577.4492 & -6181079.7789 & 1572198.3508 & 0.1668 & 0.2194 & 0.0859 \\
\hline LLAN & $12 / 14 / 2004$ & -61577.0530 & -6181079.8955 & 1572198.3815 & 0.2804 & 0.5204 & 0.1131 \\
\hline LLAN & $2 / 3 / 2005$ & -61577.2737 & -6181079.4794 & 1572198.2866 & 0.1434 & 0.2018 & 0.0652 \\
\hline LLAN & $5 / 25 / 2005$ & -61577.3241 & -6181079.6565 & 1572198.2873 & 0.0678 & 0.1090 & 0.0435 \\
\hline LLAN & $9 / 13 / 2005$ & -61577.6869 & -6181078.7602 & 1572198.0327 & 0.4369 & 0.3927 & 0.1535 \\
\hline LLAN & $11 / 9 / 2005$ & -61577.2689 & -6181079.7975 & 1572198.3272 & 0.1081 & 0.1244 & 0.0447 \\
\hline LLAN & $3 / 6 / 2006$ & -61577.1899 & -6181079.6550 & 1572198.3094 & 0.1081 & 0.1077 & 0.0451 \\
\hline LLAN & $7 / 2 / 2008$ & -61576.6145 & -6181081.0467 & 1572198.8742 & 1.4938 & 0.9268 & 0.6686 \\
\hline LLAN & $10 / 31 / 2008$ & -61577.1957 & -6181079.6939 & 1572198.2637 & 0.0079 & 0.0280 & 0.0048 \\
\hline
\end{tabular}




\begin{tabular}{|c|c|c|c|c|c|c|c|}
\hline LLAN & $7 / 28 / 2010$ & -61577.2659 & -6181079.7112 & 1572198.3317 & 0.0024 & 0.0075 & 0.0025 \\
\hline LVES & $9 / 24 / 11$ & -64418.0044 & -6181449.5909 & 1574766.2090 & 0.0049 & 0.0110 & 0.0031 \\
\hline LVES & $12 / 2 / 11$ & -64417.9873 & -6181449.6220 & 1574766.2323 & 0.0087 & 0.0128 & 0.0045 \\
\hline LVES & $1 / 8 / 12$ & -64417.9933 & -6181449.5875 & 1574766.2133 & 0.0053 & 0.0107 & 0.0038 \\
\hline LVES & $8 / 27 / 12$ & -64417.9781 & -6181449.5546 & 1574766.2153 & 0.0083 & 0.0093 & 0.0032 \\
\hline LVES & $12 / 1 / 12$ & -64417.9776 & -6181449.5636 & 1574766.2225 & 0.0050 & 0.0107 & 0.0038 \\
\hline LVES & $1 / 12 / 13$ & -64417.9647 & -6181449.5478 & 1574766.2155 & 0.0052 & 0.0106 & 0.0038 \\
\hline LVES & $3 / 29 / 13$ & -64417.9605 & -6181449.5594 & 1574766.2198 & 0.0048 & 0.0119 & 0.0035 \\
\hline MEBA & $10 / 16 / 2001$ & -60903.0298 & -6179868.3501 & 1577753.4983 & 0.0670 & 0.0610 & 0.0301 \\
\hline MEBA & $11 / 21 / 2001$ & -60902.8922 & -6179868.2643 & 1577753.4753 & 0.0696 & 0.0632 & 0.0300 \\
\hline MEBA & $3 / 20 / 2002$ & -60903.2775 & -6179868.3356 & 1577753.5387 & 0.1738 & 0.1401 & 0.0539 \\
\hline MEBA & $5 / 23 / 2002$ & -60903.1301 & -6179869.7857 & 1577753.8865 & 0.0730 & 0.0822 & 0.0411 \\
\hline MEBA & $6 / 21 / 2002$ & -60903.0766 & -6179868.2158 & 1577753.4270 & 0.0970 & 0.1132 & 0.0538 \\
\hline MEBA & $8 / 28 / 2002$ & -60903.0626 & -6179868.1394 & 1577753.5095 & 0.0654 & 0.1294 & 0.0357 \\
\hline MEBA & $11 / 26 / 2002$ & -60903.1042 & -6179868.4296 & 1577753.5553 & 0.0981 & 0.0793 & 0.0407 \\
\hline MEBA & $4 / 3 / 2003$ & -60903.1958 & -6179868.4031 & 1577753.5169 & 0.0737 & 0.0898 & 0.0329 \\
\hline MEBA & $5 / 20 / 2003$ & -60903.2855 & -6179868.3357 & 1577753.5458 & 0.0976 & 0.1237 & 0.0616 \\
\hline MEBA & 8/7/2003 & -60903.0805 & -6179868.3124 & 1577753.4956 & 0.1073 & 0.1122 & 0.0380 \\
\hline MEBA & 9/24/2003 & -60903.2126 & -6179868.3251 & 1577753.5350 & 0.1153 & 0.0864 & 0.0437 \\
\hline MEBA & $11 / 28 / 2003$ & -60903.1316 & -6179868.4197 & 1577753.5358 & 0.0970 & 0.0772 & 0.0361 \\
\hline MEBA & $12 / 14 / 2004$ & -60902.7911 & -6179868.3046 & 1577753.4851 & 0.2608 & 0.2021 & 0.0912 \\
\hline MEBA & 2/3/2005 & -60903.0641 & -6179868.4926 & 1577753.5622 & 0.1390 & 0.2585 & 0.0743 \\
\hline MEBA & $5 / 25 / 2005$ & -60903.1765 & -6179868.4845 & 1577753.5779 & 0.2322 & 0.3577 & 0.1284 \\
\hline MEBA & $11 / 9 / 2005$ & -60902.9005 & -6179868.1682 & 1577753.4026 & 0.1729 & 0.1694 & 0.0682 \\
\hline MEBA & $3 / 6 / 2006$ & -60903.2476 & -6179868.1216 & 1577753.5192 & 0.1386 & 0.1833 & 0.0684 \\
\hline MEBA & 7/2/2008 & -60903.1115 & -6179869.8698 & 1577753.8612 & 0.1751 & 0.5630 & 0.1166 \\
\hline MEBA & $10 / 31 / 2008$ & -60903.1174 & -6179868.3445 & 1577753.5444 & 0.0072 & 0.0252 & 0.0042 \\
\hline MEBA & $1 / 23 / 2009$ & -60903.1065 & -6179868.2753 & 1577753.5148 & 0.0018 & 0.0084 & 0.0028 \\
\hline MEBA & $7 / 28 / 2010$ & -60903.1088 & -6179868.3000 & 1577753.5388 & 0.0019 & 0.0075 & 0.0023 \\
\hline RABN & $10 / 16 / 2001$ & -67214.4701 & -6181106.8588 & 1571756.1948 & 0.0816 & 0.0729 & 0.0352 \\
\hline RABN & $11 / 21 / 2001$ & -67214.3574 & -6181106.7851 & 1571756.1435 & 0.0957 & 0.0976 & 0.0425 \\
\hline RABN & $1 / 16 / 2002$ & -67214.4907 & -6181106.7714 & 1571756.1740 & 0.0883 & 0.1683 & 0.0438 \\
\hline RABN & $3 / 20 / 2002$ & -67214.5016 & -6181106.8744 & 1571756.1997 & 0.0841 & 0.1139 & 0.0412 \\
\hline RABN & $6 / 21 / 2002$ & -67214.5427 & -6181106.9842 & 1571756.2598 & 0.0969 & 0.1303 & 0.0562 \\
\hline RABN & $11 / 26 / 2002$ & -67214.4363 & -6181106.7898 & 1571756.1897 & 0.1071 & 0.1065 & 0.0484 \\
\hline RABN & $1 / 22 / 2003$ & -67214.3079 & -6181106.5961 & 1571756.1595 & 0.3822 & 0.3600 & 0.1130 \\
\hline RABN & $4 / 3 / 2003$ & -67214.6460 & -6181106.8174 & 1571756.2110 & 0.1396 & 0.1934 & 0.0718 \\
\hline RABN & $5 / 20 / 2003$ & -67214.5361 & -6181106.9017 & 1571756.2029 & 0.0631 & 0.0867 & 0.0407 \\
\hline RABN & 8/7/2003 & -67214.5350 & -6181106.3564 & 1571756.1637 & 0.0677 & 0.1778 & 0.0318 \\
\hline
\end{tabular}




\begin{tabular}{|l|r|r|l|l|l|l|l|}
\hline RABN & $9 / 24 / 2003$ & -67214.6037 & -6181107.3583 & 1571756.3775 & 0.2878 & 0.2735 & 0.1108 \\
\hline RABN & $2 / 17 / 2004$ & -67214.4952 & -6181106.7656 & 1571756.1832 & 0.0753 & 0.1007 & 0.0315 \\
\hline RABN & $5 / 12 / 2004$ & -67214.6712 & -6181106.7803 & 1571756.2393 & 0.0721 & 0.0844 & 0.0344 \\
\hline RABN & $6 / 16 / 2004$ & -67214.5990 & -6181106.8397 & 1571756.2100 & 0.0634 & 0.0893 & 0.0391 \\
\hline RABN & $11 / 9 / 2004$ & -67214.3501 & -6181106.7579 & 1571756.1744 & 0.0846 & 0.0940 & 0.0362 \\
\hline RABN & $12 / 14 / 2004$ & -67214.3746 & -6181106.9278 & 1571756.2257 & 0.0975 & 0.1010 & 0.0363 \\
\hline RABN & $2 / 3 / 2005$ & -67214.2553 & -6181106.8578 & 1571756.2088 & 0.3738 & 0.6757 & 0.3494 \\
\hline RABN & $5 / 25 / 2005$ & -67214.4137 & -6181106.5675 & 1571756.2439 & 0.1719 & 0.4385 & 0.1019 \\
\hline RABN & $11 / 9 / 2005$ & -67214.7315 & -6181108.3671 & 1571756.6465 & 0.3811 & 0.7697 & 0.1518 \\
\hline RABN & $3 / 6 / 2006$ & -67214.5300 & -6181107.0486 & 1571756.3134 & 0.1127 & 0.1825 & 0.0710 \\
\hline RABN & $7 / 2 / 2008$ & -67214.5552 & -6181108.4374 & 1571756.6509 & 0.1678 & 0.5514 & 0.0937 \\
\hline RABN & $1 / 24 / 2009$ & -67214.5175 & -6181106.8634 & 1571756.2388 & 0.0031 & 0.0119 & 0.0039 \\
\hline RABN & $7 / 28 / 2010$ & -67214.5097 & -6181106.8633 & 1571756.2381 & 0.0020 & 0.0076 & 0.0024 \\
\hline
\end{tabular}


APPENDIX B - Coulomb 3.3.1 input files for each best-fit model: (a) Pre-eruption; (b) Eruption covering; and (c) Post-eruption 

(a) Pre-eruption period model input file

This is a test file for the Coulomb 1.0

This file is prepared to check simple dike opening calculation with kode 200.

$\#$ reg1= 0 \#reg2= 0 \#fixed $=1$ sym $=1$

$\mathrm{PR} 1=0.250 \quad \mathrm{PR} 2=0.250 \mathrm{DEPTH}=0.000$

$\mathrm{E} 1=8.000 \mathrm{e}+05 \mathrm{E2}=8.000 \mathrm{e}+05$

XSYM $=\quad .000 \quad \mathrm{YSYM}=\quad .000$

$\mathrm{FRIC}=\quad 0.400$

$\mathrm{S} 1 \mathrm{DR}=\quad 19.000 \mathrm{~S} 1 \mathrm{DP}=\quad-0.000 \mathrm{~S} 1 \mathrm{IN}=\quad 100.000 \mathrm{~S} 1 \mathrm{GD}=\quad 0.000$

$\mathrm{S} 2 \mathrm{DR}=\quad 90.000 \mathrm{~S} 2 \mathrm{DP}=\quad 89.999 \mathrm{~S} 2 \mathrm{IN}=\quad 30.000 \mathrm{~S} 2 \mathrm{GD}=\quad 0.000$

$\mathrm{S} 3 \mathrm{DR}=\quad 109.000 \mathrm{~S} 3 \mathrm{DP}=\quad-0.000 \mathrm{~S} 3 \mathrm{IN}=\quad 0.000 \mathrm{~S} 3 \mathrm{GD}=\quad 0.000$

\begin{tabular}{|c|c|c|c|c|c|c|c|c|c|c|}
\hline & X-start & Y-start & $X$-fin & Y-fin & & rt lat & & dip & to & \\
\hline & & & & $x y x$ & & & & & & \\
\hline & -6 . & & & & & & & & & \\
\hline 1 & -6. & & & & & & & & & \\
\hline & & & & & & & & & & \\
\hline 1 & -6.0 & & 2.7028 & -11.9351 & & & & & & \\
\hline 1 & -6.0202 & 11.6453 & 2.6595 & -11.8178 & 200 & 0.45 & 0.55 & 75.0000 & 0.87 & \\
\hline
\end{tabular}

\section{Grid Parameters}
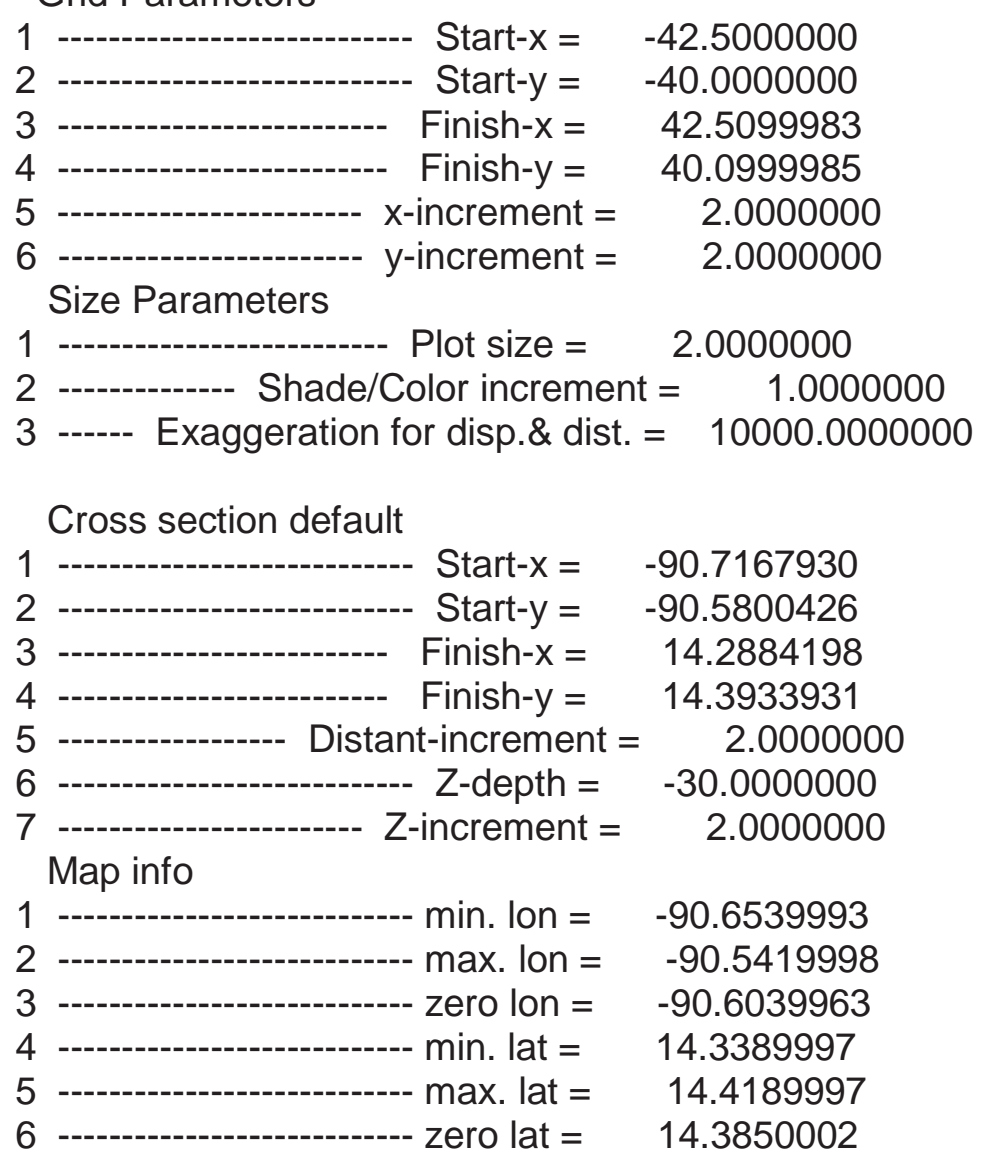
(b) Eruption period model input file

This is a test file for the Coulomb 1.0

This file is prepared to check simple dike opening calculation with kode 200.

$\#$ reg1= 0 \#reg2= 0 \#fixed= 1 sym= 1

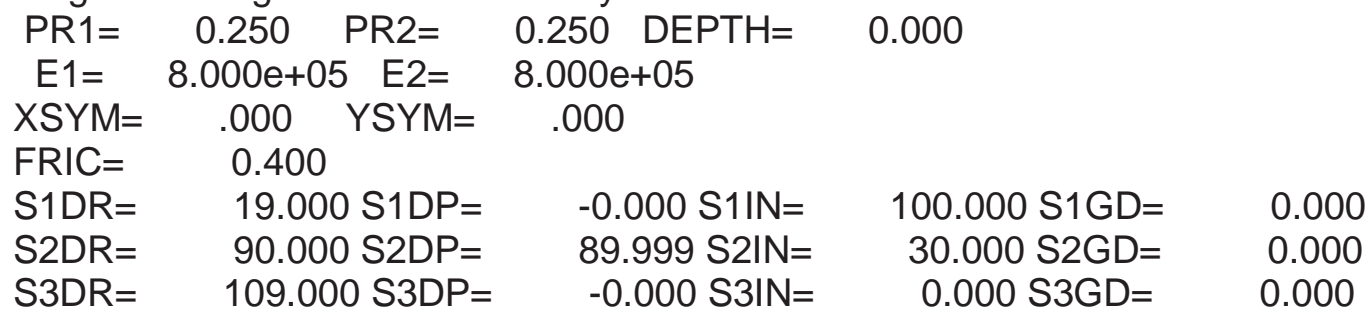

\# X-start Y-start $X$-fin $Y$-fin Kode rt.lat reverse dip angle top bot

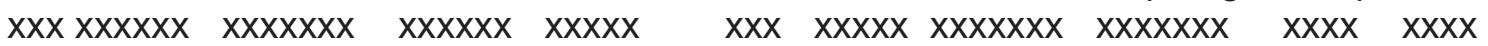

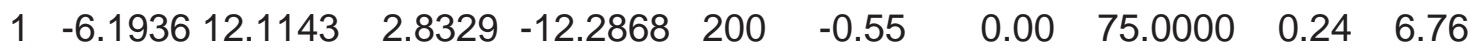
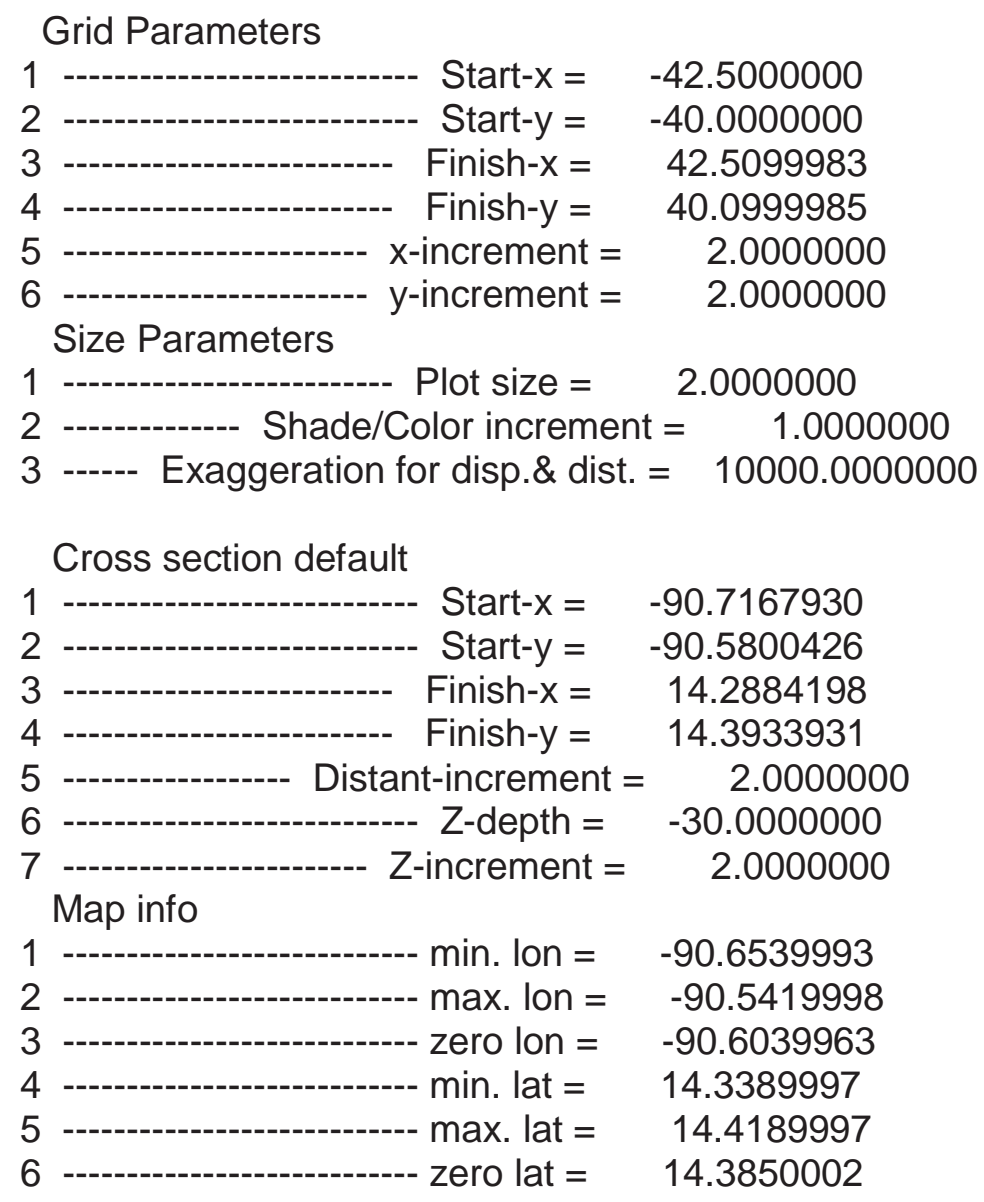
(c) Post-eruption period model input file

This is a test file for the Coulomb 1.0

This file is prepared to check simple dike opening calculation with kode 200.

$\#$ reg1= 0 \#reg2= 0 \#fixed $=1$ sym $=1$

$\mathrm{PR} 1=0.250 \quad \mathrm{PR} 2=0.250 \quad \mathrm{DEPTH}=0.000$

$\mathrm{E} 1=8.000 \mathrm{e}+05 \mathrm{E2}=8.000 \mathrm{e}+05$

XSYM $=\quad .000 \quad \mathrm{YSYM}=\quad .000$

$\mathrm{FRIC}=\quad 0.400$

$\mathrm{S} 1 \mathrm{DR}=\quad 19.000 \mathrm{~S} 1 \mathrm{DP}=\quad-0.000 \mathrm{~S} 1 \mathrm{IN}=\quad 100.000 \mathrm{~S} 1 \mathrm{GD}=\quad 0.000$

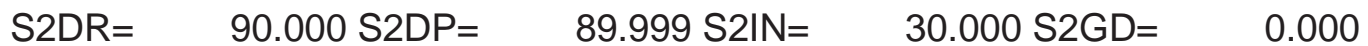

$\mathrm{S} 3 \mathrm{DR}=\quad 109.000 \mathrm{~S} 3 \mathrm{DP}=\quad-0.000 \mathrm{~S} 3 \mathrm{IN}=\quad 0.000 \mathrm{~S} 3 \mathrm{GD}=\quad 0.000$

\begin{tabular}{|c|c|c|c|c|c|c|c|c|c|c|}
\hline & X-start & Y-start & $X$-fin & Y-fin & & rt lat & & & & \\
\hline & & & & $\mathrm{XXX}$ & & & & & $<X$ & \\
\hline & -6 . & & & & & & & & & \\
\hline 1 & -6 . & & & & & & & & & \\
\hline 1 & & & & & & & & & & \\
\hline 1 & -6. & & 2.7028 & & 20 & & & & & \\
\hline 1 & -6.02 & 11.6453 & 2.6595 & -11.8178 & 20 & 0.00 & -0.025 & 75.0000 & 0.87 & \\
\hline
\end{tabular}

\section{Grid Parameters}
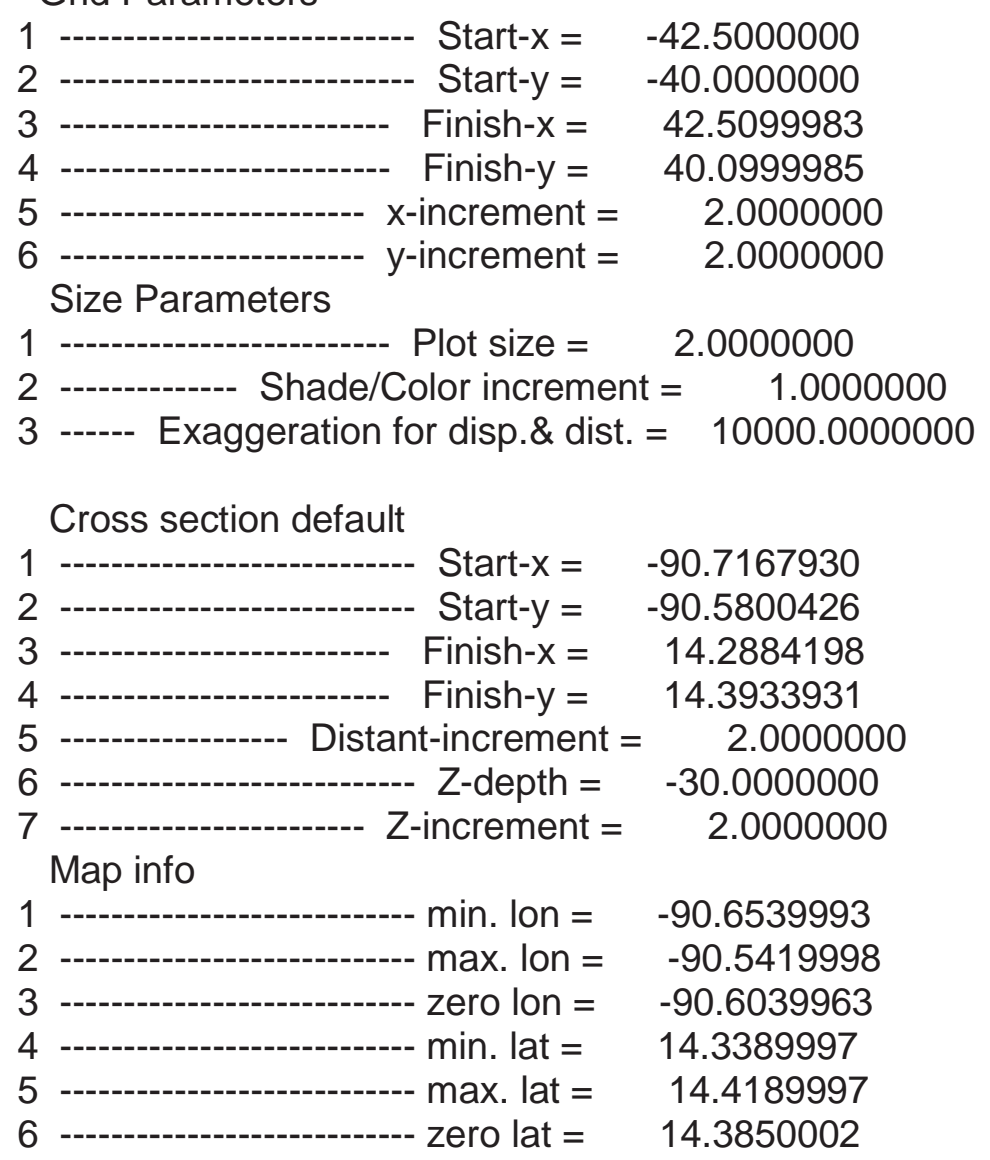